CENTRE NATIONAL DE LA RECHERCHE SCIENTIFIQUE

Cultures et Environnements. Préhistoire, Antiquité, Moyen Âge

COLLECTION D'ÉTUdES MÉdIÉVALES DE NICE

VOLUME 14

\title{
ENCYCLOPÉDIRE
}

FORMES DE L'AMBITION ENCYCLOPÉDIQUE

de L'Antiquité au Moyen ÂGe
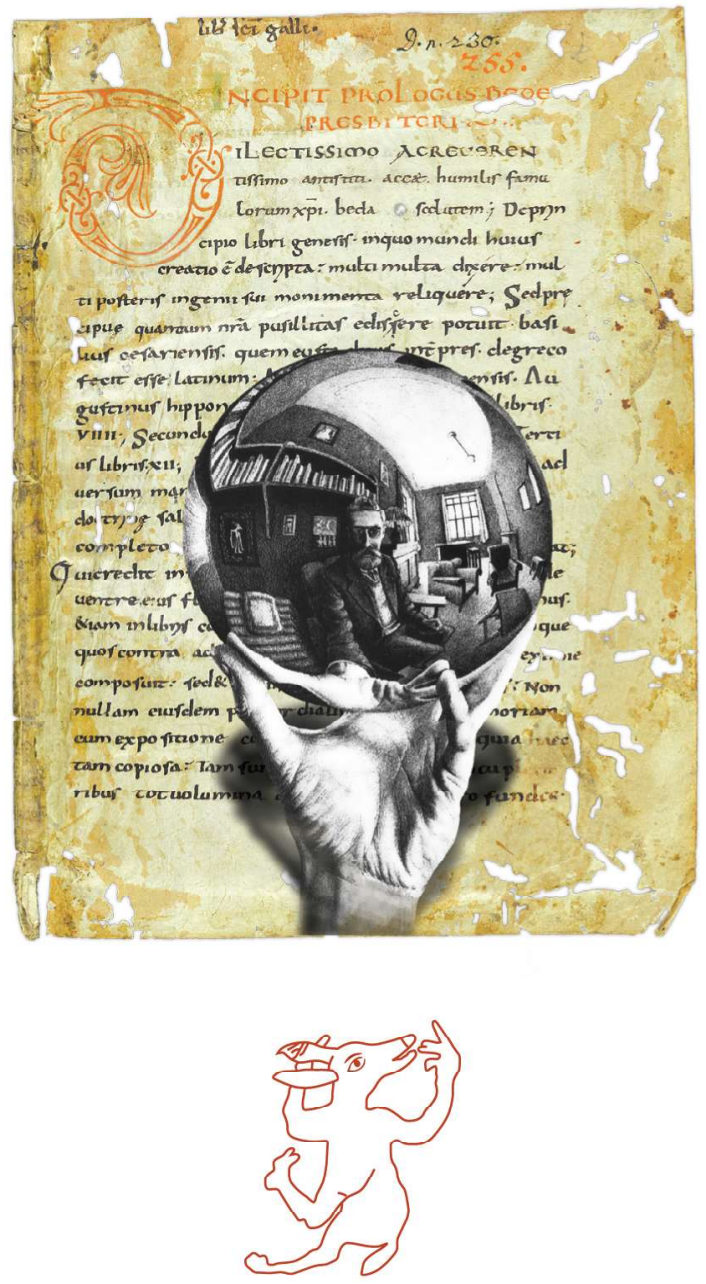

BREPOLS 
ENCYCLOPÉDIRE

FORMES DE L'AMBITION ENCYCLOPÉDIQUE

DANS L'ANTIQUité ET AU MOYEN ÂGE 


\title{
COLLECTION D’ÉTUdES MÉDIÉVALES DE NICE
}

Collection fondée par Rosa Maria DEssì, Michel LAUWERS et Monique ZERNER

\author{
Direction \\ Michel LAUWERS \\ Comité éditorial
}

Germain ButAud, Cécile CABY, Yann Codou,

Rosa Maria Dessì, Stéphanie LE BrIZ-OrGEUR

\section{Comité scientifique}

Enrico ARTIFOnI (Università di Torino), Jean-Pierre DEVROEY (Université Libre de Bruxelles), Patrick J.Geary (Institute for Advanced Study, Princeton), Dominique Iogna-Prat (EHESS, Paris), Florian MAZEL (Université de Rennes 2), Didier MÉHU (Université Laval, Québec), Jean-Claude ScHMITT (EHESS, Paris), Élisabeth ZADORA-RIO (CNRS, Tours)

Cultures et Environnements. Préhistoire, Antiquité, Moyen Âge

UMR 7264, Université Nice Sophia Antipolis - CNRS

Pôle Universitaire Saint-Jean-d'Angély

SJA3

24, avenue des Diables-Bleus

F-06357 Nice Cedex 4

$*$

Maquette

Antoine PASQUALINI

Illustration de couverture

Montage A. Pasqualini sur une lithographie de M. C. Escher (Main tenant un miroir sphérique, 1935) \& un manuscrit de Bède (Hexaémeron)

M. C. Escher, Main tenant un miroir sphérique (1935), lithographie sur papier vélin avec couche argentée,

$31,8 \times 21,4 \mathrm{~cm}$. MBAC. Don de George Escher, Mahone Bay (Nouvelle-Écosse), 1989.

(C) 2013 The M.C. Escher Company, Pays-Bas. Tous droits réservés. www.mcescher.com.

St. Gallen Stiftsbibliothek Cod. Sang. 255 (IX ${ }^{\mathrm{e}}$ siècle). Bède le Vénérable, Hexaemeron.

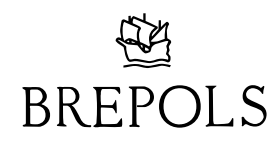


CENTRE NATIONAL DE LA RECHERCHE SCIENTIFIQUE

Cultures et Environnements. Préhistoire, Antiquité, Moyen Âge

COLLECTION D’ÉTUdES MÉDIÉVALES DE NICE

VOLUME 14

\title{
ENCYCLOPÉDIRE
}

FORMES DE L'AMBITION ENCYCLOPÉDIQUE

DANS L'ANTIQUité ET Au Moyen ÂGE

ÉTUDES RÉUNIES PAR

ARNAUD ZUCKER

\author{
(2) \\ BREPOLS
}


(C) 2013 BREPOLS PUBLISHERS, Turnhout, Belgium. All rights reserved. No part of this book may be reproduced, stored in a retrieval system, or transmitted, in any form or by any means, electronic, mechanical, photocopying, recording or otherwise, without the prior permission of the publisher.

D/2013/0095/231

ISBN 978-2-503-55148-7

Printed in the E.U. on acid-free paper 


\section{LISTE DES SIGLES ET ABRÉVIATIONS}

\section{Abréviations usuelles}

$\begin{array}{llll}\text { cf. } & \text { confer } & \mathrm{n} . & \text { note } \\ \text { chap. } & \text { chapitre } & \mathrm{n}^{\mathrm{o}} & \text { numéro } \\ \text { col. } & \text { colonne(s) } & \mathrm{p} . & \text { page(s) } \\ \text { f. } & \text { folio } & \mathrm{r} & \text { recto } \\ \text { L. } & \text { livre } & \mathrm{t} . & \text { tome } \\ \text { l. } & \text { ligne } & \mathrm{v} & \text { verso } \\ \text { ms. } & \text { manuscrit(s) } & \text { vol. } & \text { volume }\end{array}$

\section{$\underline{\text { Abréviations des titres de collection et de revue }}$}

$\begin{array}{ll}\text { AA SS } & =\text { Acta Sanctorum } \\ A B & =\text { Analecta Bollandiana } \\ B A V & =\text { Biblioteca Apostolica Vaticana } \\ B H L & =\text { Bibliotheca Hagiographica Latina } \\ B M L & =\text { Biblioteca Medicea-Laurenziana } \\ B N C & =\text { Biblioteca nazionale centrale } \\ \text { BnF } & =\text { Bibliothèque nationale de France } \\ \text { CC Ser. Lat. } & =\text { Corpus Christianorum. Series Latina } \\ C C \text { Cont. Med. } & =\text { Corpus Christianorum. Continuatio Medievalis } \\ C C M & =\text { Cahiers de Civilisation Médiévale } \\ D A C L & =\text { Dictionnaire d'Archéologie chrétienne et de liturgie } \\ D B I & =\text { Dizionario biografico degli Italiani } \\ D H G E & =\text { Dictionnaire d'Histoire et de Géographie ecclésiastiques } \\ D S & =\text { Dictionnaire de Spiritualité } \\ D T C & =\text { Dictionnaire de Théologie Catholique } \\ M E F R M & =\text { Mélanges de l'École française de Rome. Moyen Âge } \\ M G H & =\text { Monumenta Germaniae Historica } \\ P G & =\text { Patrologie grecque } \\ P L & =\text { Patrologie latine } \\ R H E & =\text { Revue d'histoire ecclésiastique } \\ \text { RIS } & =\text { Rerum Italicarum Scriptores }\end{array}$




\title{
LE « SIÈCLE DE L'ENCYCLOPÉDISME » : CONDITIONS ET CRITÈRES DE DÉFINITION D'UN GENRE ${ }^{1}$
}

\author{
ISABELLE DRAELANTS \\ Centre de médiévistique Jean-Schneider, Université de Lorraine - CNRS
}

$I^{\prime}$

est audacieux et difficile d'aborder d'une manière nouvelle l'encyclopédisme médiéval, un sujet de plus en plus prisé durant les quarante dernières années, après avoir été quasiment ignoré auparavant. C'est néanmoins le défi que se sont lancé les collègues du CEPAM de Nice pour un projet quadriennal 2007-2011; leur programme de conférences sur l'ambition encyclopédique a permis d'aborder d'une manière diachronique et comparative, plutôt que l'œuvre encyclopédique elle-même, la volonté littéraire de globalisation de l'Antiquité au Moyen Âge.

Dans ce cadre, la présente contribution ne prétend pas à l'originalité, mais tente un essai de synthèse et d'interprétation des acquis de l'historiographie. Elle s'attache à poser un certain nombre de critères pour la reconnaissance d'un genre encyclopédique médiéval. La seconde préoccupation est de caractériser les encyclopédies des années 1190-1260 comme appartenant à une période de référence ou d'apogée pour l'encyclopédisme médiéval. Cette préoccupation a pour conséquence d'envisager certaines œuvres encyclopédiques de l'époque envisagée, à savoir le Liber de natura rerum de Thomas de Cantimpré2 ${ }^{2}$ le Speculum maius de Vincent de Beauvais en trois parties (Naturale, Historiale, Doctrinale) ${ }^{3}$ et le Liber de proprietatibus rerum de Barthélemy l'Anglais ${ }^{4}$, comme des paradigmes en quelque sorte. Cela,

1. Une version orale de cette contribution a été présentée au Centre d'études Préhistoire, Antiquité, Moyen Âge (UMR 6310) de Nice, dans la section Études médiévales, le vendredi 6 avril 2007, dans un programme appelé «L'ambition encyclopédique. Typologie des encyclopédies et spécificité des programmes ». Le titre de la contribution orale était le suivant: «Les sommes encyclopédiques du XIII $^{\text {e }}$ siècle et leurs antécédents: une typologie est-elle possible?»

2. Rédigé entre 1225 et 1240 (éd. BoESE, 1973).

3. Speculum maius, rédigé en plusieurs versions entre 1240 et 1259 (cf. éd. 1961/1965). Le texte de la version trifaria (historiale, naturale, doctrinale) est mis en ligne, de pair avec d'autres encyclopédies, par l'Atelier Vincent de Beauvais, Encyclopédisme et transmission des connaissances, dans le cadre du projet SourCENCYMe (Sources des encyclopédies médiévales). Ce projet élabore un corpus annoté des encyclopédies médiévales latines, doté d'un apparat d'identification progressive des sources et d'annotations sur la transmission textuelle de celles-ci. Le corpus évolutif, actuellement accessible en réseau aux chercheurs impliqués, devrait être mis en ligne pour le public début 2014.

4. Composé entre 1230 et 1247 (cf. éd. 1601). Une nouvelle édition critique est en cours, coordonnée par Chr. Meier, H. Meyer, B. Van den Abeele et I. Ventura, aux éditions Brepols à Turnhout, dans la collection De diversis artibus. Sont déjà parus: VAN DEN ABEele, MeYer, 2005; éd. VAN DEN ABEELE, et al., 2007; LONG, 2007: 135-199; éd. VENTURA, 2007b. L'édition du livre VIII (De mundo et corporibus celestibus), par I. Draelants, E. Frunzeanu, avec la collaboration de I. Ventura, a été remise à l'éditeur en novembre 2013. 
dans la mesure où elles seront beaucoup copiées par la suite et serviront donc à leur tour de modèle, remplaçant celui des Étymologies (terminées en 622) et du De natura rerum d'Isidore de Séville ${ }^{5}$ qui avaient dominé le genre jusqu'alors.

\section{LE GENRE ENCYCLOPÉDIQUE MÉDIÉVAL : HISTORIOGRAPHIE ET CONTEXTE}

Le terme « encyclopédie » comporte autant d'équivoques que de significations. Il faut donc, comme historien, légitimer l'emploi du mot et son utilisation à propos du Moyen Âge, période où le terme est usurpé car anachronique. Comme l'ont proposé les organisateurs des journées d'études, c'est donc plutôt l'ambition encyclopédique qui devrait guider l'examen. L'ambition encyclopédique, c'est-à-dire la position de l'esprit qui vise un système, est une perspective intellectuelle théorique qui organise les sciences et présente une synthèse des savoirs dans la perspective de leur transmission, que ce soit pour empêcher la perte de ces savoirs ou en promouvoir de nouveaux. Ce qui est alors en cause est l'encyclopédisme, plus largement que les encyclopédies qui font l'objet de la présente réflexion.

De considérables progrès historiographiques ont été réalisés dans la connaissance des encyclopédies médiévales ces dernières décennies. Pour mémoire, on peut citer les travaux de réflexion historique et littéraire sur le genre ${ }^{6}$ de Christel Meier-Staubach ${ }^{7}$ et de Heinz Meyer ${ }^{8}$ dans les années 1980 et 1990 et, à l'orée de ce nouveau siècle, les travaux de M. Paulmier-Foucart et de S. Lusignan; ceux, incitatifs, de M. de Gandillac dans les années 1960, avec le numéro des Cahiers d'histoire mondiale en 1966, et ceux, précurseurs, de Michel DE BouÄRD (1930) ou de W. Goetz en $1936^{9}$. Plusieurs colloques et ouvrages collectifs ont eu pour thème l'encyclopédisme ${ }^{10}$. De nombreux textes latins ont été également sortis de

5. Éd. LindSAY, 1911. Voir aussi la nouvelle édition en cours aux Belles-Lettres, coll. Auteurs latins $d u$ Moyen Âge. Sont parus les livres II (éd. Marshall, 1983), III (éd. Gasparatto, 2009), IX (éd. Reydellet, 1984), XI (éd. Gasti, 2010), XII (éd. André, 1986), XIII (éd. Gasparotto, 2004), XIV (éd. SPeVAK, 2011), XVI (éd. FÉans Landeira, 2011), XVII (éd. André, 1981), XVIII (éd. Cantó Llorca, 2007), XIX (éd. Rodriguez-Pantoja, 1995) et XX (éd. Guillaumin, 2010).

6. Sur l'encyclopédie comme genre littéraire au Moyen Âge, voir les notices du Lexikon des Mittelalters, t. 3, notamment: Bernt, 1986; Verger, 1986; Bernt, Jung, 1986; Bitterling, 1986; Schmitt, 1986.

7. Un recueil traduit en italien par I. Ventura des articles fondateurs de Chr. Meier-Staubach, écrits dans le contexte du Sonderforschungsbereich qui s'est tenu pendant plus de quinze ans au sein du Mittellateinisches Seminar de Münster, devrait paraître dans la collection Textes et études du Moyen Âge de la FIDEM sous le titre Studi sull'encyclopedismo medievale (Brepols). La présente contribution est nourrie des travaux de MeIER-Staubach, 1984 ; MeIER, 1988; $1992 ; 1995 ; 1997$.

8. MEYer, 2002.

9. voir aussi GoETz, 1937 et 1942.

10. L'ouvrage de Fumagalli Boenio-Brocchieri (1981) a précédé les colloques suivants: «L'encyclopédisme. Actes du Colloque de Caen, 12-16 janvier 1987 » (BECQ, 1991); «Vincent de Beauvais: Intentions et réceptions d'une œuvre encyclopédique au Moyen Âge. Actes du $\mathrm{XIV}^{\mathrm{e}}$ colloque de l'Institut d'Études Médiévales, organisé conjointement par l'atelier Vincent de Beauvais (A.R.Te.M., Univ. de Nancy II) et l'Institut d'études médiévales (Université de Montréal), 
l'oubli, réévalués, édités entre 1990 et aujourd'hui ${ }^{11}$. S'y sont ajoutés récemment maintes contributions de plus en plus pointues sur telle ou telle œuvre encyclopédique déjà mise au jour ou dont on approfondissait l'étude, au point de voir naître aussi des travaux sur les «produits dérivés » que sont les traductions vernaculaires ou les réécritures d'encyclopédies dans les derniers siècles médiévaux ${ }^{12}$, ou encore sur les «encyclopédisations » de thèmes particuliers comme la botanique (herbiers encyclopédiques) ou les questions scientifiques attribuées à Aristote (Problemata physica) $)^{13}$.

Sur l'ensemble de cette production, plusieurs solutions de classement et diverses définitions ont été proposées; chacune a son intérêt, mais aucune ne permet d'englober l'ensemble de ce qu'on appelle «encyclopédies ». Se limiter à une période et à un contexte culturel (l'Occident médiéval) permet de synthétiser classement et définitions, non sans rappeler trois faits ou postulats qui résonnent presque désormais comme des lieux communs:

- le mot enkyklios paideia représente, depuis le sens que lui ont donné Quintilien et Augustin ${ }^{14}$, un programme total d'enseignement des disciplines antiques ${ }^{15}$, une instruction qui embrasse tout le cycle du savoir, étant entendu qu'il s'agit d'un savoir théorique et destiné aux hommes libres. Autrement dit, il s'agit d'englober l'ensemble des arts libéraux. Le nom d'encyclopédie est donc approprié pour bon nombre d'œuvres médiévales ou de la fin de l'Antiquité;

27-30 avril 1988 » (Paulmier-Foucart, Lusignan, Nadeau, 1990); « L'enciclopedismo medievale. Atti del convegno "l'enciclopedimo medievale", San Gimignano 8-10 ottobre 1992 » (PICONE, 1994); «Enzyklopädien der frühen Neuzeit »(EYBL, 1995); Pre-Modern Encyclopedic Texts (BINKLEY, 1997); Discours et savoirs : Encyclopédies médiévales (BAILlaud, DE Gramont, HüE, 1999); «The Medieval Hebrew Encyclopedias of Science and Philosophy. Proceedings of the BarIlan University Conference » (HaRvey, 2000); « Die Enzyklopädie im Wandel » (MeIER, SchuleR, HeCKENKAMP, 2002); «All you need to know: Encyclopaedias and the idea of general knowledge. Conference, Prangins, Switzerland, 18-20 Sept. 2003 », publié sous forme d'e-book sur le site internet www.enzyklopaedie.ch (Michel, 2006); «Une lumière venue d'ailleurs. Héritages et ouvertures dans les encyclopédies d'Orient et d'Occident au Moyen Âge. Actes du colloque de Louvain-la-Neuve, 19-21 mai $2005 »$ (de Callataÿ, Van den Abeele, 2008).

11. Une nouvelle édition de Barthélemy l'Anglais est en cours (cit. note 4), précédée par le colloque déjà cité (Van den Abeele, Meyer, 2005; voir Meyer, 2000); l'édition critique d'Arnold de Saxe est en cours (cf. Draelants, $1992 ; 1993$; 2002). Parmi de nombreux autres exemples de mise au jour d'auteurs encyclopédiques, on peut mentionner «l'Experimentator » qui aurait partie liée avec le Liber rerum cité par Thomas de Cantimpré: Deus, 1998; le Liber floridus : Derolez, 1998; Marc d'Orvieto, édité par ETZKORN (2005); Gregorius de Montesacro publié par PABST (2002); Johannes de San Giminiano (éd. OLDONI, ZAPPERI, 1993 [traduction partielle du Liber de exemplis et similitudinibus rerum]) et VAN DEN Abeele, 2002; également Thierry Engelhus (HenKel, 1991), mais aussi Conrad d'Halberstadt: Ventura, 2001 : 349-406; ou un moine de Saint-Laurent de Liège: Van den Abeele, 2004: 43-60 et Bertrand, VAN den Abeele, 2006: 37-59.

12. On a ainsi mis au jour, entre autres, les diverses adaptations du De proprietatibus rerum de Barthélemy l'Anglais et celles du Liber de naturis rerum de Thomas de Cantimpré (voir VAN DEN ABEELE, 1994; 2007a; 2008).

13. Voir Ventura, 2003b; 2006; 2007a.

14. Quintilien, L'Institution oratoire, 1.10.1, mais aussi Augustin, Contra academicos, 3.7.

15. Cf. DE RIJK, 1965 et Bos, 1989: 179-198. 
- cependant, le mot « encyclopédie » n'est apparu qu'aux Xve-Xvi ${ }^{\mathrm{e}}$ siècles, et non pour qualifier ce que nous nommons ainsi, mais comme équivalent d'orbis doctrinae, cycle de science; il n'est donc jamais employé au Moyen Âge, qui a son propre vocabulaire pour décrire ce genre littéraire - pour autant qu'il existe un genre encyclopédique en tant que tel ;

- il y eut un « siècle de l'encyclopédisme » avant l'Encyclopédie de Diderot et d'Alembert à la fin de l'Ancien Régime, et ce fut le XIII siècle, que l'on fera remonter jusqu'aux alentours de $1180^{16}$.

En dépit des périodisations traditionnelles de l'histoire, on peut constater en effet que les années 1180-1260, assez sereines d'un point de vue politique et économique, représentent une transition intellectuelle dans un Occident dominé par les échanges commerciaux, intellectuels et religieux en Méditerranée. De cette transition intellectuelle, les encyclopédies vouées à la sélection, la mise en mémoire, l'organisation des savoirs accrus à cette période - en un mot, à leur compilation - sont un témoin privilégié. Consacrées à l'accumulation de la science dans une volonté totalisante, elles illustrent mieux que toute autre littérature de l'époque la mutation épistémologique de certaines disciplines, en particulier celles issues du quadrivium de la basse Antiquité. C'est au XIII' siècle que le phénomène de compilation encyclopédique a pris sa plus grande ampleur. Il fut rendu nécessaire par l'afflux extraordinaire de connaissances qu'a connu le siècle précédent, en grande partie grâce aux traductions gréco- et arabo-latines qui rendaient à nouveau disponible un savoir antique, mais mettaient également au jour l'acquis des civilisations qui en furent les véhicules, à savoir les cultures syriaques et arabes. Ce phénomène est suivi aussi de nombre d'autres instruments de travail de la vie intellectuelle visant à organiser les connaissances: les index, les tables des matières, la systématisation de l'ordre alphabétique et de l'organisation de la mise en page, les concordances (comme celle de la Bible par le dominicain Hugues de Saint-Cher, vers 1220), les florilèges, etc. C'est donc à cette période qu'il semble légitime de chercher des paradigmes susceptibles de contribuer à la définition d'une littérature encyclopédique.

Pour illustrer notre propos, sont allégués des extraits de l'œuvre la plus explicite sur la méthode de compilation encyclopédique, le Libellus apologeticus qui figure en tête du Speculum maius de Vincent de Beauvais ${ }^{17}$, ainsi que d'autres œuvres encyclopédiques qui lui sont contemporaines.

16. L'expression et les limites chronologiques du « siècle de l'encyclopédisme » ont été popularisées par Jacques Le GoFf, 1994.

17. Le Libellus de Vincent de Beauvais a été étudié par LuSIGNAN, 1979 et précédemment par vON DEN BRINCKEN, 1978, et se trouve édité dans ses différentes versions sur le site de l'Atelier Vincent de Beauvais : http://atilf.atilf.fr/bichard/. La plus grande part en est traduite dans l'ouvrage suivant, d'où sont tirés les extraits cités (notés désormais VB, $L A$ ) : PAULMIER-Foucart, 2004. 


\section{SEPT CRITÈRES COMME ÉLÉMENTS D'UNE DÉFINITION}

En combinant éléments de critique interne et examen externe de l'objet dans son contexte, la méthode historique permet d'avancer sept critères remplis par un certain nombre d'œuvres médiévales à ambition encyclopédique; d'après ces critères, ces œuvres peuvent être regroupées, sinon classées.

\section{Compilation globalisante en un seul volume}

La volonté de rassembler, de compiler des connaissances sur tous les sujets de manière globalisante, dans un seul ouvrage, constitue l'élément premier et fondamental d'une définition de l'encyclopédie, envisagée ici comme le genre dédié à la divulgation organisée d'un savoir universel et non à la présentation générale et complète d'une seule matière.

Il y a tant de livres, une telle multitude, le temps de la vie est si bref, et la mémoire si faible, que l'esprit humain ne peut s'approprier tout ce qui a été écrit. Pour ces raisons, et pour répondre à la demande de mes supérieurs, moi, le plus petit des frères dominicains, qui ai depuis longtemps et assidûment consulté et lu avec application beaucoup de livres, j'ai choisi, selon mes possibilités, des extraits de presque tous les livres que j'ai lus, œuvres des docteurs chrétiens et des auteurs, païens, poètes et philosophes, et aussi des historiens de l'un et l'autre bord; $\mathrm{j}$ 'ai réuni et mis en ordre ces extraits, sous forme de compendium, en un seul ensemble... (VB, LA, c. 1 [Matière et but de l'ouvrage, p. 149]).

Car l'esprit [...] contemple aussi le temps du monde entier, depuis son commencement jusqu'à maintenant, en une vision d'ensemble, et il englobe ainsi la totalité des siècles à travers les diverses successions des générations et les mutations des choses (ID., c. 6 [Apologie de la nature des choses et de l'histoire des temps, p. 156]).

Qui pourrait rassembler en bref tout ce qui se trouve éparpillé, sur chaque sujet, à travers le monde, dans une telle masse, quasi infinie, de volumes, et contractant tout cela, en faire un seul volume sous forme de manuel? (ID., c. 11 [Apologie de l'unité de la matière et de sa séparation, p. 161]).

\section{Nécessité de reconstruction du savoir (mise en mémoire et mise à jour)}

La volonté de faire la somme des connaissances humaines jugées indispensables s'est traduite de différentes manières au cours des siècles, mais elle s'exerçait surtout dans des périodes où se faisait sentir la nécessité de reconstruction du savoir. Les facteurs de cette nécessité sont très divers; d'eux dépendent la diversité des productions encyclopédiques et dès lors les critères de classement. 
Certaines périodes de l'histoire ont été plus propices, pour des raisons différentes, à la mise à jour et/ou à la divulgation du savoir.

De plus, parce que ces connaissances, remplacées par d'autres, s'estompent facilement du souvenir, il m'a paru adéquat d'en donner pour mémoire [...] un condensé convenablement ordonné, auquel l'esprit du lecteur curieux pourra se référer $[\ldots]$ (VB, LA, c. 7 [Apologie de l'ensemble des sciences, p. 156]).

Ainsi le contenu dépend-il des circonstances et des époques. Les préoccupations sont différentes à la fin de l'Empire romain, où le système d'éducation est en crise, ou à la naissance du monachisme occidental, où il faut le construire; à la renaissance carolingienne, où l'on tente une uniformisation et une rénovation de l'empire romain perdu; dans le $\mathrm{XII}^{\mathrm{e}}$ siècle des écoles cathédrales de théologie où l'on commente l'œuvre du créateur comme on le ferait de la Bible; au $\mathrm{XIII}^{\mathrm{e}}$ siècle qui voit la redécouverte d'une civilisation-mère passée par diverses médiations et où l'on veut instruire par la prédication; aux XIV et $\mathrm{XV}^{\mathrm{e}}$ siècles où l'on vulgarise et laïcise les connaissances. Il dépend aussi des régions et de leur système: du degré de romanisation, dans l'Empire; du degré de christianisation, au début du Moyen Âge; du degré de pénétration de la culture de langue arabe, lors du mouvement de traduction du XII ${ }^{\mathrm{e}}$ siècle; du degré de germanisation, lors de la diffusion des universités en Europe centrale, etc. Le contenu dépend évidemment aussi du public: étudiants, clercs, laïcs ou nobles, universitaires ou gens peu instruits, etc. Autrement dit, l'œuvre encyclopédique dépend des « codes fondamentaux » d'une culture, comme les appelle Michel Foucault ${ }^{18}$, et des théories scientifiques en vigueur. C'est sur un point d'équilibre ou sous la forme d'un compromis entre ces deux dimensions, que s'exprime le mode de pensée qui régit l'œuvre encyclopédique.

\section{Auctoritates dans un «livre des livres » et bibliothèque du savoir théorique (Bibliothekersatz ${ }^{19}$ )}

La donnée fondamentale des encyclopédies est la compilation, véritable habitus de l'intellectuel médiéval, directement corrélée à la notion d'autorité (auctoritas) qui fonde toute réflexion et tout enseignement à cette époque et dont la phrase célèbre de Bernard de Chartres est exemplaire (« Nous sommes des nains juchés sur des épaules de géants... $\left.\gg^{20}\right)$. Les encyclopédies médiévales sont en effet constituées à près de quatre-vingt-dix pour cent d'un tissu de citations diverses organisées en vertu d'une logique interne. Les compilateurs rassemblent dans leurs œuvres encyclopédiques tout ce qui alimente et donne du poids aux discussions scolastiques dans les studia depuis un siècle: c'est-à-dire la «biblio-

18. FoucAult, 1966: 11-12

19. Le concept allemand utilisé par Chr. Meier-Staubach est ici particulièrement évocateur: une encyclopédie « remplace », tient lieu de bibliothèque.

20. Cette métaphore a été transmise via Jean de Salisbury (éd. HaLl, KeAts-Rohan, 1991 : 117). 
graphie autoritative » de leurs prédécesseurs dans le parcours de la connaissance, l'illustration permanente de la révérence pour les auteurs Anciens et Modernes qui illuminent de leur « autorité » telle ou telle sentence. Les auctoritates sont généralement des auteurs antiques comme Aristote ou Ptolémée, mais aussi des pères de l'Église et, peu à peu, des « docteurs » contemporains comme Jean de la Rochelle, Albert le Grand, Thomas d'Aquin. Les encyclopédies médiévales prennent d'ailleurs le soin de citer leurs sources via des références précises, qui sont formées le plus souvent d'un nom d'auteur et d'un titre d'œuvre, parfois accompagné de la référence au livre. La logique du tissage des citations, la technique de la facture d'extraits de chaque œuvre encyclopédique indique la relation qu'entretient chaque compilateur par rapport à ses sources.

Je rappelle au lecteur, pour qu'il ne soit pas perturbé s'il trouve ces opinions contraires exposées dans cette oeuvre sous le nom divers auteurs, que j'ai déclaré hautement que je n'ai pas écrit cette oeuvre en tant qu'auteur de traité, mais en tant que compilateur; et partant, je n'ai pas tenté à grand peine de mettre en concordance les dits des philosophes, mais seulement de rapporter ce que chacun d'eux a pensé ou écrit sur tel sujet ${ }^{21}$ (VB, LA, c. 8 [Apologie des dits des philosophes et des poètes, p. 158]).

Les sources excèdent cependant le champ des autorités de poids, puisque les encyclopédies cumulent par nature le savoir et que le genre s'autonourrit ${ }^{22}$. Cela d'autant plus que le Moyen Âge n'a pas « réinventé » l'encyclopédie, mais qu'il est l'héritier d'une lignée qui doit beaucoup aux grammairiens et compilateurs de la fin de l'Antiquité comme Caton, Celse ou plus encore Varron, ou, à la fin de la chaîne, Isidore de Séville et ses Étymologies, sans oublier des maillons importants comme l'Historia naturalis de Pline, dont la préface dit: ante omnia attingenda

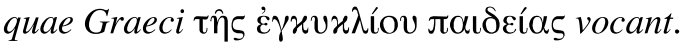

J'ai aussi été encouragé dans cette tâche par l'exemple de nos pères, à savoir Isidore de Séville, Hugues et Richard de Paris [= Saint-Victor]: le premier dans le livre des Étymologies, entre autres sujets qu'il aborde, traite en bref de chacune des sciences; le deuxième, dans le livre du Didascalicon, divise l'ensemble des sciences et subdivise chacune d'elles, en décrit brièvement la matière; le troisième, dans le Liber exceptionum, fait la même chose (VB, $L A$, c. 7, p. 156-157).

Assembler de la sorte des pensées de toutes origines pose évidemment le problème, d'une part, du rapport à la pratique et, d'autre part, de la translation de la pensée des autres sous forme de mosaïque manquant parfois d'unité et ne donnant qu'un reflet pâli des doctrines philosophiques. Mais le but des encyclopédies n'est

21. Ce passage comme plusieurs autres du Liber apologeticus est emprunté par Jean de Saint-Victor (c. 1322) pour son prologue au Memoriale temporum: «Unum autem volo premittere ego, huius operis compilator, non inventor, quod in hoc tractatu majorum auctorum predecessorum meorum, prout potero, non tamen sentenciis sed eciam verbis utar ». Cf. GuYoт-BACHY, 1993. L'extrait est cité p. 242.

22. Sur cette question et sur les types de sources utilisées par les encyclopédistes du XIII ${ }^{\mathrm{e}}$ siècle, en particulier dans le domaine de la science naturelle, cf. DRAELANTs, 2005. 
ni ici, ni là: elles visent à transmettre le savoir théorique, livresque, et à élaborer un discours sur les choses ou sur la «nature et les propriétés des choses ».

Si quelqu'un, parmi ceux qui ont scruté avec attention les propriétés naturelles des choses dans les oeuvres de différents auteurs, cherche sous son titre, dans mon ouvrage, cette matière, il trouvera là sans doute moins que ce qu'il a lu ailleurs à ce sujet, $[\ldots]$ ( VB, LA, c. 11 [Apologie de l'unité de la matière et de sa répartition, p. 161]).

Donc la première partie traite de la nature et des propriétés de toutes choses, la seconde de la matière et de l'ordre de tous les arts, la troisième de la suite de tous les temps (ID., c. 17 [Division de l'ouvrage en trois parties, p. 166]).

Ce savoir théorique, les encyclopédies le livrent en respectant une classification des connaissances livresques issues des arts libéraux, trivium et quadrivium, classification prônée par Augustin, Martianus Capella, Cassiodore, Isidore de Séville ou Bède le Vénérable ${ }^{23}$; ces œuvres s'intéressent parfois aussi aux arts mécaniques définis dès la fin de l'Antiquité ${ }^{24}$, mais les abordent d'un point de vue théorique (l'exemple-type est le Didascalicon d'Hugues de Saint-Victor ${ }^{25}$, un des modèles du Speculum maius de Vincent de Beauvais).

Pourl'auteur-compilateur d'une «bibliothèque en réduction»(Bibliothekersatz), l'encyclopédie est donc à la fois « un grand'œuvre» et un «livre des livres ». En tant que telle, elle est a priori sans originalité, si ce n'est d'ordonnancement et de choix des matières et des sources.

À ces trois premiers critères essentiels, j'ajouterais quatre autres, qui représentent la tension entre le contexte et son impact sur l'œuvre didactique: l'environnement philosophique et culturel (4), le choix de l'ordre adopté (5), les titres médiévaux (6), la réponse à la demande d'un public spécifique confrontée à une vision singulière du monde (7).

\section{Dépendance du cadre épistémologique et idéologique (contexte culturel)}

Le territoire des encyclopédies se situe à l'intersection entre l'édification morale et la formation par la science; en ce sens, leurs structures d'organisation et les choix de matières dépendent du cadre épistémologique et idéologique de l'époque de rédaction. En vertu du pivot chronologique proposé plus haut, les années 1180-1220 divisent deux périodes dominées par un contexte culturel différent.

Schématiquement, on pourrait considérer qu'avant le XIII ${ }^{\mathrm{e}}$ siècle domine ce qu'on a nommé un "platonisme augustinien" gouverné par la contemplation et la lecture de la Bible. Chrétiennes, les encyclopédies qui naissent pendant les

23. La bibliographie sur les arts libéraux est très riche. Par exemple: VRIN, 1969; LindGREN, 1992; ENGLISCH, 1994

24. Sur ce sujet, on verra entre autres le volume dirigé par JANSEN-SIEBEN, 1989

25. Voir ChÂtILlon, 1966. 
premiers siècles du Moyen Âge témoignent d'une tension entre cupiditas et curiositas, entre désir et mépris du savoir. L'esprit ne devrait aspirer qu'à la seule connaissance de Dieu. Le principe augustinien domine, selon lequel les sciences profanes constituent, certes, une propédeutique à la compréhension de la Bible, mais doivent être traitées à la manière dont les Hébreux ont réutilisé les vases d'Égypte en les fondant, ou comme une servante à laquelle on coupe les cheveux et rogne les ongles ${ }^{26}$. Les compilations mêlent ainsi désintérêt du monde, comme lieu du péché, et admiration du monde, comme œuvre de Dieu. Cette tension a dominé tout l'accès aux sciences profanes et empêché la mise à jour de nouvelles connaissances en dehors de celles justifiées par la lecture de la Bible et par le raffinement de plus en plus subtil de l'exégèse, mais elle n'a entravé ni l'invention de procédés permettant l'accès à la connaissance, ni l'émergence d'autres classifications, ni les discussions consécutives sur la nature du savoir.

$\mathrm{Au} \mathrm{XIII}^{\mathrm{e}}$ siècle, une nouvelle tension apparaît avec la découverte du caractère encyclopédique - au sens grec et antique du terme - de l'œuvre totale d'Aristote, éclatée en livres sur tous les sujets, source inépuisable de sententiae, d'auctoritates et de commentaires. S'impose une connaissance ancienne, habillée d'un mode de pensée nouveau où le désir de savoir - la curiositas - est légitimé par l'accès à la connaissance sensorielle prônée par Aristote et par ses continuateurs et commentateurs ; mais cette légitimation du désir de savoir implique la difficulté pour les « intellectuels moyens » d'absorber ces nouvelles connaissances.

\section{Ordonner et classifier (le savoir théorique) en donnant du sens}

Les auteurs d'encyclopédies antiques et médiévales rédigent leur « livre du monde » comme autant de livres de toutes les matières, en fonction du sens qu'ils veulent donner à leur somme. Le moule dans lequel les réalités seront fondues peut être étymologique et didactique, comme chez Isidore de Séville au vII siècle, ou simplement pédagogique, comme dans le cas d'Hugues de Saint-Victor au XII . Il peut être allégorique, exégétique et biblique, c'est-à-dire s'attachant à tracer un lien entre description et signification morale de la nature, comme dans le $D e$ universo de Raban Maur ${ }^{27}$, dans le De rerum natura d'Alexandre Neckam, qui est un commentaire structuré de l'Ecclésiaste ${ }^{28}$, ou dans la rélaboration appelée « Thomas III » du Liber de natura rerum de Thomas, ou encore dans les notes marginales moralisantes du De proprietatibus rerum de Barthélemy l'Anglais. Le mode de pensée peut être également axé sur la description de la nature, comme chez Alexandre Neckam ou dans le Liber rerum dont s'est servi Thomas de Cantimpré. Il peut être encore orienté philosophiquement d'après des catégories ou la classification des sciences et des arts en vigueur, comme chez Daniel de

26. Éd. MARTin, 1962

27. De universo libri XXII, éd. PL 111, col. 13-614. Voir aussi éd. CAVAllo, 1994

28. Composé vers 1200. Éd. WRIGHT, 1863 et l'étude de ZAHORA, à paraître 2013. 
Morley ${ }^{29}$, Barthélemy l'Anglais, Arnold de Saxe, Vincent de Beauvais. Le mode de pensée donne en tout cas sens à l'ordonnancement des matières: il impose un rapport d'équilibre entre les données scientifiques et leur traitement.

Quelle que soit l'époque, la volonté de rassemblement des connaissances et des savoirs nécessite, dans l'esprit du compilateur, tant une classification du savoir ${ }^{30}$ qu'un choix dans les matières en fonction de critères préalablement déterminés.

[...] mais il y a nécessité d'abréger [...] j’ai repris tout cela sous des titres précis : dans une première partie [...] tout ce qui tient à la nature des choses [naturale], et dans une deuxième, tout ce qui concerne l'ensemble des sciences [doctrinale]... (VB, LA, c. 11 [Apologie de l'unité de la matière et de sa répartition = suite de l'extrait précédent, p. 161-162]).

Pour que les différentes parties de cette oeuvre apparaissent plus clairement au lecteur, j'ai voulu la diviser en livres, et les livres en chapitres (ID., c. 3 [Manière de faire et titre du livre, p. 152]).

La première partie contient toute l'histoire naturelle, et est nommée Speculum creatorum, Miroir des créatures; la seconde expose la suite doctrinale, c'est le Speculum scientiarum, Miroir des sciences; la troisième raconte toute l'histoire temporelle et est nommée Speculum historiarum, Miroir des histoires (ID., c. 16 [Contenu de l'ouvrage], et c. 17 [Division de l'ouvrage en trois parties]).

De ce qui précède, peuvent être déduites les trois caractéristiques principales d'une encyclopédie: 1) la compilation en un ouvrage ; 2) le rassemblement de citations en vue de fournir une matière bibliographique d'accès aisé ; 3) l'organisation des matières. Il s'agit de produire un livre ordonné, soit d'après une logique applicable aux domaines des réalités décrites, soit d'après un ordre choisi arbitrairement.

\section{Ordre arbitraire}

Cet ordre peut être celui de l'alphabet (comme dans l'Historia naturalis de Juan Gil de Zamora ${ }^{31}$ vers 1300 ou dans l'Hortus sanitatis au $\mathrm{Xv}^{\mathrm{e}}$ siècle), ordre particulièrement commode pour le classement des réalités des trois règnes naturels sous forme de répertoires de plantes, pierres et animaux. On trouve de tels répertoires insérés dans les encyclopédies naturelles complètes de Barthélemy l'Anglais, Thomas de Cantimpré, Arnold de Saxe ou Vincent de Beauvais au milieu du XIII ${ }^{\mathrm{e}}$ siècle, dans des sections qui prolongent ainsi la tradition médiévale des herbiers, lapidaires et bestiaires. L'ordre alphabétique convient aussi à certaines œuvres qui relèvent davantage du florilège thématique que de l'encyclopédie, comme les recueils d'exempla ou de moralisations ${ }^{32}$, ou les remoralisations

29. La Philosophia mundi de Daniel de Morley fut écrite vers 1200 , sans qu'il puisse tenir compte des nouvelles traductions arabo-latines de Gérard de Crémone, qu'il dit avoir côtoyé (éd. SudHoff, 1917).

30. Voir notamment Dahan, 1990; HüNEMÖrder, 1987; Palmer, 1989; Hugonnard-Roche, 1984; BuRNETT, 1990 ; ZONTA, 1995.

31. Éd. Domínguez García, García Ballester, 1994.

32. Voir Ventura, 2003a. 
tardives d'encyclopédies aux XIV et $\mathrm{XV}^{\mathrm{e}}$ siècles, conçues comme des instruments systématiques de travail pour les prédicateurs.

L'ordre choisi peut aussi être celui, classique, des vices et des vertus. C'est partiellement le cas de l'Imago mundi d'Honorius Augustodunensis ( $f$. 1080$1140)^{33}$, et c'est également le plan initial - abandonné - du Speculum maius de Vincent de Beauvais et celui de la cinquième partie, morale, du De floribus rerum naturalium d'Arnold de Saxe.

L'ordre chronologique peut être utilisé concurremment. Ce peut être celui des six jours de la création et/ou des âges du monde. On le trouve chez Alexandre Neckam, dans le De hominum deificatione de Grégoire de Montesacro $(c .1230)^{34}$, dans le Speculum naturale de Vincent de Beauvais, ou encore dans les Otia imperialia de Gervais de Tilbury (offertes à l'empereur Otton VI de Brunswick par Gervais de Tilbury au tournant des $\mathrm{XII}^{\mathrm{e}}$ et $\mathrm{XII}^{\mathrm{e}}$ siècles), qui suivent la chronologie de la Genèse au Déluge pour dessiner le monde naturel ${ }^{35}$.

Par exemple, concernant la nature des choses, à savoir les quatre éléments, les mouvements de l'air et les événements atmosphériques, les sols, les pierres, les minéraux et les plantes de la terre, les astres du ciel, les oiseaux, les poissons, les animaux terrestres, les extraits des divers auteurs sont placés au début de l'ouvrage, selon l'ordre des six jours au cours desquels cela a été créé, mais beaucoup d'informations sont ajoutées dans la deuxième partie, au livre de la philosophie naturelle, car cela relève de cette matière. Ensuite, pour les corps minéraux, il en est non seulement parlé dans ces deux endroits, mais encore plus loin dans le livre des arts mécaniques, au traité de l'alchimie, pour autant que cela concerne cet art (VB, LA, c. 3 [Manière de faire et titre du livre, p. 152]).

L'ordre hiérarchique est celui adopté par le De universo de Raban Maur, où la hiérarchie des êtres est revue à partir du De natura rerum d'Isidore de Séville, de Dieu aux choses inanimées. Il s'impose aussi au premier livre intitulé De celo et mundo de l'encyclopédie d'Arnold de Saxe et au début du De proprietatibus rerum de Barthélemy, qui suit la hiérarchie des êtres du pseudo-Denys l'Aréopagite, partant de Dieu pour aller vers l'homme, en passant par les anges, l'âme rationnelle et les substances corporelles.

Le plus souvent, les deux types d'arrangement, logique et alphabétique, coexistent avec l'ordre chronologique dans les encyclopédies, mais les plus représentatives d'entre elles privilégient l'ordre logique.

\section{Ordo artium / disciplinarum}

On s'entend, depuis les travaux de Christel Meier, pour classer en deux groupes l'ordre logique: l'ordo artium ou disciplinarum d'une part, l'ordo rerum de l'autre. Certaines œuvres mêlent ces deux types, mais les choix dépendent à la

33. Éd. Flint, 1949.

34. Cf. éd. PABSt, 2002.

35. Voir éd. BanKs, BinNs, 2002. On dispose aussi d'une traduction française commentée de la $3^{e}$ decisio (DUCHESNE, 1992). 
fois d'une conception codifiée de l'ordre du monde et du niveau de science et de rationalisation du milieu naturel.

L'ordo artium ou disciplinarum, qui sous-tend l'organisation encyclopédique, se fonde sur une classification des connaissances, qu'elle soit théorique ou empirique, traditionnelle ou novatrice ${ }^{36}$. La perspective est donc plus anthropologique, tandis qu'elle est davantage cosmologique dans le cas de l'ordo rerum. Les deux systèmes de classification qui ont dominé le Moyen Âge sont celui des arts libéraux et celui proposé par la distribution des livres naturels d'Aristote. La vision du monde qu'ils lèguent fait donc tenir l'organisation des savoirs à des conceptions philosophiques, dont les plus représentées au Moyen Âge sont les conceptions chrétienne, néoplatonicienne, et aristotélicienne.

Ainsi, la théologie et la philosophie chrétiennes dominent les encyclopédies ordonnées d'après l'Hexaemeron (Alexandre Neckam, De natura rerum; Vincent de Beauvais, Speculum naturale; Grégoire de Montesacro, De hominum deificatione) ou selon la hiérarchie des êtres pseudo-dionysienne, comme la première partie du De proprietatibus rerum de Barthélemy l'Anglais, qui met l'accent sur l'interdépendance entre le monde intelligible et le monde invisible (Dieu, les anges, l'âme), avec pour relais la raison humaine. Dans cette conception du monde, la philosophie chartraine a eu une influence notoire. Elle a, en effet, imposé une théologie de la Création nourrie par un savoir tendant à l'encyclopédisme et suscité une philosophie destinée à inscrire la Création dans l'histoire des hommes. Cette philosophie chartraine a fortement influencé Vincent de Beauvais.

Le néoplatonisme, qui incite à considérer l'univers comme une série de causes et d'effets, domine les ouvrages naturalistes du XII ${ }^{\mathrm{e}}$ siècle, précurseurs des encyclopédies du siècle suivant. La documentation est néo-platonicienne, mais les œuvres sont ouvertes à la nouveauté, comme la Philosophia mundi de Guillaume de Conches, le Dragmaticon d'Hugues de Saint-Victor, l'Imago mundi d'Honorius Augustodunensis. Le néoplatonisme prévaut aussi dans les encyclopédies postérieures à 1220 , où la place des sources arabes est importante, car les auteurs arabophones utilisés en traduction ont lu Aristote, aux vIII ${ }^{e}$ et IX ${ }^{e}$ siècles, à la lumière des interprétations néo-platoniciennes ${ }^{37}$. Les encyclopédies de Barthélemy l'Anglais, d'Arnold de Saxe et de Vincent de Beauvais, comme les œuvres naturalistes d'Albert le Grand, sont influencées par l'apport gréco-arabe (lecture arabe des textes grecs, mais aussi œuvres originales venues d'Orient ou d'Al-Andalus).

L'aristotélisme est manifeste principalement dans des encyclopédies du $\mathrm{XIII}^{\mathrm{e}}$ siècle, dont la plus grande partie des sources, dans le domaine de l'étude de la nature, est nouvelle (traités d'Aristote et textes pseudo-aristotéliciens traduits du

36. Un remarquable ouvrage collectif, sous la direction d'U. SCHAEFER (1999), examine de manière approfondie les arts, leurs classements et leur utilisation dans les ouvres didactiques, dont les encyclopédies. Il est divisé en cinq parties, où les contributions suivantes servent le présent sujet: HaAs, 1999; Brinker-Von der Heyde, 1999; Englisch, 1999; SARnowsky, 1999; Kellermann, 1999; en particulier: KNOCH, 1999; DE RENTIIs, 1999; KAYLOR, 1999; entre autres FÜRBETH, 1999.

37. Un colloque très riche a examiné à nouveaux frais l'influence arabe sur la littérature didactique latine : SPEER, Wegener, 2006. 
grec et de l'arabe). C'est la belle époque de la «philosophie naturelle » qui élargit et dépasse le cadre de l'ancien quadrivium, grâce à la découverte ou au renouvellement de sciences comme l'alchimie, la médecine, l'optique. On peut citer pour exemples les encyclopédies qui ont pour objectif d'être des livres universels (Weltbücher) ou des «livres des livres » (Bibliotheksersätze) et représentent, par la notivas de leur documentation, un tournant de la culture philosophique et scientifique du temps, comme le De floribus rerum naturalium d'Arnold de Saxe et le Compendium philosophiae ${ }^{38}$. C'est aussi le cas de Barthélemy l'Anglais pour la seconde partie de son encyclopédie, consacrée au macrocosme, aux éléments, et sous-tendue par les concepts de matière et de forme ${ }^{39}$, ou pour certains livres du Speculum Doctrinale de Vincent de Beauvais.

À titre d'exemple de l'utilisation de la hiérarchie des disciplines comme principe d'accès aux textes, le fondateur et le modèle des encyclopédies médiévales reste incontestable: les Étymologies d'Isidore de Séville, avec ses dix premiers livres rangés selon les arts libéraux, associée à d'autres modèles didactiques classiques. La plus grande des encyclopédies médiévales applique, dans une de ses trois parties, le même principe. Ainsi, le Speculum doctrinale de Vincent de Beauvais expose le contenu de chacune des disciplines en suivant l'ordre du Didascalicon d'Hugues de Saint-Victor. Il égrène donc les arts libéraux et les arts mécaniques, l'ensemble de ces disciplines pouvant également se répartir selon la division tripartite aristotélicienne du savoir en théorique, pratique et logique: les arts du quadrivium entrant dans la partie théorique, les arts mécaniques, dans la pratique, le trivium dans la logique. Vincent de Beauvais tempère cette classification en faisant intervenir celles de l'Arabe Al-Fârâbî et des libri naturales d'Aristote. Il divise les dix-sept livres du Doctrinale en quatre parties: 1) logique (grammaire, dialectique, rhétorique, poésie); 2) philosophie pratique (morale, économie, politique, droit); 3) savoir mécanique, dont la médecine théorique et appliquée; 4) philosophie théorique (quadrivium), avec la physique, l'arithmétique et la théologie. Le Tresor de Brunetto Latini (1210-1290 ${ }^{40}$ - s'organise également d'après les arts libéraux. Il commence par le savoir théorique et finit par la pratique, en soumettant le premier à la seconde.

38. Le Compendium porte dans les plus anciens manuscrits le titre de Compilatio de libris naturalibus Aristotelis et aliorum quorundam philosophorum de rerum natura. Sa date de composition, sujette à discussion (probablement vers 1240-1250), doit être confirmée. E. Kuhry a entrepris une thèse de doctorat à Nancy sur cette œuvre sous la co-direction d'I. Draelants et de C. Jacquemard (soutenance décembre 2013). Elle prévoit l'édition critique des livres de philosophie naturelle du Compendium philosophiae; R. SACCENTI, durant son post-doc à l'Atelier Vincent de Beauvais, a préparé l'édition critique du livre VIII sur la morale. L'auteur de la première édition partielle (DE BOUÄRD, 1939) situe l'œuvre après la mort de Thomas d'Aquin (voir aussi DE BouÄRD, 1932).

39. Il commente, dans la préface au livre X, l'affirmation de la Métaphysique d'Aristote (discutée par Thomas d'Aquin dans le De natura materiae et dimensionibus interminatis): materia enim est causa individuationis rerum (Barthélemy l'Anglais, 1964: 468).

40. Bolton Holloway, 1986 et 1993. La bibliographie est complétée dans : Ventura, 1997: 499-528. Voir aussi VENTURA, 2004a. 


\section{Ordo rerum}

L'ordo rerum, quant à lui, offre une représentation du monde cohérente et complète de tous les phénomènes naturels connus. On peut en citer pour exemple les livres XI à XX des Étymologies (de l'homme et des animaux aux activités et productions humaines, en passant par les quatre éléments), mais aussi toutes les encyclopédies naturelles du XIII ${ }^{\mathrm{e}}$ siècle qui témoignent d'une représentation du monde en fonction de son utilisation par l'homme ( « Natur im Gebrauch des Menschen », d'après l'expression de Chr. Meier) ou en fonction du regard de la créature sur le monde.

Dans cette catégorie d'encyclopédies qui s'organisent d'après un ordo rerum, une grande part est donc occupée par les encyclopédies en forme d'image du monde, gouvernées par une vision cosmologique où la matière naturelle en rapport avec la destinée humaine constitue la plus grande part. Il s'agit d'une conception de la nature propre à toute la première partie du Moyen Âge jusqu'au tournant du XIII ${ }^{\mathrm{e}}$ siècle, et qui s'illustre admirablement dans ces vers écrits par Alain de Lille en 1147 dans sa Cosmographia ${ }^{41}$ :

$\begin{array}{ll}\text { Omnis mundi creatura } & \text { Toute créature du monde } \\ \text { quasi liber et pictura } & \text { est pour nous comme un livre et une peinture } \\ \text { nobis est, et speculum } & \text { et un miroir } \\ \text { nostrae vitae, nostrae mortis } & \text { de notre vie, de notre mort } \\ \text { nostri status, nostrae sortis (var. sortiae) } & \text { la marque fidèle } \\ \text { fidele signaculum } & \text { de notre état, de notre destinée. }\end{array}$

Cependant, par leur rapport à la nature, les encyclopédies latines sont également héritières de la Naturalis historia de Pline, qui décrit le monde en essayant de rendre compte d'un savoir séculier ${ }^{42}$. Pline voit, en effet, la nature comme « souveraine créatrice et ouvrière », « divine mère » de toute chose créée, mais une nature qui peut être imitée par l'art des hommes ${ }^{43}$.

Donner à voir une image du monde est le but, par exemple, de l'Apex physicae au XII ${ }^{\mathrm{e}}$ siècle et de la Physica d'Hildegarde de Bingen au milieu du XII ${ }^{\mathrm{e}}$ siècle,

41. Alain de Lille, Cosmographia, Rythmus, éd. PL 210, 1855, col. 579A; ce poème, appelé De miseria mundi dans les premiers manuscrits, est réédité dans D'AlVERNY, 1965. Voir GREGORY, 1992: 78 et $99-100$.

42. L'encyclopédie du Pseudo-John Folsham est inspirée de Pline et de nombreux auteurs, dont les encyclopédistes Raban Maur ou Jacques de Vitry. Elle a été mise au jour par C. HÜNEMÖRDER sous divers titres: Liber de proprietatibus rerum excerptus ex multis auctoribus; Liber de naturis rerum abreuiatus; Summa de natura et proprietatibus rerum animatarum et inanimatarum. Cf. ABRAmov, 2002 et HÜNEMÖRDER, 1997.

43. HN 22.117: Non fecit ceratum malagmata, emplastra, collyria, antidota parens illa ac diuina rerum artifex, "Cérat, onguents, emplâtres, collyres, antidotes n'ont pas été créés par la divine Mère, créatrice de l'Univers... ». Et HN 24.1: Ne siluae quidem horridiorque naturae facies medicinis carent, sacra illa parente rerum omnium nusquam non remedia disponente homini, ut medicina fieret etiam solitudo ipsa..., « Les forêts même, et la nature dans son aspect sauvage, ne sont pas dépourvues de remèdes: cette sainte mère de toutes choses en a disposé partout pour l'homme, au point que le désert même est source de remèdes ». 
ouvrage qui organise la nature en fonction des éléments et des différents tempéraments et humeurs ${ }^{44}$. Il en va de même pour l'Image du monde (1245) de Gossuin de Metz $^{45}$ ou de l'Imago mundi d'Honorius, qui a eu une influence considérable sur les naturalistes postérieurs comme Bernard Silvestre (Cosmographia, avant 1148) ou Alain de Lille (1128-1202, De planctu naturae) et jusqu'au XIII ${ }^{\text {e }}$ siècle chez Vincent de Beauvais ${ }^{46}$. C'est aussi le cas du Liber de natura rerum de Thomas de Cantimpré, intarissable sur le règne animal (l. IV à IX), le règne végétal (l. X-XII) et le règne minéral (l. XIV-XV), avant de repasser au ciel; la même tendance se retrouve dans les adaptations en langue vulgaire de son encyclopédie: traduction flamande par Jacob van Maerlant (c. 1235-c. 1300) ${ }^{47}$, Buch der Natur écrit vers 1347-1350 par Conrad de Megenberg ${ }^{48}$. C'est également une image du monde que proposent les livres VIII à XIX du De proprietatibus rerum de Barthélemy l'Anglais, partant des corps célestes et du monde pour passer par chacun des éléments habités, en terminant par les animaux et les « accidents » humains à travers toutes leurs manifestations (poids, mesures, tons, couleurs, saveurs), ainsi que de plusieurs adaptations de son encyclopédie menées pour ainsi dire en « deuxième génération d'encyclopédistes » au XIII ${ }^{e}$ siècle.

Nombre d'encyclopédies adoptent un classement par les quatre éléments. C'est le cas pour une portion des Étymologies, et en conséquence du De naturis rerum de Raban Maur qui s'en inspire directement. Honorius Augustodunensis au $\mathrm{XII}^{\mathrm{e}}$ siècle commence pour sa part avec la description de l'archetypus mundus, en détaillant les éléments et leurs mélanges dans divers phénomènes, en ramenant toutes les sciences (géographie à la terre, météorologie à l'air, astres au feu, etc.) et tous les êtres vivants à ces quatre éléments, mais en laissant aussi une place au « temps », et donc à l'histoire du monde. Alexandre Neckam adopte aussi le classement par les 4 éléments (I, c. 17: feu; I, c. 18-22: air; I, c. 1-21, eau; II, c. $48-165$ : terre).

Des titres comme reflets d'une représentation du monde (Weltanschauung) pour un « livre universel »(Weltbuch)

Les noms médiévaux de ces sommes rendent bien mieux compte que le titre moderne d' « encyclopédie » de la conception qui préside à l'écriture du Livre universel et soulignent les liens entre fond et forme.

44. Éd. Müller, Schulze, 2008 (éd. antérieure: PL 197, col. 1125-1352). Trad. MonAT, 1988-1989.

45. Éd. Prior, 1913 ; Fant, 1886 ; Connochie-Bourgne, 1999.

46. VB, $L A$, c. 3, «Manière de faire et titre du livre », p. 152: « tout ce que... j'ai pu collecter dans une quantité presque innombrable de livres, tout cela est repris en bref dans cet ouvrage; que j'ai appelé Speculum maius pour le différencier d'un autre petit livre, édité autrefois, dont le titre est Speculum vel Imago mundi, dans lequel l'ordre de ce monde sensible et sa splendeur sont décrits en peu de mots ».

47. Éd. Verwiss, 1878; voir le volume collectif édité par Berteloot, Hellfaier, 2001.

48. Éd. PfeIFFer, 1971. 
Ainsi, du $\mathrm{VI}^{\mathrm{e}}$ au $\mathrm{IX}^{\mathrm{e}}$ siècle, les noms Etymologiae ou Origines témoignent de la préoccupation de voir dans le nom des choses leur essence. Cette attitude est d'origine antique et platonicienne, elle témoigne aussi de ce que fut le réalisme médiéval (et l'anti-nominalisme) qui accorde au nom des choses une importance ontologique. On la trouvait déjà exprimée dans cette phrase de Donat rapportant les mots de Varron: Verbum a veritate dictum, « le mot [verbum] vient de vérité ${ }^{49}$.

Tout au long du Moyen Âge, les titres De natura rerum ou De proprietatibus rerum, très fréquents, soulignent l'importance de chaque partie du réel décrit, que ce soit chez Isidore de Séville, Bède le Vénérable, Raban Maur, Alexandre Neckam, Thomas de Cantimpré, Barthélemy l'Anglais, etc.

Plus spécifiques aux $\mathrm{XI}^{\mathrm{e}}$, XII ${ }^{\mathrm{e}}$, XIII ${ }^{\mathrm{e}}$ siècles, Imago mundi ou Speculum montrent, quant à eux, que le livre veut être le reflet de la création divine, comme le précise Vincent de Beauvais ${ }^{50}$ :

[...] Est miroir [speculum], tout ce qui est digne de contemplation [speculatio], c'est-à-dire d'admiration ou d'imitation. Speculum quidem eo quod quicquid fere speculatione, id est, admiratione uel imitatione dignum est (LA, c. 3 [De la manière de faire et sur le titre du livre]).

Dans les derniers siècles du Moyen Âge enfin, du XIII ${ }^{\mathrm{e}}$ au $\mathrm{XV}^{\mathrm{e}}$ siècle, Compendium et le très utilisé Flores montrent la volonté de collecter, de choisir et de rassembler les meilleurs passages, comme le font les florilèges thématiques ou alphabétiques (par exemple le De floribus rerum naturalium d'Arnold de Saxe, les Naturen Blumen de Jacob van Maerlant ou encore la Compilatio de libris naturalibus, connue plus tard comme le Compendium philosophiae, qui porte également dans certains manuscrits le titre de Medullitus).

\section{Répondre au désir de sa communauté: l'utilité}

\section{Cadre institutionnel}

Au-delà du cadre culturel au sens large - codes culturels fondamentaux et connaissances scientifiques disponibles -, le cadre institutionnel, plus étroit, est aussi déterminant, car les encyclopédies répondent toujours, jusqu'au XIII ${ }^{\mathrm{e}}$ siècle au moins, au désir d'une communauté. Autrement dit, elles sont écrites avec l'idée d'être "utiles", de remplir un rôle attendu. Cela, en fonction des circonstances, d'un milieu socio-culturel, et d'un public. Les variations typologiques de ces œuvres sont en grande partie dues à la réponse qu'adopte le compilateur face à cette question de l'utilité.

49. DonAt, Glose sur Térence, Adelphes (5.8.29), 952.3: Nam verba a veritate dicta esse testis est Varro, rapportée par COLLART (1978: 16).

50. Mar Jonsson, 1990; Luff, 1999. Plus spécifiquement sur le choix des titres de chapitres par Vincent de Beauvais, voir PAULMIER-FoucART, 1994. 
L'utilitas peut traduire deux buts généraux: d'une part l'édification (notamment par l'allégorie ou la morale ${ }^{51}$ ), d'autre part la formation par la science ${ }^{52}$. Les deux se rejoignent dans la diffusion et l'adaptation du savoir pour la prédication, caractéristique de plusieurs encyclopédies du XIII ${ }^{\mathfrak{e}}$ siècle.

Qui était capable de susciter et de mener de tels travaux d'envergure au $\mathrm{XIII}^{\mathrm{e}}$ siècle? Des ordres religieux puissants, en pleine expansion, qui devaient organiser les moyens de leur diffusion. Cette éducation de leurs membres et, à travers eux, de la population, qu'elle soit lettrée ou non, a lieu via la prédication tous azimuts et la formation des prêcheurs dans des centres d'étude, les studia. Ainsi, les franciscains et les dominicains, ordres dominants, façonnentils ces sommes encyclopédiques comme autant de moyens de concentration et de diffusion des connaissances. Barthélemy l'Anglais est franciscain, Vincent de Beauvais est dominicain, Thomas de Cantimpré est chanoine augustin, mais deviendra dominicain pendant la rédaction de son encyclopédie (les chanoines augustins ont préfiguré l'ordre dominicain). Ces œuvres sont élaborées collectivement et d'abord destinées à être utilisées par les socii des couvents; elles sont au service d'un ordre, commanditaire et destinataire ${ }^{53}$.

L'exemple de Vincent de Beauvais, qui a servi à illustrer le propos jusqu'ici, permet de récapituler ce qui a été dit. Parangon de l'encyclopédiste, il traite toutes les matières en vertu d'un triptyque (naturale, doctrinale, historiale) très révélateur d'un premier niveau de classification indiscuté à l'époque. Il recommande d'étudier les créatures du monde naturel comme miroir du créateur et aussi comme origine de l'histoire du monde (Speculum naturale); il dit qu'il faut s'approprier pour cela les sciences - la doctrina - afin de se rapprocher du modèle divin à l'image duquel l'homme a été façonné; il s'agit ainsi de réparer la Chute par l'exposé de chacune des disciplines à connaître (Speculum doctrinale). Sa position théologique, augustinienne et empruntée à Richard et Hugues de Saint-Victor, est de rétablir (opus restaurationis) par la connaissance (la doctrina du Speculum doctrinale) l'équilibre perdu depuis la Chute en restaurant la ressemblance des créatures avec le Créateur:

Le fondement de la deuxième partie est le rétablissement [reparatio] de l'homme après la chute $(L A$, c. 17, p. 167).

Ensuite, il s'agit de retracer l'histoire de l'homme et des créatures à partir des origines (la Genèse) jusqu'au jugement dernier grâce au Speculum historiale, qui comprend aussi les vies exemplaires des saints. Vincent de Beauvais propose donc de passer d'un temps cosmologique, dominé par les six jours de la création, à un temps historique où se succèdent les six âges définis par Augustin.

51. Cf. Prologue au Liber de proprietatibus rerum de Barthélemy l'Anglais (1601): Huius rei gratia praesens efficio opusculum ad aedificationem domus Domini, qui est Deus gloriosus, sublimis et benedictus in secula seculorum.

52. La formation par la science étant également une forme d'édification. GoETz (1936 et 1937), avait partagé les encyclopédies médiévales en deux classes: encyclopédies spirituelles, et encyclopédies universelles ou cosmologiques. L'une édifie par la morale, l'autre par la science.

53. «Pour ces raisons, et pour répondre à la demande de mes supérieurs, moi, le plus petit des frères dominicains $[\ldots]$ j' ai réuni et mis en ordre $[\ldots] »(\mathrm{VB}, L A$, c. 1, p. 149). 
Le Speculum morale, quatrième partie apocryphe, ne fait pas encore partie de la typologie incontestable à l'époque: sa fabrication, qui date de la fin du XIII ${ }^{\mathrm{e}}$ siècle ou du début du XIV ${ }^{\mathrm{e}}$, est extérieure au milieu dominicain d'origine (il s'agit probablement d'une œuvre franciscaine ${ }^{54}$ ) et témoigne de l'émergence d'un besoin éthique nouveau. Celui-ci s'était sans doute déjà fait jour, sinon du vivant de Vincent de Beauvais avant 1264, au moins toujours dans la phase d'élaboration continue de l'œuvre, car la quatrième version de sa longue préface au Speculum maius prévoyait déjà une forme quadrifaria.

La destination de la grande encyclopédie dominicaine et des encyclopédies en général a donc évolué en une trentaine d'années. Elle passe ainsi d'un premier objectif d'instruction des frères de la communauté dans le cadre fermé des studia (c'est-à-dire pour «l'utilité commune » ${ }^{55}$ ) vers 1230 -1240, époque de la première rédaction du Speculum maius et des encyclopédies de Thomas de Cantimpré, Arnold de Saxe, Barthélemy l'Anglais, à une époque, au-delà de 1260, où l'œuvre devient le chantier de tout un ordre, échappe en tout cas à son auteur et se dirige vers la moralisation utile aux prédicateurs et à destination d'un public plus large. On note la même évolution vers la récriture pour la diffusion, d'une part, et la moralisation, d'autre part, pour l'encyclopédie de Thomas de Cantimpré. On a pu en effet isoler au moins quatre états du Liber de natura rerum, dont deux versions sous la plume de l'auteur, et une troisième plus moralisante, elle-même divisée en une dizaine de phases de réélaboration: l'œuvre est ainsi devenue un produit d'expansion de l'ordre dominicain dans les contrées germanisées - en particulier en Bavière, Autriche, Bohême - au cours de la seconde moitié du XIII ${ }^{\mathrm{e}}$ siècle ${ }^{56}$.

Les auvres encyclopédiques connaissent toutes des réécritures, qui, après avoir été l'instrument de leur expansion culturelle, échappent à l'ordre religieux qui les a commanditées ou soutenues. Il existe ainsi nombre d'adaptations de l'œuvre naturelle de Vincent de Beauvais, qu'elles soient dominicaines, comme l'Historia naturalis de Juan Gil de Zamora, ou séculières comme le Promptus de Dietrich Engelhus (1360-1434) ${ }^{57}$, ou des exploitations pharmaceutiques comme l'Hortus sanitatis au $\mathrm{Xv}^{\mathrm{e}}$ siècle, ou encore de nombreuses reprises de la chronique du Speculum historiale, comme le Memoriale temporum du chanoine Jean de Saint-Victor ou la Chronica de Dietrich Engelhus ${ }^{58}$. On trouve également de nom-

54. Le Speculum morale est étudié par Tomas Zahora (Université de Monash, Australie), qui a accompli un post-doc à l'Atelier Vincent de Beauvais à Nancy sur ce sujet en 2012. Cf. ZAHORA, Nikulin, Mews, SQUIRE, 2012 ; ZAHORA, 2012 et 2013.

55. Selon l'expression employée par Arnold de Saxe dans son prologue général.

56. Comme le montre VAN DEN ABEELE, 1994. La version du Liber de natura rerum utilisée par Vincent de Beauvais se situe entre la deuxième version connue (éditée par $\mathrm{H}$. Boese aux côtés de la première) et le « Thomas III », comme l'a suspecté Eduard Frunzeanu dans sa thèse de doctorat: FrunZEAnU, 2007.

57. Éd. Domínguez García, García Ballester, 1994. Pour le Promptus, voir Henkel, 1991.

58. Cf. n. 23 pour le Memoriale temporum. Pour le Chronicon continens res ecclesiae et reipublicae [...] d'Engelhus et ses liens avec le Speculum historiale, voir BAUMAnN, 1995 et WeIgand, 1991: 244249. De nombreuses autres adaptations historiographiques du Speculum historiale pourraient être mentionnées, car c'est la partie du Speculum maius qui a connu la plus grande diffusion, comme l'a montré VoORBIJ, 1986 et 1991. 
breuses adaptations encyclopédiques ou des utilisations spécialisées de tel ou tel livre du De proprietatibus rerum de Barthélemy l'Anglais, qu'il s'agisse ou non de réécritures franciscaines ${ }^{59}$.

Public visé - public atteint : intention et diffusion

La forme de l'œuvre encyclopédique dépend évidemment du rôle que lui assigne le compilateur, ce rôle étant lui-même fonction du public auquel il la destine - c'est l'intention, qui n'est pas toujours en adéquation avec la diffusion réelle.

Chez le franciscain Barthélemy l'Anglais, une conception à la fois éducative et doctrinale domine: le propos est de s'intéresser à la nature pour être utile au chrétien, dispensé ainsi de recourir à d'autres livres. Il faut décrire « les propriétés des choses » qui sont mentionnées dans l'Écriture, d'après le programme souhaité par le De doctrina christiana d'Augustin - et exprimé dans la préface et dans l'épilogue du De proprietatibus ${ }^{60}$-, qui veut que les livres des paiens soient au service de l'explication de l'Écriture. De cette manière, Barthélemy prolonge la vision du monde qu'avaient les chanoines des écoles de Chartres et de Saint-Victor au XII ${ }^{\mathrm{e}}$ siècle pour justifier leur curiositas: louer l'œuvre du Créateur dans ses créatures, sans s'interdire de recueillir pour ce faire toutes les informations livresques disponibles. Cette position fait du De proprietatibus rerum un réservoir pratique de matériaux pour la prédication. Quant à l'objectif de Thomas de Cantimpré, exprimé dans le prologue du Liber de natura rerum, il est scientifique et moral: fournir aux prédicateurs, destinataires de l'œuvre, un seul petit volume où ils puissent trouver les faits et les dires des auteurs concernant la nature et les propriétés des choses créées, qui soient en même temps notables et à signification morale ${ }^{61}$. Par là, il pense contribuer à l'amélioration des mœurs et à l'augmentation de la foi.

59. Pour quelques exemples (Marcus d'Orvieto, Liber de moralitatibus; Jean de San Giminiano, Liber de exemplis et similitudinibus rerum; Multifarium; Liber similitudinum naturalium de Konrad von Halberstadt; Macrologus de Jean de Saint Laurent de Liège), voir note 11 et la partie suivante (Classements des encyclopédies médiévales).

60. Prologue du De proprietatibus rerum (1601): Utile mihi et fositan aliis, qui naturas rerum et proprietates per sanctorum libros nec non et Philosophorum dispersas non cognoverunt, ad intelligenda aenigmata scripturarum, quae sub symbolis et figuris proprietatum rerum naturalium et artificialium a Spiritu sancto sunt traditae et velatae. Épilogue : [...] Ista autem quae breuiter de rerum naturalium accidentibus interseruimus, [...] sufficiant, quia ut aestimo, rudibus et parvulis in Christo mihi similibus, quae de proprietatibus rerum naturalium in 19. particulas sint digesta, sufficere debent ad aliquam inveniendi similitudinariam rationem, qua de causa diuina scriptura rerum naturalium et earum proprietatum, tam exquisitis symbolis utitur et figuris. [...] simpliciter Sanctorum verba, et philosophorum dicta pariter et commenta veritate previa sum secutus, ut simplices et parvuli, qui propter librorum infinitatem singularum rerum proprietates, de quibus tractat scriptura investigare non possunt, in promtu invenire valeant saltem superficialiter quod intendunt.

61. Les premiers mots du prologue disent en effet (éd. BॄSE, 1973): Naturas rerum in diversis auctorum scriptis late per orbem sparsas inveniens cura labore nimio et sollicitudine non parva annis ferme quindecim operam dedi, ut inspectis diversorum philosophorum et auctorum scriptis ea, que de naturis creaturarum et earum proprietatibus memorabilia et congrua moribus invenirem, in uno volumine et hoc in parvo brevissime compilarem. 
Chez le dominicain Vincent de Beauvais, la finalité est la même:

Cette oeuvre sera d'une grande utilité $[\ldots]$ non seulement afin de connaître Dieu en lui-même et à travers ses créatures visibles et invisibles [...] mais encore afin de prêcher, lire, disputer et en général pour expliquer presque toutes les sortes de matières [...] (LA, c. 4 [Utilité de l'œuvre]).

Chez Arnold de Saxe, en revanche, aucune référence à la prédication; son encyclopédie est avant tout philosophique et veut répondre à l'"utilité commune", probablement dans un milieu scolaire. Son premier prologue, à l'instar des florilèges d'auteurs moraux rassemblés au XII ${ }^{\mathrm{e}}$ siècle, insiste sur sa volonté d'offrir un accès facile aux textes (profanes) et sur le respect des « mots mêmes » tirés de ses sources. Son De floribus rerum naturalium se veut un outil maniable fondé sur des concepts.

La nécessité de remplir ce rôle utile de partage et de diffusion du savoir justifie chez les clercs savants encyclopédistes une solide formation en sciences naturelles, que les ordres religieux dynamiques du XIII ${ }^{e}$ siècle s'emploieront à développer dans un système d'enseignement fondé sur des collègues hiérarchisés, externes ou internes aux universités naissantes, où les encyclopédies elles-mêmes jouent un rôle didactique, puisqu'on sait que le De proprietatibus rerum de Barthélemy l'Anglais a circulé à l'université de Paris sous forme de pecia $^{62}$. Lorsque le mouvement de traduction et d'adaptation vernaculaire aura commencé, dès 1260, le notaire Brunetto Latini, auteur du Trésor, indiquera dans son intentio actoris l'importance du (riche et puissant) public laïc qui comprend peu le latin mais mérite l'instruction encyclopédique recueillie chez ses prédécesseurs.

\section{Classement Des ENCYClopédies MÉdiÉVAles}

En fonction du public visé, de la communauté institutionnelle, du rôle qu'on assigne aux encyclopédies du $\mathrm{VI}^{\mathrm{e}}$ au XvI ${ }^{\mathrm{e}}$ siècle, Christel Meier classe celles-ci en huit catégories commodes, qui permettent d'éviter de tracer une évolution linéaire, qui irait de l'encyclopédie naturelle au thésaurus du savoir universel, pour une culture donnée. Ces huit catégories outrepassent largement les types médiévaux d'encyclopédies, et ne peuvent toutes s'appliquer à la transposition didactique d'un savoir théorique, telle qu'elle est considérée ici. Étant donné le poids décisif de l'autorité dans l'Antiquité et au Moyen Âge, il me semble qu'il ne faut retenir comme encyclopédies médiévales-types que celles dont le savoir est livresque et fondé sur cette "mise en abîme autoritative". En conséquence, seules les quatre ou cinq premières catégories seraient ici concernées.

Les encyclopédies monastiques d'abord, qui modèlent et plient le savoir universel aux besoins de leur institution. Le Liber floridus de Lambert de Saint-

62. Voir LIDAKA, 1997 : 396-400 (pour une discussion sur les listes parisiennes de prix, en 1275 et en 1304, où est mentionné le De proprietatibus (éd. H. Denifle, E. Châtelain, 1889: 644 et 1891: 109). 
Omer est typique de ce genre de production, menée par un seul homme avec peu de moyens et pendant plusieurs années (en perdant sa cohérence peu à peu); la copie du manuscrit de Gand est entièrement de sa main. Il en va de même pour la seule copie, aujourd'hui disparue en cendres, de l'Hortus deliciarum de la nonne Herrade de Landsberg, abbesse de Hohenburg, qui traça une sorte d'histoire du salut de la Création à l'Apocalypse ${ }^{63}$. Son intentio actoris est de sauver la connaissance de l'oubli et d'en revêtir ses compagnes avant leur mariage avec le Christ, sur un chemin vers l'éternité.

Si les encyclopédies naturelles et les encyclopédies de prêcheurs retiennent le plus l'attention ici, c'est qu'elles sont typiques du XIII ${ }^{\mathrm{e}}$ siècle, avec leurs adaptations ultérieures sous forme moralisée, à la fin du XIII' siècle jusqu'au Xv' siècle. Elles visent à faire le lien entre les choses signifiées (significans, significantia) et leur signification (significatum, significata). Parmi ces prolongements moralisés, le Liber de naturis animalium cum moralitatibus, attribué à Henricus de Schüttenhofen et rédigé au $\mathrm{XIII}^{\mathrm{e}}$ siècle $^{64}$; le Tractatus septiformis de moralitatibus rerum ou les Proprietates rerum moralisate de Marcus d'Orvieto, inspiré de Barthélemy l'Anglais à la fin $\mathrm{XIII}^{\mathrm{e}}$ siècle $^{65}$; le Liber de exemplis et similitudinibus rerum de Jean de San Giminiano, qui fait de même au XIV ${ }^{\mathrm{e}}$ siècle ${ }^{66}$; le Reductorium morale de Pierre Bersuire, au XIV ${ }^{\mathrm{e}}$ siècle, qui s'inspire également beaucoup de l'encyclopédie de Barthélemy l'Anglais ${ }^{67}$; la Moralisacio avium et quadrupedum, écrite au $\mathrm{XIV}^{\mathrm{e}}$ ou au XV ${ }^{\mathrm{e}}$ siècle ${ }^{68}$; le Multifarium, écrit vers $1273^{69}$. Dans la même catégorie peuvent être classées les traductions ou adaptations en langues vernaculaires d'œuvres encyclopédiques, qui se développent à partir de la fin du XIII ${ }^{e}$ siècle, "produits dérivés" ou satellites du genre encyclopédique, comme l'adaptation italienne du De proprietatibus rerum par Vivaldo Belcazer avant 1308, et les traductions de cette même œuvre par le moine augustin Jean Corbechon en français pour le roi de France Charles v en 1372, par John Trevisa en anglais en 1398, par Vicente de Burgos en espagnol au XV siècle et par des traducteurs restés anonymes en néérlandais, provençal/occitan et castillan ${ }^{70}$. Appartiennent encore à cette catégorie des créations originales en vernaculaire

63. L'unique manuscrit était conservé à Strasbourg et a disparu dans l'incendie de la bibliothèque en 1870 . On ne garde qu'une reconstruction basée sur des dessins à l'identique tracés par l'érudit Engelhart en 1818 (ENGELHARDT, 1818).

64. Manuscrit Wien, Ö.N.B. 1566, f. 61v-62. Voir HüNEMÖRdER, 1994 et VAN DEN AbeELE, 1994.

65. Éd. EtzKorn, 2005. Pour les rapports avec Barthélemy l'Anglais, voir MeYer, 2000 et FriedMAN, 1989.

66. Éd. R. Pafraet, c. 1477-1479, et Oldoni, 1994: 213-228. Voir aussi note 11.

67. Éd. $1731: 341-346$.

68. Manuscrit Basel, Universitätsbibliothek, F.II.10, $\mathrm{XV}^{\mathrm{e}}$ siècle, f. $35 \mathrm{v}$.

69. Sur ces différentes reprises encyclopédiques, voir VAN DEN ABEELE, 2002.

70. En préparant (avec I. Ventura et moi) l'édition critique du De mundo et corporibus celestibus qui constitue le livre VIII du De proprietatibus, Eduard Frunzeanu a trouvé un manuscrit anciennement conservé au Nationales Museum de Munich sous la cote 3631, qui conserve aux f. 114v-119v une iuxta latin-allemand de ce livre astronomique (aujourd'hui conservé à München, B.S.B., sous la cote Clm 28846). 
comme le dialogue anonyme sur les questions naturelles de Placides et Timeo, ou Li livre dou Tresor de Brunetto Latini.

Des encyclopédies universitaires, Christel Meier ne donne pas d'exemples et je ne crois pas qu'on puisse réellement les distinguer des encyclopédies de prêcheurs, qui sont directement liées à l'enseignement dans les studia et autres collèges. On peut y rattacher les encyclopédies scolaires. Ainsi Conrad de Mure écrit son Fabularius sous la forme d'un dictionnaire encyclopédique qui connut un grand succès pendant plusieurs siècles. Son utilité déclarée, qui rappelle celle qui a été mentionnée plus haut chez Arnold de Saxe, est de « souhaiter servir à l'utilité commune des jeunes $\gg^{71}$.

Des encyclopédies politiques, la plus représentative est celle de Brunetto Latini, destinée à des hommes de pouvoir ou des « gouverneurs » du Nord de l'Italie. L'auteur y résume dans le livre I les contenus de la plupart des encyclopédies, y compris l'histoire. Son objectif principal est cependant la philosophie pratique, qu'il divise, d'une part, en éthique et économique comme pratique privée (l. II), et, d'autre part, en politique comme pratique publique utilisant, par exemple, la rhétorique (1. III).

Les encyclopédies médicales sont, quant à elles, des encyclopédies spécialisées, répondant au besoin d'une "profession" particulière. Sont-ce encore des encyclopédies? La dimension universelle manquant, elles n'entrent pas dans le cadre tracé par cette contribution, même si la compilation à partir de tous les livres disponibles n'est pas une caractéristique exclusive des encyclopédies et ne suffit donc pas à les définir; car c'est aussi un trait de la « réencyclopédisation » de disciplines particulières, comme la botanique ${ }^{72}$. On se trouve dans ce cas de figure pour l'Hortus sanitatis de Jacob von Meydenbach (c. 1470), dont les contenus excèdent la visée médicale ou pharmacologique, et pour son antécédent par Jean de Cuba, le Gart der Gesundheit. L'arrangement de l'Hortus sanitatis s'émancipe des herbiers en se divisant en cinq traités dédiés aux quatre éléments et en considérant toutes les choses animées (plantes, animaux, pierres) comme un mélange de tempéraments ${ }^{73}$. Trois siècles plus tôt, la Physica d'Hildegarde de Bingen

71. Éd. VAN DE Loo, 2006. Le Fabularius est composé alphabétiquement, pour offrir un guide didactique complet pour la lecture des auctores (en particulier les poètes). Il comprend un grand nombre d'entrées dédiées à des hommes politiques ou des figures mythologiques de l'Antiquité (tirées de son propre Novus Graecismus), mais peu de personnages médiévaux. Il réserve son introduction à une concordance entre histoire biblique et profane. Conrad consacre un appendice aux pierres, plantes et arbres, et renvoie à son De naturis animalium pour les animaux, et à son De propriis nominibus fluviorum et montium pour la géographie. Il agit donc comme un naturaliste polygraphe qui n'insère pas tout dans son encyclopédie. Le « fil rouge » de son cadre mental est la rhétorique et la philologie, reprenant en cela le modèle et la méthode isidoriennes.

72. RiHa, 1993. Voir Ventura, 2003b.

73. Le livre sur les poissons de l'Hortus sanitatis est maintenant doté d'une édition critique et d'une identification complète de ses sources grâce au projet « ICHTYA » mené à Caen par C. Jacquemard, M.-A. Avenel, B. Gauvin, P.-Y. Buard et M. Bisson. Cette édition multimodale paraît en 2013 aux Presses universitaires de Caen, sous forme papier et sous forme électronique. La version électronique (dotée des identifications de sources) est en ligne dans le corpus « SouRCENCYME » des encyclopédies 
reste, quant à elle, une encyclopédie cosmologique dont le mode d'explication privilégié est d'ordre physique, malgré l'ambiguïté entre la nature-physis et ses applications médicinales et pharmacologiques, la physica.

Des encyclopédies de type économique, mentionnées aussi par Christel Meier, ne se rencontrent qu' au $\mathrm{xvI}^{\mathrm{e}}$ siècle, comme la Cyclopaedia Paracelsica Christiana écrite en 1585 en langue vernaculaire, par Samuel Siderocrates, encyclopédie qui vise le public des marchands allemands mais aussi les médecins et les apothicaires, ainsi que les enseignants. On sort ici complètement du genre et de l'époque envisagés dans cette contribution, car l'intention est « anti-humaniste » et polémique, à l'encontre de l'ancien système de savoir des arts libéraux, elle exprime un a priori contre les professions académiques au profit des professions pratiques.

De même, les encyclopédies domestiques sont un genre tardif, qui ne se rencontre qu'à partir du début du XvI $I^{e}$ siècle. Ces œuvres se concentrent sur les besoins de l'oikos, de la gestion domestique. Elles sont donc axées sur la pratique (cuisine, horticulture, chasse, médecine pratique, dévotion, arts, météorologie, etc.) et ont des points communs avec les anciennes encyclopédies monastiques.

Certains types d'ouvrages sortent enfin de la classification assez lâche que nous venons de parcourir. C'est le cas de traités sans visée encyclopédique affichée, mais au très large contenu, tel que le Liber introductorius de Michel Scot (mort, croit-on, en 1237) ${ }^{74}$. Cette œuvre originale a été écrite dans le milieu cosmopolite de la cour sicilienne de l'empereur Frédéric II. Peu orthodoxe, mais aussi moins clairement organisée car sans plan global annoncé, elle touche à un grand nombre de domaines mais vise à faire de l'astrologie-astronomie la science capitale des arts libéraux. Les questions naturelles y sont nombreuses. Sa proximité, à la fois spatiale et temporelle, avec les entreprises de traductions n'est pas le moindre de ses intérêts.

médiévales constitué à Nancy à l'Atelier Vincent de Beauvais sous la direction d'I. Draelants. Pour un nouveau point historiographique sur l'Hortus sanitatis, on consultera Kentron 49, cahier spécial, 2013 et JACQUEMARD et al., 2013.

74. Pour la bibliographie sur Michel Scot et le Liber introductorius, voir entre autres BuRnETT (2005: 344-345). L'état initial du Liber introductorius est impossible à déterminer à l'heure actuelle, mais on en distingue deux versions (EDwARDs, 1985), dont la plus longue est conservée dans le manuscrit München, B.S.B., Clm 10268, où l'on a reconnu l'intervention de Barthélemy de Parme, et la version courte dans le manuscrit Paris, B.N.F. nouv. acq. lat. 1401. L'œuvre comprend trois parties : la première surtout est astronomique et métaphysique, le Liber quatuor distinctionum (ou Liber introductorius); Liber particularis (chronique, météorologie, astronomie, réponses à des questions scientifiques de l'empereur); Liber phisionomie (surtout sur la génération et la corruption, la biologie). Les savoirs théoriques et pratiques y sont mêlés (beaucoup de notices commencent par de noticia cognoscendi, ou des démonstrations par et est sciendum quod). Le Liber introductorius reste pour la plus grande part inédit, malgré des tentatives successives d'édition de la première partie par H. MEIER (1928, tapuscrit conservé au Warburg Institute, Londres) et du prologue par G. EDWARDS (idem) et des transcriptions partielles (exemple le catalogue d'étoiles: ACKERMANN, 2009; voir aussi BAUER, 1983); plusieurs chercheurs envisagent l'édition de la première partie, parmi lesquels A. FidORA, G. GREBNER, S. AKASOY à Francfort (Sonderforschungsbereich « Naturwissenschaften am Hof Friedrichs II. »), mais aussi G. PABST et Ch. BuRNETT. L'édition du Liber particularis est en cours à partir du manuscrit Oxford, Bodl. Can. Misc. 555, par Oleg VosковоYnikov, qui lui a consacré sa thèse de doctorat (2006). 
Sortent également des sept critères retenus ici les encyclopédies et dictionnaires alphabétiques comme le Macrologus écrit par un moine de Saint-Laurent de Liège, après $1450^{75}$; le Compendium moralitatum de Jacques de Lausanne; le Repertorium morale de Pierre Bersuire. Les recueils d'exempla moralisés sur la nature, et les florilèges scientifiques moralisés ne sont pas non plus à proprement parler des encyclopédies. Le Lumen anime, dont on distingue trois versions ${ }^{76}$, et les collections d'extraits moralisés pour la prédication, comme le Liber similitudinum naturalium de Conrad d'Halberstadt ${ }^{77}$, doivent être considérés comme un témoignage de la vitalité des encyclopédies plutôt qu'un de leurs dérivés. Elles constituent une sorte de bibliothèque allégorisée à l'usage des prêcheurs.

Enfin, restent en marge des encyclopédies, avec des sujets encyclopédiques, mais une forme plus libre et plus originale, les questions naturelles sur tous les sujets, comme celles d'Adélard de Bath ou les Problemata inspirés des problèmes attribués à Aristote.

\section{POUR CONCLURE}

Les encyclopédies antiques et médiévales appartiennent à une longue lignée d'œuvres diverses, souvent très diffusées, comme le prouve l'abondante tradition manuscrite du Liber de natura rerum ou du De proprietatibus rerum. Répondant à leur objectif premier, elles sont très utilisées par d'autres compilateurs, comme on peut le constater par exemple dans les cercles dominicains, avec l'utilisation immédiate que fait Albert le Grand de ses prédécesseurs, Thomas de Cantimpré et Arnold de Saxe ${ }^{78}$. Dès lors, l'encyclopédisme antique et médiéval est à la fois un genre qui s'auto-nourrit et un genre protéiforme, qui s'adapte constamment aux circonstances, aux matières, aux méthodes. Il est donc particulièrement difficile d'en proposer une définition unique qui permette une typologie, car le genre s'échappe lorsqu'on veut le contenir dans une catégorie et les exemples-limite se font toujours plus nombreux.

L'historien doit aussi rester attentif à ne pas commettre d'anachronisme; il ne faut donc pas prétendre définir l'encyclopédisme médiéval comme un genre imperméable, mais s'appuyer sur les genres littéraires définis par les auteurs médiévaux eux-mêmes, qui choisissent leur titre d'œuvre soit en fonction de leur méthode de compilation (compendium, compilatio, abbreviatio, alphabetum, flores, thesaurus, medullitus...), soit en référence à des correspondances spirituelles (similitudines...) ou à une vision du monde (imago mundi, speculum, hortus deliciarum...), soit

75. VAN DEN ABEele, 2004.

76. Rouse, 1971.

77. L'édition est en cours par I. Ventura. Un seul manuscrit est conservé: Berlin, Staatsbibl. Preuss. Kulturb., Theol. Lat. f. 315 (Ventura, 2001).

78. Sur cette question, voir: Draelants, Paulmier-Foucart, 2004 et Draelants, 2010. 
en vertu de l'attention qu'ils portent à certains phénomènes (proprietates rerum, natura rerum, virtutes, mirabilia mundi, etc.).

Au terme de ce parcours, il faut admettre qu'une typologie unique des encyclopédies n'est pas possible, mais qu'il existe néanmoins des critères - ni exclusifs, ni suffisants - permettant de tenter une définition générale. Ceux-ci sont particulièrement adaptés à une génération de référence, celle des encyclopédistes œuvrant entre 1220 et 1255 , qui rédigent le même type d'ouvrage à la demande de leur ordre en quête d'érudition et d'ouverture au monde: une imago mundi ou un « miroir » du monde fondé sur des bases philosophiques.

Ces critères sont d'abord liés à des facteurs externes, conjoncturels, à savoir: une nécessité de reconstruction du savoir à l'époque du compilateur, provoquant une "mise en mémoire" d'un ensemble de connaissances dans une volonté totalisante, ou bien une «mise à jour »; un arsenal scientifique ou idéologique existant comme référent; un savoir théorique, livresque, disponible, et des conditions favorables de diffusion. Ils sont ensuite liés à des ingrédients internes, à savoir: la compilation par citations ou par cumul de "bibliographie"; un choix des matières en fonction des branches spécifiques de connaissances dans le chef du compilateur, et une classification du savoir par celui-ci (un outil pour la structure), qui débouchent sur un système d'organisation; une destination de l'œuvre en fonction d'un public et d'une "utilité", et surtout, la volonté d'être d'un usage pratique et maniable. Avec ce dernier critère est rejoint le premier argument de cet exposé: la nécessité, imposée par les circonstances d'une époque donnée, d'une mise en mémoire organisée de l'information. En général, ces éléments sont exposés comme une profession de foi dans le prologue de l'œuvre encyclopédique, comme l'illustrent les exemples qui parsèment cette contribution.

Les encyclopédies médiévales constituent donc à la fois une organisation des connaissances globales, à l'instar des classifications des sciences - elles ont donc un rapport direct aux arts libéraux et à leur évolution -, et un genre littéraire, scientifique et didactique dominé par une vision du monde.

Une définition adaptée aux œuvres naturalistes a été donnée par B. Van den Abeele en $2007^{79}$ : « Le genre encyclopédique médiéval rassemble des compilations thématiques et ordonnées de connaissances relatives à plusieurs disciplines, touchant principalement l'univers et la nature, et rédigées dans une perspective didactique et édifiante à partir d'un travail de mise en extraits d'œuvres reconnues pour leur autorité. » Il complète: « Le croisement des critères retenus permet de faire le départ entre les encyclopédies et certains genres voisins, qui partagent l'une ou l'autre de leurs caractéristiques: les florilèges et recueils de citations, les ouvrages lexicographiques, les sommes spécialisées telles les sommes médicales, juridiques ou théologiques. »

D'une manière plus générale, une définition finale peut être avancée en fonction des traits récurrents qui caractérisent le genre littéraire et didactique des

79. Lors de la soutenance de sa thèse d'agrégation (le 30 octobre 2007 à Louvain-la-Neuve), portant sur les « Fortunes et mutations des encyclopédies médiévales ». 
encyclopédies: un arrangement systématique de l'information globale en fonction d'une l'utilité particulière, débouchant sur un livre universel et une bibliothèque en réduction. L'utilité à laquelle répond l'encyclopédie dépend de prémices spécifiques à l'époque et à la culture ambiante, de sorte que le savoir ainsi globalisé est transposé comme une vision du monde particulière. 


\title{
BIBLIOGRAPHIE
}

\author{
SOURCES PRIMAIRES
}

\section{Adelard De Bath}

Burnett C. (éd.), 1998 - Adelard De Bath. Quaestiones naturales, dans BurnetT C., Conversations with his nephew, Cambridge/New York/Melbourne (Cambridge Medieval Classics, 9), p. 81-235.

\section{Aelred de Rievaulx}

RACITI G. (éd.), 2005 - Aelred de Rievaulx. Homeliae de oneribus propheticis Isaiae, Turnhout (CC Cont. Med., 2D).

\section{Al-Battani}

Mahometis Albatenii De scientia stellarum de numeris stellarum et motibus liber [traductus a Plato Tiburtino] cum aliquot additionibus Joannis Regiomontani ex bibliotheca Vaticana transcriptus, Bologne, 1645.

Peyroux J. (trad.), 2003 - Al-Battani. Livre sur la science des étoiles, avec quelques additions de Jean Regiomontanus, trad. du latin en français, d'après la traduction latine de Plato Tiburtinus du ms arabe de la bibliothèque Vaticane, Paris.

Regiomontanus J. (éd.), 1645 - Muhammad Ibn-Ğābir al-Battān. De numeris stellarum et motibus, Bologne.

\section{AL-BITRÛJî}

CARMody F. J. (éd.), 1952 - Al-Bitrûjî. De motibus celorum, critical ed. of the Latin translation of Michael Scot, Berkeley.

\section{Al-Ghunaim}

'Abdullah Y. (éd.), 2006 - Al-Ghunaim. Arabic Geographic Manuscripts at the Bodleian Library, Oxford.

\section{Al-Wațāț, Muhamad ibn Ibrāhīm}

Al-Ḥarabī, 'Abd al-Razzāo Ạ̣mad (éd.), 2000 - Al-Wațwāt, Muhamad ibn Ibrāhīm. Mabāhiğ al-fikar wa-manāhiğ al-'ibar, Beyrouth.

SEZGin F. (éd.), 1990 - Al-Wațwāt, Muhamad ibn Ibrāhīm. Mabāhiğ al-fikar wa-manāhiğ al-'ibar, Frankfurt am Main.

\section{Albert le Grand (Albertus Magnus)}

Angel M. (trad.), 1995 - Albert le Grand. Le Monde minéral : les pierres, "De mineralibus" livres I et II, Paris (Sagesses chrétiennes).

Borgnet A. (éd.), 1890 - Alberti Magni, Ratisbonensis episcopi, ordinis praedicatorum Opera omnia, ex editione Lugdunensi [1651], religiose castigata [...] etiam revisa et locupletata, vol. 5, Paris (Mineralium libri V), p. 1-116.

Geyer B. (éd.), 1960 - Sancti doctoris ecclesiae Alberti Magni [...] Opera omnia, ad fidem codicum manuscriptorum edenda, apparatu critico notis prolegomenis indicibus instruenda, curavit Institutum Alberti Magni Coloniense, t. 16. I : Metaphysica, libri quinque priores, Aschendorff (Albertus Magnus Institut).

GeYer B. (éd.), 1964 - Sancti doctoris ecclesiae Alberti Magni [...] Opera omnia, ad fidem codicum manuscriptorum edenda, apparatu critico notis prolegomenis indicibus instruenda, curavit Institutum Alberti Magni Coloniense, t. 16. II : Metaphysica, libri VI-XIII, Aschendorff (Albertus Magnus Institut). 
Hossfeld P. (éd.), 2003 - Sancti doctoris ecclesiae Alberti Magni [...] Opera omnia, ad fidem codicum manuscriptorum edenda, apparatu critico notis prolegomenis indicibus instruenda, curavit Institutum Alberti Magni Coloniense, t. 6, pars 1: Meteora, Aschendorff (Albertus Magnus Institut).

Kitchell K. F., Resnick I. M. (trad.), 1999 - Albertus Magnus. On Animals. A Medieval Summa Zoologica, Baltimore.

Meyer E. F., Jessen C. (éd.), 1867 - Albertus Magnus. De vegetabilibus, Berlin (repr. Frankfurt a. M., 1982).

Moulin I. (trad.), 2009 - Albert le Grand. Métaphysique, Livre XI, Traités II et III, Paris (Sic et non).

STADler H. (éd.), 1916-1921 - Albertus Magnus. De animalibus, 2 vol., Aschendorff, (Beiträge zur Geschichte der Philosophie des Mittelalters, 15-16).

Sтroick C. (éd.), 1968 - Sancti doctoris ecclesiae Alberti Magni [...] Opera omnia, ad fidem codicum manuscriptorum edenda, apparatu critico notis prolegomenis indicibus instruenda, curavit Institutum Alberti Magni Coloniense, t. 7. I : De anima, Aschendorff (Albertus Magnus Institut).

VERNIER J.-M. (éd. et trad.), 2009-Albert le Grand. Livre sur la nature et l'origine de l'âme [Liber de natura et origine animae], Paris (Epistémologie et philosophie des sciences).

Wyckoff D. (trad.), 1967 - Albert the Great. Book of minerals, Oxford.

Alcuin

Alcuinus. Grammatica, PL 101, col. 849-902.

Aldhelm de Malmesbury

Aldhelmus. Epistola ad Acircium sive Liber de septenario, de metris aenigmatibus ac pedum regulis, $P L$ 89, col. 162-238.

EHwaLd R. (éd.), 1984 - Aldhelmi opera, Berlin, 1913-1919, 2 vol. (MGH. Auctores antiquissimi, 15 , réimpr. fac-similé, Munich).

D'Alembert Jean Le Rond

Discours Préliminaire de l'Encyclopédie, 1976 [1751], Paris.

Alexandre de Villedieu

REICHLING D. (éd.), 1893 - Das Doctrinale des Alexander de Villa-Dei. Kritisch-exegetische Ausgabe mit Einleitung, Verzeichniss der Handschriften und Drucke nebst Registern, Berlin (réimpr. New York, 1974).

\section{Alexandre Neckam (Alexandre Nequam)}

WRIGHT T. (éd.), 1863 - Alexandri Neckam De naturis rerum: libri duo, with the poem of the same author, De laudibus divinae sapientiae, London (Rerum Britannicarum Medii Aevi Scriptores, 34).

\section{Alia Musica}

Chailley J. (éd.), 1964 - Alia Musica (traité de musique du IXe siècle), Paris (Publications de l'Institut de Musicologie, 6).

Alsted J. H.

Encyclopaedia philosophica, Lyon, 1610.

Encyclopaedia septem tomis distincta, Herborn, 1630.

Scientiarum omnium Encyclopaideia, Lyon, 1649.

Ambroise de Milan (Ambrosius Mediolanensis)

BANTERLE G. (trad.), 2002 - Ambrogio. Esamerone, Rome (Collana di testi antichi, 164). 
Schenkl C. (éd.), 1897 - Ambrosius. Exameron. De Paradiso. De Cain et Abel. De Noe. De Abraham. De Isaac. De Bono mortis, Vienne (CSEL, 32, 1), p. 3-261.

\section{ANONYMA DE MUSICA SCRIPTA BELLERMANNIANA}

NAJock D. (éd.), 1975 - Anonyma de musica scripta Bellermanniana, Leipzig.

ANONYMI ARS LECTORIA

Sivo V. (éd.), 1979 - Anonymi Ars lectoria e codice Parisino Latino 8499, Bari.

ANoNymi MontePESSULANENSIS DiCtionaRiUs

Grondeux A. (éd.), 1998 - Anonymi Montepessulanensis Dictionarius. Glossaire latinfrançais du ms. Montpellier H236, Turnhout (CC Cont. Med., Series in- $4^{\circ}$, II).

ANONYMI ARTIUM MAGISTRI QUAESTIONES SUPER LIBRUM ETHICORUM ARISTOTELIS

Costa J. (éd.), 2010 - Anonymi artium magistri quaestiones super librum ethicorum Aristotelis (MS Paris, BnF, lat. 14698), Turnhout (Studia Artistarum, 23).

Apollonios Dyscole

Lallot J. (éd. et trad.), 1997 - Apollonios Dyscole. De la construction, Paris (Histoire des doctrines de l'Antiquité classique, 19).

Apulée le Grammairien

Osann F. (éd.), 1826 - L. Caecilii Minutiani Apuleii De orthographia fragmenta et Apuleii minoris De nota aspirationis et De diphthongis libri duo, Darmstadt.

Aristide Quintilien

Mathiesen T. J. (trad.), 1983 - Aristides Quintilianus : On music in three books, New Haven/Londres (Music Theory Translation Series).

Winnington-Ingram R. P. (éd.), 1963 - Aristidis Quintiliani De musica libri tres, Leipzig. Winterbotтом M. (éd.), 1970 - M. Fabi Quintiliani Institutionis oratoriae libri duodecim, 2 vol., Oxford.

ARISTOTE

De l'Âme

Jannone A. (éd.), Barbotin E. (éd. et trad.), 2009 - Aristote. De l'Âme, Paris $(C U F, 171)$.

Tricot J. (trad.), 1969 - Aristote. De l'Âme, Paris, 1969.

Éthique à Nicomaque

Barthélemy Saint-Hilaire J., Gomez-Muller A. (trad.), 1992 - Aristote. Éthique à Nicomaque, Paris.

Gauthier R. A., Jolif J. Y. (trad.), 1958-1959 - Aristote. Éthique à Nicomaque, Louvain.

Gauthier R. A. (éd.), 1972a - Aristoteles Latinus. Ethica Nicomachea, translatio antiquissima libri II-III sive "Ethica vetus" et translatio Antiquioris quae supersunt sive "ethica nova", "Hoferiana", "Borghesiana", Leiden/Bruxelles ( $A L$, 26.1-3, fasc. secundus).

Gauthier R. A. (éd.), 1972b - Aristoteles Latinus. Ethica Nicomachea, translatio Roberti Grosseteste Lincolniensis sive "Liber ethicorum" A. recensio pura, Leiden/Bruxelles (AL, 26.1-3, fasc. tertius).

Gauthier R. A. (éd.), 1973 - Aristoteles Latinus. Ethica Nicomachea, translatio Roberti Grosseteste Lincolniensis sive "Liber ethicorum" B. recensio recognita, Leiden/Bruxelles (AL, 26.1-3, fasc. quartus).

Tricot J. (trad.), 1959 - Éthique à Nicomaque, Paris.

Tricot J. (trad. et index), 2007 - Aristote, Éthique à Nicomaque, Paris. 
De l'Interprétation

Minio-Paluello L. et al. (éd.), 1965 - Aristoteles Latinus. De interpretatione vel Peri ermenias, translatio Boethii, specimina translationum recentiorum, Leiden $(A L, 2.1-2)$.

Métaphysique

Tricot J. (trad.), 1986 - Aristote. Métaphysique, t. II, Paris.

Météorologiques

GroisARD J. (trad.), 2008 - Météorologiques, Paris 2008.

Ross W. D., Webster E. W., Forster E. S. (éd. et trad.), 1931 - The Works of Aristotle. Vol. 3. Meteorologica, Oxford.

Parties des Animaux

Folster K. et al. (trad.), 1951 - Aristotle's "De anima" in the version of William of Moerbeke, and the Commentary of St Thomas Aquinas, Londres.

LENNOx J. G. (trad.), 2001 - On the parts of Animals, Oxford.

Pellegrin P. (trad.), 2011 - Les Parties des animaux, Paris.

SiweK P. (éd.), 1954 - Aristotelis De anima libri tres, voll. I-III, Roma (Pontificia Universitas Gregoriana, textus et documenta, series philosophica, 9).

Parva Naturalia

Tricot J. (trad.), 1999 [1951] - Aristote. Parva naturalia suivi du traité pseudo-aristotelicien De spiritu, Paris.

Physica

Bossier F., Brams J., Mansion A. (éd.), 1990 - Aristoteles Latinus. Physica [translatio vetus et translatio Vaticana], Leyde/New York, 2 vol. (AL, 7.2).

ARISTOXÈne

DA Rios R. (éd.), 1954 - Aristoxeni elementa harmonica, Rome.

Pighi G. B. (éd. et trad.), 1959 - Aristoxeni rhythmica, Bologne.

Asclépiade de MYrléa

Pagani L. (éd.), 2007 - Asclepiade de Mirlea. I frammenti degli scritti omerici, Roma.

Athénée de Naucratis

KaIBEL G. (éd.), 1887-1890 - Athenaei Naucratitae. Dipnosophistarum libri quindecim (3 vol.), Leipzig.

Audax

KEIL H. (éd.), 1880 - Audacis excerpta de Scauro et Palladio, GL 7, p. 320-361.

Augustin

Cité de Dieu

Dombart B., Kalb A. (éd.), 1955 - Sancti Avrelii Augustini De civitate Dei libri XI-XXII, Turnhout (CC Ser. Lat., 48).

Hoffmann E. (éd.), 1898 - Sancti Avrelii Avgvstini episcopi De Ciuitate Dei libri XXII, Prague (CSEL, 40).

Doctrine chrétienne

Martin J. (éd.), 1962 - Augustin. De doctrina christiana, II, c. 30 et 40, Turnhout (CC Ser. Lat., 32).

Genèse au sens littéral

Zycha J. (éd.), 1894 - Sancti Avrelii Augustini De Genesi ad litteram libri duodecim. [...], Prague-Leipzig-Vindobonae (Corpus scriptorum ecclesiasticorum latinorum; Academiae litterarum Caesareae Vindobonensis, xxviii.sectionis iii pars [ii]). 
Musique

Finaert G., Thonnard F.-J. (éd. et trad. ), 1947 - Augustin. De Musica, in CEuvres de Saint Augustin. La Musique, Bruges (Bibliothèque Augustinienne, 1/VII, IV).

Ordre

Knöll P. (éd.), 1922 - Sancti Aureli Augustini Contra Academicos libri tres, De beata vita liber unus, De Ordine libri duo, Vienne-Leipzig (CSEL, 63).

Règles

Martorelli L. (éd.), 2011 - Ps. Aurelii Augustini Regulae, Hildesheim.

Rétractations

Knöll P. (éd.), 1895 - Sancti Avrelii Augustini Retractationum libri duo, Vienne (CSEL, 36).

\section{Aulu-Gelle}

Hosıus K. (éd.), 1959 - Auli Gellii Noctium atticarum libri XX, Stuttgart.

Julien Y. (éd. et trad.), 1998 - Aulu-Gelle. Les Nuits Attiques, Paris, t. 4 (CUF, 345).

Marache R. (éd. et trad.), 1967-1989 - Aulu-Gelle. Les Nuits Attiques, Paris, t. 1-3 (CUF, $189,235,288)$

\section{Bacon, Roger}

Nolan E., Hirsch S. A. (éd.), 1902 - The Greek Grammar of Roger Bacon and a Fragment of His Hebrew Grammar Edited from the Mss with Introduction and Notes, Cambridge.

\section{BARTHÉLEMY L'ANGLAIS}

Bartholomaeus Anglicus. De genuinis rerum coelestium, terrestrium et infrarum proprietatibus libri XVIII, [...] procurante Georgio Bartholdo Pontano a Braitenberg, Frankfurt, 1601 (éd. anast., 1964)

CoRbechon J. (trad.), 1528 - Barthélemy l'Anglais. Le proprietaire en françois, Paris.

Van den Abeele B. et al. (éd.), 2007 - Bartholomaeus Anglicus. De proprietatibus rerum. Volume I : Prohemium, Livre I-IV, Turnhout (De diversis artibus 78, NS 41).

Ventura I. (éd.), 2007b - Bartholomaeus Anglicus. De proprietatibus rerum.Volume VI: Livre XVII, Turnhout (De diversis artibus 79, NS 42).

BÈdE LE VÉNÉRABLE

Burnett C. (éd.), 1985 - Pseudo-Bede. De mundi celestis terrestrisque constitutione, Londres. Fraipont J. (éd.), 1955 - Bedae venerabilis opera. Pars III, Opera homiletica, Pars IV, Opera rhytmica, 1 vol., Turnhout (CC Ser. Lat., 121).

Jones C. W. (éd.), 1975-1980 - Bedae venerabilis opera. Pars VI, Opera didascalica, 3 vol., Turnhout (CC Ser. Lat., 123A-123C).

\section{Bernard de Clairvaux}

Leclerce J., Talbot C. H. et Rochais H.-M. (éd.), 1975 - Sermones de diversis, dans Sancti Bernardi opera, vol. 6.1, Rome.

\section{Bersuire, Pierre}

Berchorii Repertorium morale, Nuremberg, 1494.

ENGels J. (éd.), 1966 - Petrus Berchorius. Reductorium morale, Liber XV: Ovidius moralizatus, cap. I, De formis figurisque deorum. Textus e codice Brux., Bibl. Reg. 863-869 critice editus, Utrecht.

Huisch J. W. (éd.), 1731 - Petri R. P. Berchorii Pictaviensis Ordinis Benedicti S., Dictionarium, vulgo Reductorium morale (...), Cologne.

Keerberg J. (éd.), 1609 - Opera omnia Petri Berchorii totam S. Scripturae, morum, naturae historia complectentia, Amsterdam. 
Koberger P. (éd.), 1517 - Morale reductorium super totam Bibliam: fratris Petri Berthorii Pictavensis..., Nüremberg.

REYNOLDS W. (éd.), 1977 - « De formis figurisque deorum/ From On the images and figures of the gods », Allegorica, 2.3, 1977, p. 62-89.

VAN Der BıJL M. S. (éd.), 1971 - «Petrus Berchorius, Reductorium morale, liber XV: Ovidius moralizatus, cap. II », Vivarium, 9, p. 25-48.

ZEINER J. (éd.), 1474 - Liber Bibliae moralis, seu Reductorium morale super totam Bibliam F. Petri Berchorii, Ulm.

\section{BIBLE}

Froenlich K. (intro.), Gibson M. T. (éd.), 1992 - Biblia latina, cum glossa ordinaria, facsimile reprint of the editio princeps, [chez] Adoph Rusch of Strassburg, 1480-1481, 4 vol., Turnhout.

\section{BoÈCE}

Institution arithmétique

Guillaumin J.-Y. (éd. et trad.), 1995 - Boèce. Institution arithmétique, Paris, $(C U F, 329)$.

Institution musicale

Friedlein G. (éd.), 1867 - Boetii De institutione arithmetica libri II., De institutione musica libri $V$, Leipzig.

Meyer C. (trad. et notes), 2004 - Boèce. Traité de la musique, Turnhout.

\section{BONIFACE}

Gebauer G. J., LöfStedt B. (éd.), 1980 - Bonifatii Ars grammatica, Turnhout (CC Cont. Med., 133B).

\section{BRUNetTo Latini}

Baldwin S., Barrette P. (éd.), 2003 - Brunetto Latini. Li livre dou Tresor, Arizona Center for Medieval and Renaissance studies, Tempe (Arizona).

Beltrami P. G., Squillaciotti P., Torri P., Vatteroni S. (éd.), 2007 - Brunetto Latini. Tresor, Torino.

Carmody F. J. (éd.), 1948 - Brunetto Latini. Li livre dou Tresor, Berkeley/Los Angeles, (rééd. Genève, 1998).

Chabaille P. (éd.), 1863 - Li livre dou Tresor par Brunetto Latini, Paris, 1863.

Ribémont B., Menegaldo S. (trad.), 2013 - Brunetto Latini. Le Livre du trésor, livre I, Paris, 2013.

\section{BuFfon}

De la manière d'étudier et de traiter l'Histoire naturelle. Premier discours de l'Histoire naturelle, générale et particulière, avec la description du Cabinet du Roy, Paris, 1986

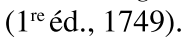

Cassiodore

Adriaen M. (éd.), 1958 - Cassiodorus. Expositio psalmorum I-LXX, Turnhout (CC Ser. Lat., 97).

FerRé, 1999 - Cassiodore. Institutions, livre II : introduction, traduction et commentaire, thèse soutenue en 1999 à l'Université de Saint-Étienne.

\section{Censorinus}

RocCa-SERRA G. (trad.), 1980 - Censorinus. Le jour natal, Paris (Histoire des doctrines de l'Antiquité classique, 5). 
Sallmann N. (éd.), 1983 - Censorini de die natali liber ad Q. Caerellium. Accedit Anonymi cuiusdam epitoma disciplinarum fragmentum Censorini, Leipzig.

\section{Chambers E.}

Cyclopaedia, or, An universal dictionary of arts and sciences : Containing the Definitions of the Terms, and Accounts of the Things Signify'd Thereby, in the Several Arts, both Liberal and Mechanical, and the Several Sciences, Human and Divine: the Figures, Kinds, Properties, Productions, Preparations, and Uses, of Things Natural and Artificial; the Rise, Progress, and State of Things Ecclesiastical, Civil, Military, and Commercial: with the Several Systems, Sects, Opinions, etc; among Philosophers, Divines, Mathematicians, Physicians, Antiquaries, Criticks, etc.: The Whole Intended as a Course of Ancient and Modern Learning, Londres, 1728., London, 1571.

\section{Chen SHOU}

Chen Shou, Sanguo zhi [Histoire des Trois Royaumes], Weishu [Livre des Wei], Pékin, Zhonghua shuju, 1959.

CI NOUS DIT

Blangez G. (éd.), 1979 - Ci nous dit. Recueil d'exemples moraux, Paris, t. 1.

Blangez G. (éd.), 1986 - Ci nous dit. Recueil d'exemples moraux, Paris, t. 2.

\section{ConRad de Hirsau}

Huygens R. B. C., 1955 - Conrad de Hirsau. Dialogus super auctores, Bruxelles (Collection Latomus, 17).

\section{Conrad de Megenberg}

Pfeiffer F. (éd.), 1861 - Das Buch der Natur von Konrad von Megenberg. Die erste Naturgeschichte in deutsche Sprache, Stuttgart (repr. Hildesheim, 1962 et 1971).

STEer G., LuFf R. (éd.), 2003 - Conradus de Megenberg, Buch der Natur. II. Kritischer Text nach der Handschriften, Tübingen, 2003 (Texte und Textgeschichte, 54.

\section{Conrad de Mure}

VAN DE LOo T., 2006 - Conradi de Mure Fabularius, Turnhout (Instrumenta lexicologica latina. CC Cont. Med., 210).

CORPUS GLOSSARIORUM LATINORUM [= CGL]

Goetz G., Löwe G. (éd.), 1888-1923 - Corpus glossariorum Latinorum, 7 vol., Leipzig.

Cyrano de Bergerac

Histoire comique des États et Empires de la Lune, Paris, 1787 [1657].

DANIEL De Morley

SudHOFF K. (éd.), 1917 - Daniel von Morlay. Liber de naturis inferiorum et superiorum, dans Archiv für Geschichte der Mathematik, der Naturwissenschaften und der Technik, 8, 1917, p. 1-40.

DiDEROT D.

Encyclopédie ou Dictionnaire raisonné des sciences, des arts et des métiers, par une société de gens de Lettres, Paris, 1751-1772.

«Prospectus », « Encyclopédie », Euvres complètes, tome 2, Paris, Le Club Français de Livre, 1970.

\section{Dioscoride (Pedianus)}

Wellmann M. (éd.), 1907 - Pedanii Dioscuridis Anazarbei De Materia Medica Libri quinque, Berlin. 
Érotien

Nachmanson E. (éd.), 1918 - Erotiani Vocum hippocraticarum collectio, Uppsala.

ÉTIENNE de Bourbon

Berloz J. (éd.), 2006 - Stephanus de Borbone. Tractatus de diversis materiis predicabilibus. Liber tertius. De eis que pertinent ad donum scientie et penitentiam, Turnhout (CC Cont. Med., 214B ; Exempla medii aevi, 3).

Berlioz J., Eichenlaub J.-L. (éd.), 2002 - Stephanus de Borbone. Tractatus de diversis materiis predicabilibus. Prologus - Liber primus. De dono timoris, Turnhout (CC Cont. Med., 124).

\section{EUCHER DE LYON}

Eucherius Lugdunensis Episcopus. Instructionum ad Salonium libri duo, PL50, col. 773-822.

Mandolfo C. (éd.), 2004 - Eucherii Lugdunensis Opera pars 1. Formulae spiritualis intellegentiae. Instructionum libri duo, Turnhout (CC Ser. Lat., 66).

Eugène de Tolède

Alberto P. F. (éd.), 2005 - Eugenii Toletani opera omnia, Turnhout (CC Ser. Lat., 114).

Eusèbe de Césarée

Timm S. (éd.), 2005 - Eusebius von Caesarea. Das Onomastikon der biblischen Ortsnamen, Berlin.

ÉVRARD DE BÉTHUNE

Wrobel J. (éd.), 1887 - Der Graecismus von Eberhard von Béthune, Breslau.

\section{Évrart de ContI}

Guichard-Tesson F., Roy B., 1993 - Évrart de Conti. Le Livre des eschez amoureux moralisés, Montréal (CERES Bibliothèque du Moyen français, 2).

Legaré A.-M. (éd.), Guichard-Tesson F., Roy B., 1991 - Le Livre des échecs amoureux: Bibliothèque nationale [ms. fr. 9197], Paris.

Favonius Eulogius

Van Weddingen R.-E. (éd.), 1957 - Favonii Eulogii Disputatio de somnio Scipionis, Bruxelles (Latomus, 27).

\section{Festus (Paulus Festus)}

LindSAY W. M. (éd.), 1913 - Sexti Pompei Festi De verborum significatu quae supersunt cum Pauli epitome, Leipzig.

\section{Firmin Le Ver}

Merrilees B., Edwards W. (éd.), 1994 - Firmini Verris Dictionarius : Dictionnaire latinfrançais de Firmin Le Ver, Turnhout (CC Cont. Med., Series in-4 ${ }^{\circ}$, I).

Gervais de Tilbury

Banks S. E., Binns J. W. (éd. et trad.), 2002 - Gervase of Tilbury. Otia Imperialia. Recreation for an emperor, Oxford (Oxford Medieval Texts).

Duchesne A. (trad.), 1992 - Gervais de Tilbury. Le Livre des merveilles : divertissement pour un empereur (troisième partie), Paris (La Roue à livres).

\section{GiLbert D'AuXerre}

ANDRÉE A. (éd. et trad.), 2005 - Gilbertus Universalis. Glosa ordinaria lamentationes Ieremie Prophete : Prothemata et Liber I, Stockholm (Acta universitatis Stockholmiensis. Studia latina Stockholmiensia, 52). 


\section{GLOSSA ORDINARIA}

Dove M. (éd.), 1997 - Glossa ordinaria. Pars 22, In canticum canticorum, Turnhout (CC Cont. Med., 170).

GLOSSARIA LATINA [= GLOSS.L.]

Lindsay W. M. et al. (éd.), 1926-1931 - Glossaria Latina iussu Academiae Britannicae edita, 5 vol., Paris.

\section{Gossuin de Metz}

Connochie-Bourgne C. (éd.), 1999 - Gossuin de Metz. L'Image du monde, une encyclopédie du XII e siècle. Édition critique et commentaire de la première version, thèse d'État, Paris IV-Sorbonne.

Prior O. H. (éd.), 1913 - L'image du monde de maître Gossuin, rédaction en prose, texte du ms. Bibl. nat. Fr. 574, Lausanne/Paris.

\section{GRAMMATICAE ROMANAE FRAGMENTA [= GRF]}

FunAioli I. (éd.), 1907 - Grammaticae Romanae Fragmenta, Leipzig.

\section{GRAMMATICI LATINI [= GL]}

KEIL H.(éd.), 1855-1880 - Grammatici Latini, 7 vol., Leipzig.

Keil H., Hagen H. (éd.), 1870 - Supplementum continens Anecdota Helvetica, vol. 8, Leipzig.

\section{Gregoire de Montesacro}

Pabst B. (éd.), 2002 - Gregor von Montesacro und die geistige Kultur Süditaliens unter Friedrich II. mit Text- und quellenkritischer Erstedition der Vers-Enzyklopädie Peri ton anthropon theopiisis (De hominum deificatione), Stuttgart (Montesacro-Forschungen, 2).

\section{GrÉGOIRE LE GRAND}

Gregorius Magnus. Dialogorum Libri IV De Vita Et Miraculis Patrum Italicorum, PL 77, col. 149-430.

Adriaen M. (éd.), 1979-1985 - Gregorius Magnus. Moralia in Iob, Turnhout (CC Cont. Med., 143-143B).

Gillet R., de Gaudemaris A. (éd. et trad.), 1989 - Grégoire le Grand. Morales sur Job, Paris (Sources Chrétiennes, 32 bis).

\section{Guillaume de Conches}

Ronca I., Badia L., Pujol J. (éd.), 1997 - Guillelmis de Conchis Opera omnia, t. I: Dragmaticon philosophiae, éd. Ronca I., Summa de philosophia in vulgari, Turnhout (CC Cont. Med., 152).

CETEDOC (éd.), 2001 - Guillelmis de Conchis "Dragmaticon philosophiae” : [enumeratio, concordantia et index formarum], Turnhout (CC Instrumenta lexicologica latina. Series A, 103).

Gratarolus G. (éd.), 1567 - Dragmaticon sive Dialogus de substantiis physicis ante annos ducentos confectus a Vuilhelmo Aneponymo philosopho, Strasbourg (reprod. fac-similé, Francfort, 1967).

Maurach G. (éd.), 1980 - Wilhelm von Conches. Philosophia mundi, Pretoria.

Nauta I. (éd.), 2008 - Guillelmi de Conchis Glosae super Boetium, Turnhout (CC Instrumenta lexicologica latina, Fasc. 117 Series A).

Ronca I., Curr M. (trad.), 1997 - A Dialogue on natural philosophy (Dragmaticon philosophiae), translation of the new Latin critical text with a short intro. and explanatory notes, Notre Dame [Indiana]. 


\section{Guillaume Durand}

Davril A., Thibodeau T. M. (éd.), 1995 - Guillelmi Duranti Rationale divinorum officiorum I-IV, Turnhout (CC Cont. Med., 140).

\section{Guillaume Le Breton}

Daly L. W., Daly B. A. (éd.), 1975 - Summa Britonis sivi Guillelmi Britonis Expositiones vocabulorum Biblie, 2 vol., Padoue.

\section{Hautfuney, Jean}

Paulmier-Foucart M., 1980 - « Jean Hautfuney, Tabula super Speculum historiale fratris Vincentii. Présentation - Édition A-L », Spicae - Cahiers de l'Atelier Vincent de Beauvais, 2, p. 19-263.

Paulmier-Foucart M. (éd.), 1981 - « Jean Hautfuney, Tabula super Speculum historiale fratris Vincentii. Présentation de la deuxième partie de l'édition - Édition M-Z - Édition de la Table des Flores - Exemple de traitement informatisé... », Spicae - Cahiers de l'Atelier Vincent de Beauvais, 3, p. 7-208.

\section{Henri Bate}

Boese H., STEel C. (éd.), 1990 - Henricus Bate. Speculum divinorum et quorundam naturalium, On Platonic Philosophy, Parts XI-XII, Louvain (Ancient and Medieval Philosophy. Series 1 [AMPhl], 12).

Guldentops G. (éd.), 2002 - Henricus Bate. Speculum divinorum et quorundam naturalium, Parts XIII-XVI: On Thinking and Happiness, Louvain (AMPh1, 21).

STEEL C. (éd.), 1993 - Henricus Bate. Speculum divinorum et quorundam naturalium, Parts IV-V: On the Nature of Matter, on the Intellect as Form of Man, Louvain (AMPh1,9).

Steel C. (éd.), 1994 - Henricus Bate. Speculum divinorum et quorundam naturalium, Parts VI-VII : On the Unity of Intellect, on the Platonic Doctrine of the Ideas, Louvain (AMPhl, 10).

Steel C., Guldentops G. (éd.), 1996 - Henricus Bate. Speculum divinorum et quorundam naturalium, Parts XX-XXIII : On the Heavens, the Divine Movers, and the First Intellect, Louvain $(A M P h 1,23)$.

VAN DE Vyver E. (éd.), 1960 - Henricus Bate. Speculum divinorum et quorundam naturalium, Introduction ; Littera dedicatoria - Tabula capitulorum - Proemium - Pars I, Louvain-Paris (Philosophes Médiévaux, 4).

VAN de Vyver E. (éd.), 1967 - Henricus Bate. Speculum divinorum et quorundam naturalium, Partes II-III, Louvain-Paris (Philosophes Médiévaux, 10).

\section{Henri de Herford}

Palazzo A. (éd.), Sturlese L. (intr.), 2004 - Enrico di Herford, Catena aurea entium. Tabula quaestionum, VIII-X, Pise (Centro di Cultura Medievale, Scuola Normale Superiore di Pisa, 12).

Sturlese L. (éd.), 1987 - Enrico di Herford, Catena aurea entium. Tabula quaestionum, I-VII, Pise (Centro di Cultura Medievale, Scuola Normale Superiore di Pisa, 2).

Hilaire de Poitiers

Doignon J. et al. (éd.), 1997-2009 - Tractatus super Psalmos (CC Ser. Lat., 61, 61A, 61B). SMulders P. (éd.), 1979-1980 - De trinitate (CC Ser. Lat., 62, 62A).

\section{Hildegarde de Bingen}

Monat P. (trad.), 1988-1989 - Hildegarde de Bingen. Le Livre des subtilités des créatures divines, Grenoble, 2 vol. (Atopia, 7). 
Müller I., Schulze C. (éd.), 2008 - Physica, Edition der Florentiner Handschrift (Cod. Laur. Ashb. 1323, ca 1300) im Vergleich mit den Textkonstitution der 'Patrologia Latina' (Migne), Hildesheim/Zurich/New York (éd. antérieure: PL 197, col. 1125-1352).

Honorius Augustodunensis

Honorius Augustodunensis. De imagine mundi libri tres, PL 172, col. 119-187.

Funt V. (éd.), 1949 - « Honorius Augustodunensis. Imago mundi », dans Archives d'histoire doctrinale et littéraire du Moyen Âge, 82, p. 7-153.

LuCENTini P. (éd.), 1974 - Honorius Augustodunensis. Clavis physicae, Rome (Temi e testi, 21).

Hucbald de SAINT-Amand

Chartier Y. (trad.), 1995 - Hucbald de Saint-Amand. L'Euvre musicale d'Hucbald de Saint-Amand. Les Compositions et le Traité de musique, Saint-Laurent, Québec (Cahiers d'études médiévales. Cahier spécial, 5).

Hugues de Fouilloy (Hugo de Folieto)

Hugonis opera dogmatica continuatio. De bestiis et aliis rebus, PL 177, col. 15-163.

Hugutio de Pise (Hugues)

Cecchini E., Arbizzoni G., Lanciotti S., Nonni G., Sassi M. G., Tontini A. (éd. crit. princeps), 2004 - Uguccione da Pisa. Derivationes, edizione critica princeps, 2 vol., Florence (Edizione nazionale dei testi mediolatini, Serie I, 6).

Cremascoli G. (éd.), 1978 - Huguccione da Pisa. De dubio accentu. Agiographia. Expositio de symbolo Apostolorum, Spoleto.

IbN Fap̣l Allāin al-'UMarī

Masālik al-abșār fi mamālik al-amșār fi l-hayawān wa-l-nabāt wa-l-ma'ādin, Al-Qāhira, 1996.

Masālik al-abșār fi mamālik al-amșār, Al-'Ayn, 25 vol., 2008.

ISIDORE DE SÉVILLE

De ecclesiasticis officiis

Lawson C. M. (éd.), 1989 - Sancti Isidori episcopi Hispalensis De ecclesiasticis officiis, Turnhout (CC Ser. Lat., 113).

Étymologies

ANDRÉ J. (éd. et trad.), 1981 - Isidore de Séville. Étymologies XVII. De l'agriculture, Paris.

ANdRÉ J. (éd. et trad.), 1986 - Isidore de Séville. Étymologies XII. Des animaux, Paris.

Cantó Llorca J. (éd. et trad.), 2007 - Isidore de Séville. Étymologies XVIII. De bello et ludis, Paris.

Feáns Landeira J. (éd. et trad.), 2011 - Isidore de Séville. Etimologías xvi. De las piedras y de los metales, Paris.

GaSParotto G. (éd. et trad.), 2004 - Isidore de Séville. Étymologies XIII. De mundo et partibus, Paris.

Gasparatto G. (éd.), Guillaumin J.-Y. (trad.), 2009-Isidore de Séville. Étymologies iII. De mathematica, Paris.

Gasti F. (éd. et trad.), 2010 - Isidore de Séville. Étymologies XI. De homine et portentis, Paris.

Guillaumin J.-Y (éd. et trad.), 2010 - Isidore de Séville. Étymologies Xx. De penu et instrumentis domesticis et rusticis, Paris.

LiNDSAY W. M. (éd.), 1911 - Isidori Hispalensis episcopi Etymologiarum sive Originum libri $x \mathrm{x}$ recognovit brevique adnotatione critica instruxit, 2 vol., Oxford. 
LindSAY W. M. (trad.), 1911 - Isidorus Hispalensis, "Etymologiarum" sive “Originum" libri XX, Oxford (rééd. 1989-1991).

Marshall P. K. (éd. et trad.), 1983 - Isidore de Séville. Étymologies II. Rhetoric, Paris. Reydellet M. (éd. et trad.), 1984 - Isidore de Séville. Étymologies Ix. Les langues et les groupes sociaux, Paris.

Rodriguez-Pantoja M. (éd. et trad.), 1995 - Isidore de Séville. Étymologies XIX. De naves, edificios y vestidos, Paris/Cordoue.

SPEvaK O. (éd. et trad.), 2011 - Isidore de Séville. Étymologies XIV. La terre, Paris.

Liber Differentiarum sive De proprietate sermonum

Sancti Isidori Hispalensis episcopi, Differentiarum sive De proprietate sermonum libri duo, PL 83, col. 9-98.

Andrés S Sanz M. A. (éd.), 2006 - Isidori Hispalensis episcopi Liber differentiarum [II], Turnhout (CC Ser. Lat., 111, 1).

Codoñer C. (éd. et trad.), 1992 - Isidoro de Sevilla. "De differentiis", libro I, Paris (Auteurs latins du Moyen Âge, 8).

De natura rerum

Fontaine J. (éd.), 1960 -Isidore de Séville. De natura rerum. Traité de la nature, Bordeaux.

JACOB DE MAERLANTS

Verwus E. (éd.), 1878 - Jacob Van Maerlant. Naturen Bloeme, Groningen.

JAMBLIQUe

Pistelli H. (éd.), 1894 - Iamblichi in Nicomachi Arithmeticam Introductionem Liber, Leipzig, éd. revue par U. Klein, Stuttgart, 1975.

JEAN BELETH

DouteIL H. (éd.), 1976 - Iohannis Beleth Summa de ecclesiasticis officiis, Turnhout (CC Cont. Med., 41A).

\section{Jean DE Garlande}

BLATt Rubin B. (trad.), 1981 - The Dictionarius of John de Garlande, Lawrence, 1981.

HaYe T. (éd.), 1995 - Johannes de Garlandia. Compendium Gramatice, Cologne/ Weimar/Vienne.

SCheler A. (éd.), 1865 - « Trois traités de lexicographie latine du XII et du XIII ${ }^{\mathrm{e}}$ siècle », Jahrbuch für Romanische und Englische Literatur, 6, Leipzig, p. 142-162.

\section{JEAN DE GÊNES}

Summa quae vocatur Catholicon edita a fratre Joanne de Janua, Venise, 1490.

Lichtenstein H. (éd.), 1487 - Catholicon edita a fratre Johanne de Janua Balbi, Cologne. ZAINER G. (éd.), 1460 - Summa quae vocatur Catholicon edita a fratre Johanne de Janua Balbi, Moguntiae (réimpr. anast., Farnborough, 1971).

JEAN DE SAINT-Victor

Guyot-Bachy I., Poirel D. (éd. et trad.), 2002 - Jean de Saint-Victor. Traité de la division des royaumes. Introduction à une histoire universelle, Turnhout (Sous la règle de saint Augustin).

\section{JeAn DE SALisbury}

Hall J. B., Keats-Rohan K. S. B. (éd.), 1991 - Ioannis Saresberiensis. Metalogicon, Turnhout (CC Ser. Med., 98). 


\section{JEAN GERSON}

GlorieuX P. (éd.), 1973 - Jean Gerson. CEuvres complètes, Contra superstitionem sculpturae leonis, Paris, t. 10.

JÉRôME

Hieronymus. Liber nominum Hebraicorum scripturae sacrae, PL 23, col. 1146-1176.

S. Eusebii Hieronymi Commentariorum in epistolam Beati Pauli ad Titum liber unus, PL 26, col. 555-599.

de Lagarde P. (éd.), 1959 - Hieronymi Quaestiones Hebraicae in Libro Geneseos, Turnhout (CC Cont. Med., 72).

JeAn de SAn Gimignano

Oldoni M. (éd.), Zapperi A. (trad.), 1993 - Giovanni da San Gimignano. Un enciclopedismo dell'anima, Città di San Gimignano [traduction partielle du Liber de exemplis et similitudinibus rerum].

Pafraet R. (éd.), 1478-1479 - Johannes de Sancto Geminiano. Liber de exemplis ac similitudinibus rerum.

\section{Jiang ShaOyu}

Huangchao leiyuan [Jardin des catégories de la dynastie], réimpr. Kyoto 1981 [éd. japonaise 1615-1624].

Juan Gil de Zamora (Johannes Aegidius Zamorensis)

Domínguez García A., L. García Ballester (éd. et trad.), 1994 - Johannis Aegidii Zamorensis, Historia naturalis, 3 vol., Junta de Castilla y León (Estudios de historia de la ciencia y de la técnica, 11).

\section{LACTANCE}

Brandt S., von Laubmann G. (éd.), 1890 - Lactantius. Opera omnia (...) Pars I, Sectio I. Divinae institutiones et epitome divinarum institutionum, Vienne/Prague/Leipzig (CSEL, 19).

JAHNkE $\mathbf{R}$ (éd.), 1898 - Lactantii Placidi qui dicitur Commentarii in Statii Thebaide et Commentarium in Achilleidem, Leipzig.

Pannier L., Paris G. (éd.), 1882 - Les Lapidaires français du Moyen Âge des XII ${ }^{e}$ XIII et XIV siècles, réunis, classés et publiés, accompagnés de préfaces, de tables et d'un glossaire, Paris (réimpr. fac-similé, Genève, 1973).

Lecoy de la Marche, A.

Anecdotes historiques, légendes et apologues d'Étienne de Bourbon, Paris, 1877.

LIBER GLOSSARUM

GoETZ G., 1893 - Der Liber glossarum, Leipzig (Abhandlungen der philologisch-historischen Classe der königlich-sächsischen Gesellschaft der Wissenschaften, XIII [2]).

GoETz G. (éd.), 1894 - Liber glossarum (excerpta), Leipzig (CGL 5, p. 159-255).

LIVRE DE SYDRAC LE PHILOSOPHE, VOIR SYDRAC

LIU SU

Sui Tang jiahua [Précieuses paroles des Sui et des Tang], Pékin, 1979.

MACROBE

Les Saturnales

Bornecque H., Richard F. (éd. et trad.), 1937 - Macrobe. Les Saturnales, Paris.

GuITtARD C. (trad.), 1997 - Macrobe, Les Saturnales, Paris, t. 1 (livres 1-3).

KASTER R. A. (éd.), 2011 - Macrobii Ambrosii Theodosii Saturnalia, Oxford/New York. 
KaSter R. A. (trad.), 2011 - Macrobius. Saturnalia, Cambridge, 3 vol.

WiLlis J. A. (éd.), 1963 - Macrobius. Saturnalia, Leipzig, 2 vol.

Songe de Scipion

Armisen-Marchetti M. (éd. et trad.), 2001-2003 - Macrobe. Commentaire au Songe de Scipion, Paris, 2 vol. (CUF, 360, 373).

Marc d'Orvieto (Marcus d'Orvieto)

EtzKonn G. J. (éd.), 2005-Marci de Urbi Veteri Liber De Moralitatibus, Saint Bonaventure U.P., 3 vol. (Franciscan Institute Publications).

Martianus Capella

Guillaumin J.-B. (éd. et trad.), 2011 - Martianus Capella. Les Noces de Philologie et de Mercure. Livre IX. L'Harmonie, Paris (CUF, 401).

Willis J. (éd.), 1983 - Martianus Capella. De nuptiis Philologiae et Mercurii, Leipzig.

Michael Scot (Michaelus Scottus)

Liber introductorius

MeIER H. (éd.), 1928 - [Transcription du manuscrit de Munich, copie au Warburg Institute, Londres, cote FAH 1437, quatre volumes dactylographiés]

\section{Muhammad IBn Mahmūd Ṭūsĩ}

Sutûda M. (éd.), 1387 - Muhammad ibn Mahmmūd Țūsī, 'Ağà'ib al-mahlūqāt wa-garā'ib al-mawğūdāt, Téhéran.

\section{MUSICI SCRIPTORES GRAECI}

voN JAN C. (éd.), 1895 - Musici scriptores graeci: Aristoteles, Euclides, Nicomachus, Bacchius, Gaudentius, Alypius et melodiarum veterum quicquid exstat, Leipzig, réimpr. fac-similé 1995.

\section{Nicolas de Lyre}

Nicolaus de Lyra. Postilla super totam Bibliam, Venise, 1488, reprod. num. Cambridge, c. 1990 (Italian books before 1601, 418.5).

\section{Nicolas de Strasbourg}

Pellegrino G. (éd.), Sturlese L. (intro.), 2009 - Nikolaus de Strassburg. Summa (II, L. 2, tr. 1-2), Hambourg (CPhTMA, 5.2.1).

Pellegrino G. (éd.), 2009 - Nikolaus de Strassburg. Summa (II, L. 2, tr. 3-7), Hambourg (CphTMA, 5.2.2).

Suarez-Nani T. (éd.), 1990 - Nikolaus de Strassburg. Summa (II, L. 2, tr. 8-14), Hambourg, (CphTMA, 5.2.3).

\section{OSBERn De Gloucester}

Busdraghi P., et al. (éd.), 1996 - Osberno. Derivazioni, 2 vol., Spoleto.

PaPIAS

Ars grammatica

Cervani R. (éd.), 1998 - Papiae Ars grammatica, Bologne.

Elementarium Vocabularium

Elementarium doctrine rudimentum, Milan, 1476 (réimpr. anast., Turin, 1966).

Papias Vocabulista, Elementarium doctrinae rudimentum, Venetiis, 1496 (réimpr. anast., Turin, 1966).

DE ANGelis V. (éd.), 1977-1978 - Papiae Elementarium Littera A (A-Aequus, AequusAmiferme), 2 vol., Milan (Testi e documenti per lo studio dell'antichità, 58). 
Ridder K. (éd.), 1980 - Papiae Elementarium Littera A. Littera A, Ani-Azoni, Milan, 1980 (Testi e documenti per lo studio dell'antichità, 58, III)

von Pforr, A.

GeISLER F., 1960 - Beispiele der alten Weisen des Johann von Capua. Übersetzung der hebräischen Bearbeitung des indischen Pañcatantra ins Lateinische, Berlin.

Phocas

KEIL H. (éd.), 1868 - Phocas. Ars de nomine et verbo, Leipzig, GL 5, p. 410-439.

Pierre Helie (Petrus Helias)

Reilly L. (éd.), 1993 - Petrus Helias. Summa super Priscianum, 2 vol., Toronto.

Pierre le Chantre (Petrus Cantor)

Boutry M. (éd.), 2004 - Petrus Cantor. Verbum adbreviatum Textus conflatus, Turnhout (CC Cont. Med., 196).

Sylwan A. (éd.), 1992 - Petrus Cantor. Glossae super Genesim. Prologus et capitula 1-3, Göteborg.

Pierre le Mangeur (Petrus Comestor)

Scolastica historia magistri Petris Comestoris, Chambéry, 1485 (réimpr. num. Cambridge, c. 1990, French Books before 1601, 345.1).

CTLO (éd.), 2007 - Petrus Comestor. Scolastica historia : Liber Genesis. Enumeratio, concordantia et index formarum, Turnhout (CC Instrumenta lexicologica latina. Series $A, 160)$.

Sylwan A. (éd.), 2005 - Petrus Comestor. Scolastica historia. Genesis, Turnhout (CC Cont. Med., 191).

Placidus (Placide)

Götz G., Löwe G. (éd.), 1894 - Placidus. Liber glossarum. Glossaria reliqua (CGL 5, p. 1-158).

Pirie J. W. et Lindsay W. M. (éd.), 1930-1932 - « Placidi glossae », dans Lindsay W. M. (dir.), Glossaria latina, iussu Academiae britannicae edita, 5 vol., Poitiers/Paris, vol. 4.

\section{Placides et Timéo}

Thomasset C. (éd.), 1980 - Placides et Timéo ou Li secrés as philosophes, Genève/Paris (Textes littéraires français, 289).

Vérard A. (éd.), ca 1504 - Le cuer de philozophie, Paris (exemplaire consulté: BnF, RES-R-840).

Platon

Rivaud A. (éd. et trad.), 1925 - Platon. Timée, Paris $(C U F, 30)$.

Pline l'Ancien

BARChIESI A. et al. (éd.), 1982 - Plinio. Storia naturale, Turin.

BEAUJEU J. (éd. et trad.), 1950 - Pline l'Ancien. Histoire naturelle, Livre II, Paris (CUF, 133).

Polemius Silvius

Mommsen T. (éd.), 1857 - Polemii Silvii Laterculus, Leipzig (Abhandlungen der philologisch-historischen Klasse der königlichsächsischen Gesselschaft der Wissenschaften, II.B).

Pollux

BETHE E. (éd.), 1900-1917 - Pollucis Onomasticon, Leipzig.

Priscien de Césarée

Hertz, Keil H. (éd.), 1855-1859 - Prisciani grammati Caesariensis Institutionum grammaticarum libri xviii, ex recensione, 2 vol., Leipzig, GL 2-3. 


\section{Raban MaUR}

Rabanus Maurus. Commentariorum in Genesim libri quatuor, PL 107, col. 439-669.

Rabanus Maurus. De universo libri duo, PL 111, col. 9-614.

Rabanus Maurus. Excerptio de arte grammatica Prisciani, PL 111, col. 613-678.

Cavallo G. (éd.), Leonardi C., Braga G. et al., 1994 - Rabano Mauro De rerum naturis, Codex Casinensis 132, Archivio dell'Abbazia di Montecassino, Turin, 3 vol.

Raoul le Breton (RAdulphus Brito)

Costa J. (éd.), 2004 - Le quaestiones di Radulfus Brito sull'Ethica Nicomachea. Introduzione e testo critico, Turnhout (Studia Artistarum, 17).

\section{Remi D'AuXerre (Remigius AutisSiodorensis)}

Remigius Autissiodorensis. Commentum Einsidlense in Donati artem maiorem (= Commentum in Donati artem maiorem sec. cod. Einsidlensem 172, libri I-II), GL 8 (Anecdota Helvetica quae ad grammaticam Latinam spectant), p. 219-266.

Huygens R. B. C. (éd.), 2000 - Remi d'Auxerre, Commentarius in Prisciani tractatum De nomine et pronomine et verbo, dans Serta mediaevalia. Textus varii saeculorum X-XIII in unum collecti, Turnhout (CC Cont. Med., 171), p. 11-23.

Richard de SAINT-Victor

Châtillon J. (éd.), 1958 - Richard de Saint-Victor : Liber exceptionum, Paris.

ROBERT DE BORON

MichA A. (éd.), 1979 - Robert de Boron. Merlin, Roman du XIII siècle, Genève.

SALERNITAN QUESTIONS

Lawn B. (éd.), 1979 - The Prose Salernitan Questions, edited from a Bodleian Manuscript (Auct. F.3.10). An anonymous collection dealing with science and medicine, written by an Englishman c. 1200, with an appendix and ten related collections, Londres/Oxford (Auctores Britannici Medii Aevi, 5).

Scalich, Paul (Skalić, Scaliger)

Encyclopaedia, seu Orbis disciplinarum, tam sacrarum quam prophanum Epitome, Bâle, 1559.

\section{SCHOLIA BEMBINA}

MountFord J. F. (éd.), 1934 - The Scholia Bembina, Liverpool.

Sedulius Scottus

Löfstedt B. (éd.), 1977 - Sedulius. In Donati artem maiorem, Turnhout (CC Cont. Med., 40B).

\section{SEGUIN}

KnEEPKens C. H., RejJnders H. F. (éd.), 1979 - Magister Siguinus Ars lectoria. Un art de lecture à haute voix du onzième siècle, Leyde.

SERGIUS

KeIL H. (éd.), 1864 - [Sergii] explanationes in artes Donati, Leipzig, GL 4, p. 486-565.

SERVIUS

Thilo G., Hagen H. (éd.), 1878-1901 - Servii grammatici qui feruntur in Vergilii carmina commentarii, 4 vol., Leipzig.

STRabo Walahfrid (STRabus)

Biblia sacra cum Glossa ordinaria primum quidem a Strabo Fuldensis collecta, novis Patrum, graec. et lat., explicationibus locupletata, et Postilla Nicola Lirani [...] cum additionibus Pauli Burgensis [...] et Matthiae Thoringe replicis, opera et studio Theolog. 
Duacensium studi emendatis ... omnia denuo recensuit R.P. doctor Leander a San Marino..., Anvers, 1634.

Walafridus Strabo Fuldensis, liber Genesis, PL 113, col. 67-182 (Liber Genesis cum Walafridi Strabi glossa ordinaria et Anselmi Laudunensis glossa interlineari).

SUÉTONE

Reifferscheid A. (éd.), 1860 - Suetonii. Tranquilli praeter Caesarum libros reliquiae, Leipzig, p. 247-254.

\section{SUMMARIUM HEINRICI}

Hildebrandt R., De Bidder L. (éd.), 1974-1995 - Summarium Heinrici I-III, Berlin /New York (Quellen und Forschungen Sprach- und Kulturgeschichte der Germanischen Völker, neue Folge, 61, 78 et 109).

\section{Sunesen, ANDERS}

Ebbesen S., Mortensen L. B. (éd.), 1985-Andreae Sunonis Filii Hexaemeron, Copenhague.

\section{SYDRAC (SYDRACH)}

Burton Tl. (éd.), Schaer F., Masters B., Flanagan S. et al., 1998-1999 - Sidrak and Bokkus, a parallel text edition from Bodleian Library, ms Laud, misc 559 and British Library, Ms Lansdowne 793, Oxford (Early english texts society. Original series, 311-312), vol. 1: Introduction, Prologue and Books I-II, et vol. 2 : Books III-IV, Commentary, Appendices, Glossary, Index.

Du Pré G., Vidoue P. (éd.), 1531 - Sydrach le grant philosophe. La Fontaine de toutes sciences, Paris (exemplaire consulté: $\mathrm{BnF}, 8-\mathrm{S}-1764)$.

Ruhe E. (éd.), 2000 - Sydrac le philosophe. Le Livre de la fontaine de toutes sciences, Edition des enzyklopädischen Lehrdialogs aus dem XIII. Jahrhundert. Wiesbaden (Wissensliteratur im Mittelalter, 34).

Sgrilli P. (éd.), 1984 - Il "Libro di Sidrac" Salentino, Pise (Biblioteca degli studi mediolatini e volgari, NS 7).

STEINER S.-M. (éd.), 1994 - Un témoignage de la diffusion encyclopédique au XIII siècle. Le Livre de Sidrach. Édition critique d'après les manuscrits de Paris et de Rome (Premier Prologue. Catalogue des Questions. Second Prologue), Melun (Mémoires, 2).

\section{SyNONYMa CiCERONIS}

GATTI P. (éd.), 1993 - Lexicographica 2, "Synonyma Ciceronis": arba, humus, Genova (Publicazioni del D.Ar.Fi.Cl.Et, NS 149).

Gutri P. (éd.), 1994 - Synonyma Ciceronis. La raccolta Accusat-Lacescit, Trente (Labirinti : collana del Dipartimento di scienze filologische e storische, 9).

\section{Tertullien}

Tertullianus. Liber de praescriptionibus adversus haereticos, PL 2, col. 9-74.

\section{THLL}

WöLfFlin E., Leo F. (éd.), 1900-... - Thesaurus linguae Latinae (TL), Leipzig.

\section{Thomas D'AQUin}

Zimmermann A., Kopp C. (éd.), 1988 - Thomas von Aquin: Werk und Wirkung im Licht neutre Forschungen, Berlin/New York (Miscellanea Mediaevalia, 19).

\section{Thomas de Cantimpré}

BOESE H. (éd.), 1973 - Thomas Cantimpratensis, Liber de natura rerum secundum diversos philosophos, Berlin/New York.

Tuo, Tuo

Songshi [Histoire des Song], Pékin, 1977 [1345]. 


\section{VARRON}

Collart J. (éd.), 1954 - Varron. De lingua Latina livre V, Paris.

\section{VINCENT DE BEAUVAIS}

Bibliotheca Mundi. Vincentii Burgundi... Speculum quadruplex siue Speculum maius, 4 vol., Douai, 1624 (éd. anast., Graz, 1961-1965).

\section{Vincente Coronelli}

Coronelli V., 1701-1706 - Biblioteca universale sacro-profana, antico-moderna: in cui si spiega con ordine alfabetico ogni voce, anco straniera, che può avere significato nel nostro idioma italiano, appartenente a'qualunque materia, Venise.

Vita ARISTOTELIS MarCIANA

GIGON O., 1962 - Vita Aristotelis Marciana, Berlin (Kleine Texte für Vorlesungen and Übungen, Heft, n. 81)

VitruVe

SAliou C. (éd. et trad.), 2009 - Vitruve. De l'Architecture. Livre V, Paris (CUF, 393).

WANG, YingLIN

Yuhai [La mer des jades], Taibei, 1977 [1352].

WENYING

Yuhu qinghua [Propos distingués à Yuhu], Pékin, 1984.

Wowern, JoHann von

De polymathia tractatio, Basel, 1603. 


\section{SOURCES SECONDAIRES}

Abramov D., 2002 - « Die moralisierende Enzyklopädie Liber de naturis rerum von Pseudo-John Folsham », dans Die Enzyklopädie im Wandel vom Hochmittelalter bis zur frühen Neuzeit. Akten des Kolloquiums des Projekts D im Sonderforschungsbereich 231 (29.11.1996-01.12.1996), Munich (Münstersche Mittelalter-Schriften, 78), p. 123-154

ACKermann S., 2009 - Sternstunden am Kaiserhof: Michael Scotus und sein Buch von den Bildern und Zeichen des Himmels, Frankfurt am Main.

Adorno F., 1998 - «Vivere secondo natura : natura e ragione nello Stoicismo », dans UGLIONE R. (éd.), L'uomo antico e la natura, Turin, p. 129-146.

Aertsen J. A. et al., 2001 - Nach der Verurteilung von 1277. Philosophie an der Universität von Paris im letzten Viertel des 13. Jahrhunderts. Studien und Texte, Berlin/New York (Miscellanea Mediaevalia, 28).

Afshar I., 1985 - « 'Ajāà'eb al-maklūqāat » dans YArShater E. (éd.), Encyclopaedia Iranica, I, London, p. 698-699.

Al-NuWAYRī, 1923-1998 - Nihāyat al-arab fi funūn al-adab, Al-Qāhira, 33 vol.

D’Alverny M.-T., 1965 - Alain de Lille. Textes inédits, Paris.

Amelung I., 2007 - « New Maps for the Modernizing State: Western Cartographic Knowledge and its Application in 19th and 20th Centuries », dans Bray F., DorofeEva-LichtMann V., MÉTAILIÉ G. (dir.), Graphics and Text in the Production of Technical Knowledge in China: The Warp and the Weft, Leiden.

AMSLer M. E., 1989 - Etymology and Grammatical Discourse in Late Antiquity and the Early Middle Ages, Amsterdam/Philadelphie.

Anderson G., 1997 - « The Sophistic Environment », dans Aufstieg und Niedergang der römischen Welt, 2, 34.3, p. 2173-2185.

Anderson G., 2000 - « The Banquet of Belles-Lettres. Athenaeus and the Comic Symposium », dans Braund D. \& WiLKINs J. (dir.), Athenaeus and his World, Exeter, p. 316-326.

ANdré J., 1955 - « Pline l'Ancien botaniste », REL, 33, p. 297-318.

ANDRÉ J., 1959 - « Erreurs de traduction chez Pline l'Ancien », REL, 37, p. 203-215.

ANDRÉ J., 1971 - Emprunts et suffixes nominaux en latin, Genève, 1971.

Anzulewicz H., Senner W. et al. (éd.), 2001 - Albertus Magnus. Zum Gedenken nach 800 Jahren. Neue Zugänge, Aspekte und Perspektiven, Berlin (Quellen und Forschungen zur Geschichte des Dominikanerordens, 10).

Anzulewicz H., 2009 - « Albertus Magnus und die Tiere », dans Obermaier S. (éd.), Tiere und Fabelwesen im Mittelalter, Berlin-New York, p. 29-54.

Arnar A. S., 1990 - Encyclopedism from Pliny to Borges, Chicago.

ARNOLD K., 1976 - « Konrad von Megenberg als Kommentator der Sphaera des Johannes von Sacrobosco », Deutsches Archiv für Erforschung des Mittelalters, 32.1, p. 147-186.

Astarita M. L., 1993 - La cultura nelle Noctes Atticae, Catane.

Aujac G., 1993 - La Sphère, instrument au service de la découverte du monde d'Autolycos de Pitanè à Jean de Sacrobosco, Caen.

Bagley P. J., 1992 - « On the Practice of Esotericism », Journal of the History of Ideas, 53.2, p. 231-247.

BAIER T., 1997 - Werk und Wirkung Varros im Spiegel seiner Zeitgenossen: von Cicero bis Ovid, Stuttgart. 
Baillaud B., de Gramont J., HüE D. (éd.), 1999 - Discours et savoirs : Encyclopédies médiévales, Paris.

BaIN E., 2007 - «"Homme et femme il les créa" (Gen. 1, 27): le genre féminin dans les commentaires de la Genèse au XII ${ }^{\mathrm{e}}$ siècle », Studi Medievali, 48.1, p. 229-270.

BaKhtine M., 1978 - Esthétique et théorie du roman, Paris.

Balansard A., 2001 - 'Techné' dans les Dialogues de Platon. L'empreinte de la sophistique, Sankt Augustin.

Balazs E., 1968 - La Bureaucratie céleste, Paris.

BaLme D. B., 1962 - « Development of Biology in Aristotle and Theophrastus: Theory of Spontaneous Generation », Phronesis, 7, p. 91-104.

BaLme D. M., 1987 - «The place of biology in Aristotle's philosophy », dans GotThelf A., LenNox J. G. (dir.), Philosophical issues in Aristotle's biology, p. 9-20.

Baratin M., Desbordes F., 1981 - L'Analyse linguistique dans l'Antiquité classique. I. Les théories, Paris.

BARBÉRIS J.-M., 2005 - « Le processus dialogique dans les phénomènes de reprise en écho », dans Bres J., Haillet P. P., Mellet S., NølKe H., Rosier L. (dir.), Dialogisme et polyphonie. Approches linguistiques, Bruxelles, p. 157-172.

Barbero G., 1990 - « Contributi allo studio del Liber glossarum », Aevum, 64, p. 151-174.

Barbero G., 1993 - « Per lo studio delle fonti del Liber Glossarum : il MS. Amploniano F.10 », Aevum, 67, p. 253-278.

BAUER U., 1983 - Der Liber introductorius des Michael Scotus in der Abschrift CLm 10268 der Bayerischen Staatsbibliothek München. Ein illustrierter astronomisch-astrologische Codex aus Padua, 14. Jahrhundert, München.

Baumann A., 1995 - Weltchronistik in the Outgoing Middle Ages. Heinrich of Herford, Gobelinus Person, Dietrich Engelhus, Francfort (Europäische Hochschulschriften, Reihe 3, 653).

Baumgartner E., Harf-Lancher L. (dir.), 2002 - Seuils de l'euvre dans le texte médiéval, Paris.

BAUSANi A., 1978 - L'enciclopedia dei fratelli della purità, Napoli.

BaUSANI A., 1985 - «L'enciclopedia e il mondo arabo-islamico medievale », Rivista critica de storia della filosofia Firenze, 40.1, p. 137-146.

Bazàn B. C., Wippel J. W., Fransen G., Jacquart D. (dir.), 1985 - Les Questions disputées et les questions quodlibétiques dans les Facultés de théologie, de droit et de médecine, Turnhout (Typologie des Sources du Moyen Âge Occidental, 44-45).

Beagon M., 2007 - « Situating Nature's Wonders in Pliny's Natural History », dans Bispham E. et Howe G. (éd.), avec MatThews E., 'Vita vigilia est'. Essays in Honour of Barbara Levick, Londres, p. 19-40.

BecQ A. (éd.), 1991 - L'Encyclopédisme. Actes du Colloque de Caen (1987), Paris.

BELARDI W., 2002 - L'etimologia nella storia della cultura occidentale, 2 vol., Rome.

Belaval Y., 1985 - «Diderot et l'encyclopédisme », Encyclopaedia Universalis, p. 437.

BÉLIS A., 1986 - Aristoxène de Tarente et Aristote. "Le traité d'harmonique”, Paris.

BÉlis A., 1996 - « Harmonique », dans Brunschwig J., Lloyd G. (éd.), Le Savoir grec. Dictionnaire critique, Paris, p. 352-367.

Bélis A., 2005 - « Musicales grecques (Théories) » dans Leclant J. (éd.), Dictionnaire de l'Antiquité, Paris, p. 1475-1479.

Bellino F., 2008 - Le Meraviglie del creato et le stranezze degli esseri, Milano. 
Benatouïl T., 2002 - «Logos et scala naturae dans le stoïcisme de Zénon et Cléanthe », Elenchos, 23, 2, p. 297-331.

BÉnatouïl T., Draelants I. (dir.), 2011 - Expertus sum: l'expérience par les sens dans la philosophie naturelle médiévale, Firenze (Micrologus' Library, 40).

BENEDETTI M. (éd.), 2001 - Fare etimologia. Presente, passato e futuro nella ricerca etimologica. Atti del Convegno Università per Stranieri, Siena, 2-3 ottobre 1998, Roma.

BEnEdiktson D. T., 1993 - «A Survey of Suetonius Scholarship, 1938-1987 », The Classical World, 86, p. 377-447.

Berlekamp P., 2011 - Wonder, Image and Cosmos in Medieval Islam, Yale, 2011.

Berlioz J., Polo de Beaulieu M. A., 2000 - « Les prologues des recueils d'exempla », dans Hamesse J. (éd.), Les Prologues médiévaux. Actes du Colloque international organisé par l'Academia Belgica et l'École française de Rome avec le concours de la F.I.D.E.M. (Rome, 26-28 mars 1998), Turnhout (Textes et études du Moyen Âge, 15), p. 275-321.

BERNDT R., 1987 - « Note sur la tradition manuscrite et l'édition du Tractatus in Hexaemeron de Hugues de Rouen », Revue d'Histoire des Textes, 17, p. 353-367.

BERNT G., 1986 - « Enzyklopädie II.1 : Lateinisches Mittelalter », Lexikon des Mittelalters, 3, col. 2032-2033.

Bernt G., Jung M.-R., 1986 - « Enzyklopädie III.1: Romanische und niederländische Literaturen », Lexikon des Mittelalters, 3, col. 2034.

Berteloot A., Hellfaier D., 2001 - Jacob Van Maerlants Der naturen bloeme und das Umfeld. Vorläufer - Redaktionen - Rezeption, Münster/New York (Niederlande-Studien, 23).

BERTINI F., 1981 - « La tradizione lessicografica latina fra tardo antico e alto medioevo », La cultura in Italia fra tardo antico e alto medioevo, I, Roma, p. 397-409.

Bertrand P., Van den Abeele B., 2006 - « Recyclage de contenus et récupération de pièces d'archives dans le Macrologus encyclopédique de Saint-Laurent de Liège (c. 1470-1480) », dans Claassens G. H. M., Verbeke W. (éd.), Medieval Manuscripts in Transition. Tradition and Creative Recycling, Leuven (Mediaevalia lovaniensia. Series 1, studia, 36), p. 37-59.

Besnier B., 1999 - « La conception stoïcienne de la nature », dans Cusset C. (éd.), La nature et ses représentations dans l'Antiquité, Paris, p. 119-131.

BEYER DE RYKe B., 2003 - « Le miroir du monde : un parcours dans l'encyclopédisme médiéval », Revue belge de philologie et d'histoire, 81.4, p. 1243-1275.

BiAnchi L., 1990 - Il vescovo e i filosofi. La condanna parigina del 1277 e l'evoluzione dell'aristotelismo scolastico, Bergame (Quodlibet, 6).

Binkley P. (éd.), 1997 - Pre-Modern Encyclopedic Texts. Proceedings of the second COMERS Congress, Groningen, 1-4 July 1996, Leiden/New York/Köln.

BIONDI L., 2011 - Recta scriptura. Ortografia ed etimologia nei trattati mediolatini del grammatico Apuleio, Milan, 2011.

BISChOFF B., 1966 - « Die Kölner nonnenhandschriften und das Scriptorium von Chelles », dans Bischoff B. (éd.), Mittelalterliche Studien, I, Stuttgart, p. 16-34.

BischofF B., 1981 - « Die Bibliothek im Dienste der Schule », dans Bischoff B. (éd.), Mittelalterliche Studien, III, Stuttgart, p. 213-233.

BitTerling K., 1986 - «Enzyklopädie III.2 : Englische Literatur », Lexikon des Mittelalters, 3, col. 2034-2035.

BLACHÈRE R., 1975 - « Quelques réflexions sur les formes de l'encyclopédisme en Égypte et en Syrie du VIII $/ \mathrm{XIV}^{\mathrm{e}}$ siècle à la fin du IXe/ $/ \mathrm{Xv}^{\mathrm{e}}$ siècle », dans BlachËre R. (éd.), Analecta, Damas, p. 521-540. 
BLAIR A., 1999 - « Authorship in the Popular "Problemata Aristotelis" », Early Science and Medicine, 4, p. 190-227.

Boissat D., 1971 - «Questions de classe: question de mise en scène, question de mise en demeure », dans Kerbrat-Orecchioni C. (dir.), La Question, Lyon (Linguistique et sémiologie), p. 263-294.

Boisson C., Kirtchuk P., BÉJoInt H., 1991 - « Aux origines de la lexicographie: les premiers dictionnaires monolingues et bilingues », International Journal of Lexicography, 4.4, p. 261-315.

Bolton Holloway J., 1986 - Brunetto Latini : an Analitic Bibliography, London (Research Bibliographies \& checklists, 44).

Bolton Holloway J., 1993 - Twice-told Tales : Brunetto Latini and Dante Alighieri, New York.

Bona I., 1991 - Natura terrestrium (Plin. NH VIII), Gênes.

Bonneldi M., 2004 - « La lexicographie philosophique antique », dans Darbo-Peschanski C. (dir.), La citation dans l'antiquité, Grenoble, p. 85-93.

Bonst A., 1994 - Das Buch der Naturgeschichte. Plinius und seine Leser im Zeitalter des Pergaments, Heidelberg.

Bos A. P., 1989 - « Exoterikoi logoi and enkyklioi logioi in the Corpus Aristotelicum and the Origin of the Idea of the enkykios paideia », Journal of the History of Ideas, 1, p. 179-198.

Botтero J., 1997 - « L'écriture, le développement et la diffusion du savoir en Mésopotamie ancienne », dans SCHAER R. (éd.), Tous les savoirs du monde. Encyclopédies et bibliothèques, de Sumer au XXIe siècle, Paris, p. 26-31.

DE BoÜARD M., 1930 - « Les encyclopédies médiévales : sur "la connaissance de la nature et du monde" au Moyen Âge », Revue des questions historiques, 112, p. 258-304.

DE BouÄRD M., 1932 - «Une encyclopédie médiévale jusqu'à présent inconnue, le Compendium philosophiae », Revue Thomiste, 15, p. 118-143 et p. 301-330.

DE Boü̈rd M. (éd. partielle), 1939 - Une nouvelle encyclopédie médiévale. Le Compendium philosophiae, Paris, p. 121-206.

DE BoÜARD M., 1991 - « Réflexions sur l'encyclopédisme médiéval », dans BECQ A. (éd.), L'encyclopédisme. Actes du colloque de Caen, 12-16 janvier 1987, Paris, p. 281-90.

Bouchet F., 2008 - Le discours sur la lecture aux XIV et XV : pratiques, poétique, imaginaire, Paris.

Bourgain P., 1989 - « Le sens de la langue et des langues chez Roger Bacon», dans Contamine G. (éd.), Traducteurs et traductions au Moyen Âge. Actes du Colloque International du CNRS, Paris, p. 317-331.

Bourgain P., 2001 - « Les verbes en rapport avec le concept d'auteur », dans ZimmERMAnN M. (éd.), Auctor et auctoritas. Invention et conformisme dans l'écriture médiévale. Actes du colloque tenu à l'Université de Versailles-Saint-Quentin-en-Yvelines (14-16 juin 1999), Paris (Mémoires et documents de l'École des Chartes, 59), p. 361-374.

BraUn L., 1973 - « Hellenistische Erklärungen des Nestorbechers », Mnemosyne, 26, p. 47-54.

BRAY L., 1990 - Dictionnaires. Encyclopédie Internationale de lexicographie, vol. 2, Berlin/New York, p. 1796-1798 et 1800-1801.

Bres J., 2005 - « Savoir de quoi on parle: dialogue, dialogal, dialogique; dialogisme, polyphonie... », dans Bres J., Haillet P. P., Mellet S., Nølke H., Rosier L. (dir.), Dialogisme et polyphonie. Approches linguistiques, Bruxelles, p. 47-61.

BrinKer-von der HeYde C., 1999 - « Durch Bildung zur Tugend: Zur Wissenschaftslehre des Thomasin von Zerclære », dans SCHAEFER U. (éd.), Artes im Mittelalter, Formationen und transformationen des Wissens, Berlin, p. 34-52. 
Brunschwig J., 1996 - « La connaissance », dans Brunschwig J., Loyd G. E. R. (dir.), Le Savoir grec: dictionnaire critique, Paris, p. 112-131.

BUFFIÈRE F., 1958 - Les mythes d'Homère et la pensée grecque, Paris.

Bullough V. L., Brundage J. A. (éd.), 1996 - Handbook of Medieval Sexuality, New York, (Garland Reference Library of the Humanities).

BuRIDANT C., 1986 - « Lexicographie et glossographie médiévales. Esquisse de bilan et perspectives de recherche », dans BURIDANT C. (éd.), Lexique, 4 (La Lexicographie au Moyen Âge), p. 9-46.

Buridant C., 1990 - « Définition et étymologie dans la lexicographie et la lexicologie médiévales », dans Chaurand J., Mazière F. (éd.), La Définition. Actes du Colloque la Définition organisé par le CELEX de l'Université Paris-Nord (Paris 13, Villetaneuse) à Paris, le 18 et 19 novembre 1988, Paris, p. 43-59.

Buridant C., 1998 - «Les paramètres de l'étymologie médiévale », dans BuRIDANT C. (éd.), Lexique, 14 (L'Étymologie, de l'Antiquité à la Renaissance), p. 11-56.

Burnett C. S. F., 1990 - «Innovations in the Classification of the Sciences in the Twelfth Century », dans Asztalos M., Murdoch J. E., Niniluoto I. (éd.), Knowledge and the Sciences in Medieval Philosophy. Proceedings of the eight International Congress of Medieval Philosophy, Helsinki 24-29 August 1987, t. 2, Helsinski (Publications of LutherAgricola Society. Series B, 19), p. 25-42.

Burnett C., 1995 - " Master Theodore, Frederick II's Philosopher », Federico II e le nuove culture. Atti del XXXI Convegno Storico internazionale, Todi, 9-12 ottobre, 1994, Spoleto, p. 225-285.

Burnett C., 2005 - « Michael Scot », dans Glick T. F., Livesey St. J., Wallis F. (éd.), Medieval Science, Technology, and Medecine. An Encyclopedia, p. 344-345.

Burton T. L. (éd.), 1998 - Sidrak and Bokkus. A parallel-text edition from Bodleian Library, MS Laud Misc. 559 and British Library, MS Lansdowne 793, Vol. I: Introduction, Prologue, and Books I-II, Oxford (EETS, 311).

CAdDen J., 1999 - Meaning of Sex Difference in the Middle Ages : Medicine, Science, and Culture, Cambridge (Cambridge History of Medicine).

CAdDen J., 2001 - « Nothing natural ist shameful : vestiges of a debate about sex and science in a group of late-medieval manuscripts », Speculum, 76, p. 66-89.

de Callatä̈ G., Van den Abeele B. (éd.), 2008 - Une lumière venue d'ailleurs. Héritages et ouvertures dans les encyclopédies d'Orient et d'Occident au Moyen Âge. Actes du colloque de Louvain-la-Neuve, 19-21 mai 2005, Louvain-la-Neuve.

Cambiano G., 1991 - Platone e le tecniche, Rome et Bari (1éd. 1971).

Canto Llorca J., 1991 - « La erudición virgiliana a fines del s. IV : Macrobio, Saturnalia, 6 », dans Ramos Guerra A. (éd.), Homenaje Codoñer C., Salamanque, p. 29-44.

CAPElli L. M., 1897 - Primi studi sulle enciclopedie medioevali. Le fonti delle enciclopedie latine del XII secolo, Modène.

Capitani U., 1972 - «Celso, Scribonio Largo, Plinio il Vecchio e il loro attegiamento nei confronti della medicina popolare », Maia, p. 120-140.

Capponi F., 1987 - « Cultura scientifico-naturalistica di Plinio », dans Pigeaud J., Oroz J. (éd.), Pline l'Ancien, témoin de son temps, Salamanque/Nantes, p. 131-146.

CAPPONI F., 1990 - 'Natura Aquatilium' (Plin. NH IX), Gênes.

CaPponi F., 1994 - 'Entomologia pliniana' (NH, XI, 1-120), Gênes.

Cardelle De Hartmann C., 2007 - Lateinische Dialoge 1200-1400: literaturhistorische Studie und Repertorium, Leyde/Boston (Mittellateinische Studien und Texte, 37). 
Cardini F., 1994 - « Parole introduttive », dans Picone M. (éd.), L'Enciclopedismo medievale, Ravenna, p. 9-14.

Carruthers M., 2002 (traduction française) - Le Livre de la Mémoire. La mémoire dans la culture médiévale, Paris (éd. angl. : The Book of Memory, Cambridge, 1990).

della Casa A., 1981 - «Les glossaires et les traités de grammaire du Moyen Âge », dans LEFEVRE Y. (éd.), La Lexicographie du latin médiéval et ses rapports avec les recherches actuelles sur la civilisation du Moyen-âge, Paris, p. 35-46.

CAssin B., 2006 - Google-moi. La deuxième mission de l'Amérique, Paris.

CÉARD J., 1997 - « Le commentaire, ou l'encyclopédisme non méthodique de la Renaissance », dans Bouffartigue J., Melonio F. (éd.), L'entreprise encyclopédique, Littérales, 21, p. 79-101.

Chailley J., 1960 - L'Imbroglio des modes, Paris.

Chailley J., 1979 - La Musique grecque antique, Paris (Collection d'études anciennes).

Chapoutot-Remadi M., 1990 - « Les encyclopédies arabes de la fin du Moyen Âge », dans BecQ A. (dir.), L'encyclopédisme. Actes du Colloque de Caen, 12-16 janvier 1987, Paris, p. 267-279.

Chapoutot-Remadi M., 1995 - « Nuwayrī », dans Encyclopédie de l'Islam, 2e éd., Leiden, VIII, p. 158-162.

Charaudeau P., Maingueneau D. (dir.), 2002 - Dictionnaire d'analyse du discours, Paris.

Charlet J.-L., 2004-2005 - «L'encyclopédisme latin humaniste : de la lexicographie à l'encyclopédie (Xve-début Xvi ${ }^{\mathrm{e}}$ s.) », Moderni e antichi, 2-3, p. 285-306.

ChÂtIllon J., 1948 - «Le contenu, l'authenticité et la date du Liber exceptionum et des Sermones centum de Richard de Saint-Victor », Revue du Moyen Âge latin, 4, p. 23-52 et 343-366.

Châtillon J., 1966 - « Le Didascalicon d'Hugues de Saint Victor », Cahiers d'histoire mondiale, $\mathrm{n}^{\circ}$ spécial Encyclopédies et civilisations, 9, p. 539-552.

Chenu M.-D., 1976 - La théologie au douzième siècle, Paris.

Citroni-Marchetti S., 1982 - « Juvare Mortalem. L'ideale programmatico della NH di Plinio nei rapporti con il moralismo stoico-diatribico », Atene e Roma, 27, p. 124-148.

Citroni-Marchetti S., 1991 - Plinio il Vecchio e la tradizione del moralismo romano, Pise.

Citroni-Marchetti S., 1992 - «Filosofia e ideologia nella Naturalis historia di Plinio », $A N R W$, II, 36. 5, p. 3249-3306.

Codoñer C., 1985 - « La etimología en Isidoro de Sevilla », dans Melena J. L. (éd.), Symbolae Ludovico Mitxelena septuagenario oblatae, 1, Vitoria, p. 275-286.

Codoñer C., 1986 - «Antecedentes del diccionario. El libro x de Etymologiae », Los Visigodos. Historia y civilización, Alcalá de Henares, p. 351-371.

Codoñer C., 1991 - « De l'Antiquité au Moyen Âge: Isidore de Sévile », dans BECQ A. (dir.), L'Encyclopédisme. Actes du colloque de Caen, 12-16 janvier 1987, Paris, p. 19-35.

Codoñer C., 1998 - « Evolución de la lexicografía latina medieval », dans Pérez González M. (éd.), Actas II Congreso Hispánico de Latín Medieval (León, 11-14 de Noviembre de 1997), 1, León, p. 39-50.

Codoñer C., 2012 - « La enciclopedia. Un género sin definición. Siglos I a. C. - VII d. C. », Giornate Filologiche Genovese, L'enciclopedismo dall'Antichità al Rinascimento, Gênes, p. 115-153.

Coitier D., de Brabanter P., Dendale P., 2009 - « La notion de prise en charge : mise en perspective », Langue Française, 162, p. 3-27.

Collart J., 1978 - Varron, grammaire antique et stylistique latine, Paris. 
Collinot A., 1985 - « L'ouverture des dictionnaires. Remarques sur les titres et préfaces des dictionnaires français du $\mathrm{XvI}^{\mathrm{e}}$ siècle », Lexique, 3, p. 11-31.

Collison R., 1964 - Encyclopaedias : Their History troughout the Ages, New York.

Congar Y.-M., 1963 - « Le thème de Dieu-créateur et les explications de l'Hexaemeron dans la tradition chrétienne ", L'homme devant Dieu. Mélanges offerts au Père Henri de Lubac, 1, Paris, p. 189-222.

Connochie-Bourgne C., 1996 - « Je, qui cest escrit en fis... Brunet Latin et Gossuin de Metz font entendre leurs voix », Cahiers Diderot, 8, p. 57-79.

Connochie-Bourgne C., 1999 - L'Image du monde, une encyclopédie du XIII siècle, édition

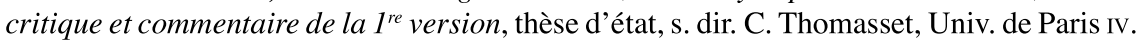

Connochie-Bourgne C., 2005 - «La tour de Boctus le bon roi dans le Livre de Sydrach », dans Gingras F., Laurent F., Le Nan F., Valette J.-R. (éd), « Furent les merveilles pruvees et les aventures truvees ». Hommage à Francis Dubost, Paris, p. 163-176.

Connochie-Bourgne C., 2006 - « Mise en récit et discours scientifique : les encyclopédies du $\mathrm{XIII}^{\mathrm{e}}$ siècle en langue vulgaire », dans THOMASSET C. (dir.), L'écriture du texte scientifique au Moyen Âge, Paris, p. 117-132.

Conte G. B., 1991 - « L'inventario del mondo. Forma della natura e progetto enciclopedico nell'opera di Plinio il Vecchio », dans ConTe G. B, Generi e lettori, Lucrezio, l'elegia d'amore, l'enciclopedia di Plinio, Milan, p. 95-144.

Copeland R., Sluiter I. (éd.), 2009 - Medieval Grammar \& Rhetoric. Language Arts and Literary Theory, $A D$ 300-1475, Oxford.

Corbin H., 1964 - Histoire de la philosophie islamique, Paris.

Del Corno D., 1998 - « L'uomo e la natura nel mondo greco », dans Uglione R. (éd.), L'uomo antico e la natura, Turin, p. 93-104.

Cotta Ramosino L., 2004 - Plinio il Vecchio e la tradizione storica di Roma nella Naturalis Historia, Alessandria.

Courcelle P. (éd.), 1939 - « Étude critique sur les commentaires de Boèce », AHDLMA, 12, 1939 , p. 5-140.

Craemer-Ruegenberg I., Anzulewicz H. (éd.), $\mathbf{2 0 0 5}^{2}$ - Albert der Große, Leipzig (Dominikanische Quellen und Zeugnisse, 7).

Cremascoli G., 2001 - « Intorno alle Derivationes di Osberno di Gloucester », dans LunARDINI V. (éd.), Pan, 18-19 (Miscellanea di studi in memoria di Cataldo Roccaro), p. 171-184.

Crubellier M., Pellegrin P., 2002 - Aristote. Le philosophe et les savoirs, Paris.

da Cruz Pontes J. M., 1986 - « Astrologie et apologétique au Moyen Âge », dans Wenin C. (éd.) L'homme et son univers au Moyen Âge. Actes du septième Congrès international de philosophie médiévale (30 août - 4 septembre 1982), Louvain-la-Neuve, p. 631-37.

Cureton G., Rieu C., 1843 - Codices Arabicos Amplectens, Londres.

Cusset C., 1999 - La nature et ses représentations dans l'Antiquité, Paris.

Dahan G., 1987 - «Une introduction à l'étude de l'Écriture au XII ${ }^{\mathrm{e}}$ s.: le Prologue du Commentaire du Pentateuque de Rainaud de Saint-Eloi », Recherches de théologie ancienne et médiévale, 54, p. 27-51.

DAHAN G., 1990 - « La classification des savoirs auX XII et XIII ${ }^{\mathrm{e}}$ siècles », L'enseignement philosophique, 40.4, p. 5-27.

Dahan G., 1992 - «L'exégèse de Genèse 1, 26 dans les commentaires du XII ${ }^{\mathrm{e}}$ siècle », Revue des études augustiniennes, 38, p. 124-153. 
Dahan G., 1995 - « Nommer les êtres : exégèse et théories du langage dans les commentaires médiévaux de Genèse 2, 19-20 », dans EBBESEN S. (éd.), Sprachtheorien in Spätantike und mittelalter, Tübingen, p. 55-74.

Dahan G., 1999a - «Encyclopédies et exégèse de la Bible aux XII ${ }^{\mathrm{e}}$ et XIII ${ }^{\mathrm{e}}$ siècles », Cahiers de Recherches Médiévales (XIII $-X V^{e}$ s.), 6, p. 1-23.

Dahan G., 1999b - L'exégèse chrétienne de la Bible en Occident médiéval XII -XIV siècle, Paris.

Dahan G. (éd.), 2013 - Pierre le Mangeur ou Pierre de Troyes, maître du XII siècle, Turnhout (Bibliothèque d'Histoire culturelle du Moyen Âge, 12).

Dalmedico A. D., Pestre D., 1998 - «Comment parler des sciences aujourd'hui », dans Jourdant B. (dir.), Impostures scientifiques. Les malentendus de l'affaire Sokal, Paris, p. 77-105.

DALY L. W., 1967 - Contributions to a history of alphabetization in Antiquity and the Middle Ages, Bruxelles.

Darnton R., 1982 - L'Aventure de l'Encyclopédie, Paris.

DEGREgorio S., 2002 - « "Nostrorum socordiam temporum": The reforming impulse of Bede later esegesi », Early Medieval Europe, 11.2, p. 117-122.

DeGregorio S., 2010 - « The Venerable Bede and Gregory the Great: exegetical connections, spiritual departures », Early Medieval Europe, 18.1, p. 43-60.

Deleuze G., 1988 - Abécédaire (réalisation: Boutang P.-A.).

Demiéville P., 1925 - «Compte rendu de Che-yin Song Li Ming-tchong Ying tsao fa che », Bulletin de l'École française d'Extrême-Orient, 25, p. 213-264.

Denifle H., Châtelain E. (éd.), 1889 - De proprietatibus: Chartularium universitatis Parisiensis, I, Paris.

Denifle H., Châtelain E. (éd.), 1891 - De proprietatibus: Chartularium universitatis Parisiensis, II, sectio 1, Paris.

Derolez A., 1998 - The Autograph Manuscript of the Liber floridus. A Key to the Encyclopedia of Lambert of Saint-Omer, Turnhout (CC Autographa Medii Aeui, 4).

Derrida J., 1972 - La Dissémination, Paris.

DeSbORdes F., 1990 - Idées romaines sur l'écriture, Paris/Lille.

Desbordes F., 1998 - «La pratique étymologique des Latins », dans Buridant C. (éd.), Lexique, 14 (L'Étymologie, de l'Antiquité à la Renaissance), p. 69-79.

Desrousseaux A.-M., 1956 - Athénée de Naucratis. Les Deipnosophistes. Livres 1-2, Paris $(C U F, 126)$.

Detienne M., 1981 - L'invention de la mythologie, Paris.

Détrie C., Siblot P., Vérine B., 2001 - Termes et concepts pour l'analyse du discours. Une approche praxématique, Paris (Lexica, 7).

DEus J., 1998 - Der « Experimentator » - eine anonyme lateinische Naturenzyklopädie des frühen 13. Jahrhunderts, dissertation, Hamburg.

Diesner H.-J., 1976 - « Lexikographie und Enzyklopädie in der Antike », dans DiesNer H.-J., GuRST G. (dir.), Lexika gestern und heute, Leipzig, p. 11-60.

Dionisotri A. C., 1996 - « On the Nature and Transmission of Latin Glossaries », dans HAMESSE J. (éd.), les Manuscrits des lexiques et glossaires de l'Antiquité Tardive à la fin du Moyen Âge, Louvain-la Neuve, p. 202-252.

Doddy A., 2010 - Pliny's Encyclopedia. The Reception of the Natural History, Cambridge.

Dorion L.-A., 1997 - « La "dépersonnalisation" de la dialectique chez Aristote », Archives de philosophie, 60.4, p. 597-561. 
Draelants I., 1992 - «Une mise au point sur les oeuvres d'Arnold de Saxe, $1^{\mathrm{e}}$ partie », Bulletin de philosophie médiévale, 34, p. 164-180.

Draelants I., 1993 - « Une mise au point sur les oeuvres d'Arnold de Saxe, $2^{\mathrm{e}}$ partie », Bulletin de philosophie médiévale, 35, p. 130-149.

Draelants I., 2002 - «Introduction à l'étude d'Arnoldus Saxo et aux sources du Defloribus rerum naturalium », dans MeIER C. (éd.), Die Enzyklopädie im Wandel vom Hochmittelalter bis zur frühen Neuzeit. Akten des Kolloquiums des Projekts D im Sonderforschungsbereich 231 (29.11.-01.12.1996), Munich (Münstersche Mittelalter-Schriften, 78), p. 85-122.

Draelants I., 2005 - « La science naturelle et ses sources chez Barthélemy l'Anglais et les encyclopédistes contemporains », dans VAN DEN Abeele B., Meyer H. (éd.), Bartholomäus Anglicus, De proprietatibus rerum. Texte latin et réception vernaculaire, Lateinischer Text und volkssprachige Rezeption, Turnhout, (De diversis artibus, 74, NS 37), p. 43-99.

Draelants I., 2010 - « La science encyclopédique des pierres au $13^{\mathrm{e}}$ siècle : l'apogée d'une veine minéralogique », dans Thomasset C., Ducos J., Chambon J.-P. (éd.), Aux origines de la géologie de l'Antiquité à l'âge classique. Actes du Colloque de la Sorbonne, 10-12 mars 2005, Paris, p. 91-139.

Draelants I., Paulmier-Foucart M., 2004 - « Échanges dans la societas des naturalistes au milieu du XIII ${ }^{\mathrm{e}}$ siècle: Arnold de Saxe, Vincent de Beauvais et Albert le Grand », dans James-Raoul D., Soutet O. (dir.), Par les mots et par les textes..., Mélanges de langue, de littérature et d'histoire des sciences médiévales offerts à Claude Thomasset, Paris, p. 219-231.

DrèGE J.-P., 1991 - Les bibliothèques en Chine au temps des manuscrits (jusqu'au $X^{e}$ siècle), Paris.

DRÈGE J.-P., 2007 - « Des ouvrages classés par catégories: les encyclopédies chinoises », Extrême-Orient Extrême-Occident, Saint-Denis, p. 19-38.

DRÈge, J.-P., à paraître - «Les encyclopédies », dans Drege J.-P. (dir.), La fabrique du lisible : La mise en texte des manuscrits chinois, Paris.

Dreyer M., 1998 - « Ethik als Wissenschaft nach Albertus Magnus », dans AerTsen J. A., SPEER A. (éd.), Was ist Philosophie im Mittelalter? Qu'est-ce que la philosophie au Moyen $\hat{A}$ ge? What is Philosophy in the Middle Ages? Akten des X. Kongresses für Mittelalterliche Philosophie der Société Internationale pour l'Étude de la Philosophie, Berlin/New York (Miscellanea Mediaevalia, 26), p. 1017-1023.

Dronke P. (éd.), 1988 - A History of Twelfth-Century Western Philosophy, Cambridge.

Ducatez G., 1985 - « La Tuhfa al-albāb d'Abū Hāmid al-Andalusī al-Ġarnātī », Revue des études islamiques, 53, p. 141-241.

DuCÈNE J.-C., 2005 - « Soufisme et cosmographie musulmane auX XII ${ }^{\mathrm{e}}$ et XIII ${ }^{\mathrm{e}}$ siècles : convergence ou influence à propos d'une conception commune du monde? », dans Dierkens A., Beyer DE RyKe B. (éd.), Mystique: la passion de l'Un, de l'Antiquité à nos jours, Bruxelles, p. 205-214.

DuCÈNE J.-C., 2006a - « Le Hortus rerum mirabilium (Rome, 1584-85): une cosmographie arabe oubliée », Zeitschrift der Deutschen Morgenländischen Gesellshaft, 156, p. 81-93.

DuCÈNE J.-C., 2006b - De Grenade à Bagdad. La relation de voyage d'Abû Hâmid al-Gharnâtî (1080-1168), Paris.

Ducos J., 1995 - « Le clerc et les météores : constitution et évolution d'une culture encyclopédique », Senefiance, 37 (Le clerc au Moyen Age), p. 151-164.

Ducrot O., 1980 - Dire et ne pas dire, Paris. 
Duсroт O., 1981 - «La valeur argumentative de la phrase interrogative », dans BANGE P. et al. (éd.), Logique, argumentation, conversation. Actes du Colloque de Pragmatique, Fribourg (Sciences pour la communication, 5), p. 79-110.

Ducrot O., 1984 - Le Dire et le dit, Paris.

Duсrот O., 1989 - «Énonciation », Encyclopedia Universalis, VIII, p. 388-392.

DüRING I. (éd.), 1930 - Die Harmonielehre des Klaudios Ptolemaios, Göteborg (Göteborgs Högskolas Arsskrift, 36).

DürING I., 1957 - Aristotle in the Ancient Biographical Tradition, Göteborg.

Duval F., Vielliard F., 2007 - Miroir des classiques, Paris (Éditions en ligne de l'École des chartes, 17), http://elec.enc.sorbonne.fr/miroir/.

EDwards G., 1985 - « The Two Redactions of Michael Scot's Liber introductorius », Traditio, 41, p. $329-340$.

Ellis A. G., Edwards E., 1912 - A Descriptive list of the Arabic Manuscripts aquired by the trustess of the British Museum since 1894, London.

ENGelhardt C. M., 1818 - Herrad von Landsperg und ihr Werk : "Hortus deliciarum », ein Beytrag zur Geschichte des Mittelalters, Stuttgart/Tübingen.

ENGlisch B., 1994 - Die Artes liberales im frühen Mittelalter (5.-9. Jh.). Das Quadrivium und der Komputus als Indikatoren für Kontinuität und Erneuerung der exakten Wissenschaften zwischen Antike und Mittelalter, Stuttgart (Sudhoffs Archiv Beihefte, 33).

ENglisch B., 1999 - «Artes und Weltsicht bei Roger Bacon », dans Schaefer U. (éd.), Artes im Mittelalter, Formationen und transformationen des Wissens, Berlin, p. 53-67.

ERnst U., 1989 - " Neu aufgefundene Handschriften des "Elucidarium" von Honorius Augustodunensis », Scriptorium, 43, p. 289-312.

Eybl F. et al. (éd.), 1995 - Enzyklopädien der frühen Neuzeit. Beiträge zu ihrer Erforschung, Tübingen.

FANT C., 1886 - L'Image du monde, poème inédit du milieu du XIII siècle, étudié dans ses diverses rédactions françaises d'après les manuscrits des bibliothèques de Paris et de Stockholm, Uppsala.

Fedeli P., 1998 - « L'uomo e la natura nel mondo romano », dans Uglione R. (éd.), L'uomo antico e la natura, Turin, p. 105-125.

Fernandez M., 2007 - «Wikipédia, le rêve de Diderot? », Philosophie Magazine, 9.

Ferrari M., 1972 - « Il "Liber glossarum" e la cultura ecclesiastica a Monza e Milano in età carolingia », Ricerche storiche sulla Chiesa Ambrosiana, 3, p. 45-53.

FINZI V., 1894 - « Di un inedito volgarizzamento dell'Imago mundi di Onorio d'Autun », ZrP, 18 , p. $1-75$.

Flasch K. (éd.), 1984 - Von Meister Dietrich zu Meister Eckhart, Hambourg (CphTMA, 2).

Flasch K., 2006 - Meister Eckhart. Die Geburt der deutschen Mystik aus dem Geist der arabischen Philosophie, Munich.

FLASCh K., IMBaCH R., 2003 - Meister Eckhart in seiner Zeit, Düsseldorf (Schriftenreihe der Identity Foundation, 7).

Flint V., 1982 - « Honorius Augustodunensis Imago Mundi », AHDLMA, 49, p. 7-153.

Flint V., 1995 - «Honorius Augustodunensis of Regensburg », dans GEARY P. (éd.), Authors of the Middle Ages. Historical and Religious Writers of the Latin West, vol. II, 5-6, Variorum, Aldershot/Brookfield, p. 91-183.

FlüEler C., 2004 - « Ethica in Wien anno 1438. Die Kommentierung der Aristotelischen Ethik an der Wiener Artistenfakultät », dans KNAPP F. P., MiethKe J., NIESNER M. (éd.), Schriften im Umkreis mitteleuropäischen Universitäten um 1400. Lateinische und volkssprachige Texte 
aus Prag, Wien und Heidelberg: Unterschiede, Gemeinsamkeiten, Wechselbeziehungen, Leyde / New York / Cologne (Education and Society in the Middle Ages and the Renaissance, 20), p. $92-140$.

FöGEN T., 2005 - Antike Fachtexte, Ancient Technical Texts, Berlin/New York.

Fögen T., 2010 - « Plinius der Ältere zwischen Tradition und Innovation: Zur Ideologie' der Naturalis historia », dans KRAMER N., ReITZ C. (éd.), Tradition und Erneuerung. Mediale Strategien in der Zeit der Flavier, Berlin/New York, p. 41-61.

Fontaine J., 1966 - « Isidore de Séville et la mutation de l'encyclopédisme antique », Cahiers d'histoire mondiale, 9, Paris / Neufchâtel, p. 519-538.

FonTaine J., 1978 - « Cohérence et originalité de l'étymologie isidorienne », dans RodRíguez E., Iturriaga J. (éd.), Homenaje a Eleuterio Elorduy, Miscelanea S. J. en honor de E.E., S.J. con ocasión de su 80 aniversario, Bilbao, p. 113-144.

Fontaine J., 1979 - « La situation de la rhétorique dans la culture tardive : observations sur la théorie isidorienne de l'étymologie (Étym., I, 29) », dans CHEVALLIER R. (éd.), Colloque sur la rhétorique Calliope I, Paris (Caesarodunum, 14 bis), p. 197-205.

Fontaine J., 1981 - «Aux sources de la lexicographie médiévale : Isidore de Séville, médiateur de l'étymologie ancienne », dans LeFÈvre Y. (éd.), La Lexicographie du latin médiéval et ses rapports avec les recherches actuelles sur la civilisation du Moyen Âge, Paris, p. 97-103.

Fontaine J., 1983 [1959] - Isidore de Séville et la culture classique dans l'Espagne wisigothique, Paris, 3 vol.

Fontaine J., 1986 - « Cassiodore et Isidore: l'évolution de l'encyclopédisme latin du $\mathrm{vI}^{\mathrm{e}}$ au $\mathrm{VII}^{\mathrm{e}}$ siècle », dans LeanZA S. (éd.), Flavio Magno Aurelio Cassiodoro. Cosenza-Squillace 19-24 settembre 1983, Soveria, p. 72-91.

Fontaine J., 2000 - Isidore de Séville. Genèse et originalité de la culture hispanique au temps des Wisigoths, Turnhout.

de Fontenelle B., 1991 - Entretiens sur la pluralité des mondes habités, dans de Fontenelle B. (éd.), Euvres complètes, t. II, Paris (Corpus des auvres de philosophie en langue française, 43).

ForNARA W., 1983 - The Nature of History in Ancient Greece and Rome, Berkeley/ Los Angeles/Londres.

Forster R., 2006 - Das Geheimnis der Geheimnisse. Die arabischen und deutschen Fassungen des pseudo-aristotelischen Sirr al-asrar/Secretum secretorum, Wiesbaden (Wissensliteratur im Mittelalter, 43).

Forster R., 2007 - « Enzyklopädie oder Fürstenspiegel? Arabische, lateinische und deutsche Fassungen des pseudo-aristotelischen Secretum Secretorum », dans Michel P., Herren M., RüESCH M. (éd.), Allgemeinwissen und Gesellschaft. Akten des internationalen Kongresses über Wissenstransfer und enzyklopädische Ordnungssysteme, Aachen, p. 257-273.

Foucault M., 1966 - Les mots et les choses, Paris.

Fowler R. L., 1997 - « Encyclopaedias: Definitions and Theoretical Problems », dans Binkley P. (éd.), Pre-Modern Encyclopaedic Texts. Proceedings of the Second COMERS Congress, Groningen, 1-4 July 1996, Leiden/New York/Köln, p. 3-29.

Franco L., 1994 - « Vincenzo Coronelli : Vita e opere. Aggiornamenti », Nuncius, 9.2, p. 517-541.

French R., 1994 - Ancient Natural History, Londres / New York.

French R., Greenaway F., 1986 - Science in the Early Roman Empire. Pliny the Elder, his Sources and Influence, Londres/Sydney.

Friedman J.-B., 1989 - « Peacocks and Preachers : Analytic Technique in Marcus of Orvietos' Liber de moralitatibus, Vatican lat. Ms. 5933 », dans Clark W. B., McMunn M. (éd.), 
Beasts and Birds in the Middle Ages. The Bestiary and its Legacy, Philadelphia (The Middle Ages), p. 179-196.

Frunzeanu E., 2007 - Les configurations de la natura dans le Speculum maius de Vincent de Beauvais, thèse de doctorat, Montréal, Faculté des études supérieures.

FuChs H., 1962 - «Enkyklios Paideia », Reallexikon für Antike und Christentum, 5, p. 365-398.

Fumagalli M., Boenio-Brocchieri T., 1981 - Le Encyclopedie dell' Occidente medioevale, Turin (Pedagogia, 20).

Fumagalli M., Parodi M., 1985 - « Due enciclopedie dell'occidente medievale: Alessandro Neckam e Bartolomeo Anglico », Rivista di storia della filosofia, 40, p. 51-90.

Fürbeth F., 1999 - «Die Stellung der artes magicae in den hochmittelalterlichen Divisiones philosophiae », dans Schaefer U. (éd.), Artes im Mittelalter, Wissen und Magie, Berlin, p. 249-262.

GaIDE F., 2003 - « Aspects divers des principes de sympathie et d'antipathie dans les textes thérapeutiques latins », dans PALMIERI N. (éd.) Rationnel et irrationnel dans la médecine ancienne et médiévale, Saint-Étienne, p. 129-144.

GaIllard-Seux P., 1994 - La médecine chez Pline l'Ancien. Ses rapports avec la magie, thèse de l'Université de Paris IV-Sorbonne.

GaILlard-SeuX P., 1998 - «A propos des livres XXVIII-XXIX-XXX de l'Histoire naturelle de Pline l'Ancien », Latomus, 57.2, p. 625-633.

Gaillard-Seux P., 2003 - « Sympathie et antipathie dans l'Histoire naturelle de Pline l'Ancien », dans PALMIERI N. (éd.), Rationnel et irrationnel dans la médecine ancienne et médiévale, Saint-Etienne, p. 113-128.

Galimberti-Biffino G., 2007 - «Loquere uerbis praesentibus $(1,10,4)$ : il criterio dell'elegantia in Gellio », Latomus, 66, p. 929-941.

DE GANDillac M., 1966a - « Encyclopédies prémédiévales et médiévales », Cahiers d'Histoire mondiale, 9.3, p. 483-518.

DE Gandilliac M. et al., 1966b - La Pensée encyclopédique au Moyen Âge, Paris / Neufchâtel (Cahiers d'histoire mondiale, 9).

Ganz D., 1991 - « Heiric d'Auxerre, glossateur du Liber glossarum », dans IognA-Prat D., JEUdy C., Lobrichon G. (éd.), L'École carolingienne d'Auxerre. De Murethach à Remi 830-908. Entretiens d'Auxerre 1989, Paris, p. 297-312.

GATTI P., 2001 - Studi osberniani, Genova.

Gautier Dalché P., 1991 - « La Descriptio mappe mundi de Hugues de Saint-Victor : retractatio et addimenta », dans LongÈre J. (éd.), L'abbaye parisienne de Saint-Victor au Moyen Âge, Turnhout (Bibliotheca victorina, I), p. 143-179.

Gavollle E., 2000 - 'Ars'. Étude sémantique de Plaute à Cicéron, Louvain/Paris.

Genette G., 1987 - Seuils, Paris.

Gerosa M., 1911 - La prima enciclopedia romana: i libri ad Marcum filium di Catone Censorio, Pavia.

GiACONE R., 1973 - « Sul concetto di "Enciclopedia" nel pensiero classico e medioevale: nota introduttiva », Rivista di studi classici, 21, p. 1-7.

Giacone R., 1974 - «Arti liberali e classificazione delle scienze: l'esempio di Boezio e Cassiodoro », Aevum, 48, p. 58-72.

Gigon O., 1966 - « Plinius und der Zerfall der antiken Naturwissenschaft », Arctos, 4, p. 23-45.

Glick T. F., Livesey S. J., Wallis F. (éd.), 2005 - Medieval Science, Technology, and Medicine- An Encyclopedia, New York.

Godin C., 1998 - La Totalité, 2, Les Pensées totalisantes, Seyssel. 
Godin C., 2002 - La Totalité, 6, La totalité réalisée, Seyssel.

Goetz W., 1936 - «Die Enzyklopädien des 13. Jhs. Ein Beitrag zur Entstehung der Laienbildung », Zeitschrift für deutsche Geistergeschichte, 2, p. 227-256.

Goetz W., 1937 - « Die Enzyklopädien des 13. Jhs. Ein Beitrag zur Entstehung der Laienbildung », Zeitschrift für deutsche Geistergeschichte, 3, p. 1-24.

GoETz W., 1942 - Italien im Mittelalter, 2, Leipzig, p. 62-107.

Goldust B., 2008 - « Macrobe Vergiliomastix? (à propos de Sat., 5, 2, 1) », Latomus, 67, 4, p. $1049-1050$.

Goldlust B., 2009 - «Un manifeste sur l'organicité littéraire: la préface des Saturnales de Macrobe », dans Galand-Hallyn P., ZarinI V. (éd.), Manifestes littéraires dans la latinité tardive. Poétique et rhétorique. Actes du colloque international de Paris, Paris, p. 275-293.

Golduust B., 2010 - Rhétorique et poétique de Macrobe dans les Saturnales, Turnhout.

Goldlust B., 2012 - « Cnaius Gellius ou Aulu-Gelle ? Cnaius Gellius et Aulu-Gelle ? À propos de Macr., Sat., 3, 17, 3 », Latomus, 71.4, p. 1151-1155.

Goldstein-PrÉaud T., 1981 - "Albert le Grand et les questions du XIII siècle sur le $D e$ Animalibus d'Aristote », History and Philosophy of the Life Sciences, 3.1, p. 61-71.

GoMEs J., 2005 - « L'Exégèse monastique au XII siècle : tropologie, intériorité et subjectivité chez Guibert de Nogent », Bulletin du centre d'études médiévales d'Auxerre (BUCEMA), 9.

Gontero-Lauze V., 2010 - Sagesses minérales. Médecine et magie des pierres précieuses au Moyen Âge, Paris.

Gottschall D., 2004 - Konrad von Megenbergs "Buch von den natürlichen Dingen". Ein Dokument deutschsprachiger Albertus Magnus-Rezeption im 14. Jahrhundert, Leyde/Boston (STGgM, 83).

Granger G. G., 1976 - La théorie aristotélicienne de la science, Paris.

Gregory T., 1955 - Anima Mundi: la filosofia di Guglielmo di Conches e la scuola di Chartres, Florence.

GreGORY T., 1975 - « La nouvelle idée de nature et de savoir scientifique au XII ${ }^{\mathrm{e}}$ siècle », dans Murdoch J. E., Sylla E. D. (éd.), The Cultural Context of Medieval Learning, Dordrecht/ Boston, p. 193-218.

Gregory T., 1992 - Mundana Sapientia : forme di conoscenza nella cultura medievale, Roma.

Grellard C., Morel P.-M., 2010 - Les Parva naturalia d'Aristote, Fortune antique et médiévale, Paris.

Grente G. (éd.), 1954 - Dictionnaire des lettres françaises. Le dix-septième siècle, Paris.

GrÉvin B., 2002 - «Systèmes d'écriture, sémiotique et langage chez Roger Bacon », Histoire Épistémologie Langage, 24.2, p. 75-111.

Griffin M., 2007 - « The Elder Pliny on Philosophers », dans Bispham E., HowE G. (éd.), avec Matthews E., 'Vita vigilia est'. Essays in Honour of Barbara Levick, Londres, p. 85-101.

Grimal P., 1966 - « Les encyclopédies antiques », Cahiers d'histoire mondiale, 9, Paris / Neufchâtel, p. 459-482.

Grimal P., 1987 - «Pline et les philosophes », dans Pigeaud J. et Oroz J. (éd.), Pline l'Ancien, témoin de son temps, Salamanque/Nantes, p. 239-249.

Grondeux A., 2000 - Le Graecismus d'Évrard de Béthune à travers ses gloses. Entre grammaire positive et grammaire spéculative $d u X_{I I t}^{e}$ au $\mathrm{XV}^{e}$ siècle, Turnhout.

Grondeux A., 2009 - « Liber glossarum », dans Stammerjohann H. (éd.), Lexicon Grammaticorum. A Bio-bibliographical Companion to the History of Linguistics, Tübingen, p. 905-906. 
Grondeux A., Rosier-Catach I., 2011 - « Les Glosulae super Priscianum et leur tradition », dans Rosier-CATACH I. (éd.), Arts du langage et théologie aux confins des XI et XII siècles. Textes, maîtres, débats, Turnhout, p. 107-179.

Gros P., 1994 - «Munus non ingratum: le traité vitruvien et la notion de service », dans Le projet de Vitruve. Objet, destinataires et réception du 'De Architectura', Rome, p. 75-90.

GueSPIN L., 1985 - «Nous, la langue et l'interaction », Mots, 10, p. 45-61.

Guillaumin J.-B., 2009 - « La place et le statut de la musique dans l'encyclopédisme de Martianus Capella », Bulletin de l'Association Guillaume Budé, 1, p. 169-185.

Guillaumin J.-B., 2012 - « De l'hapax littéraire au néologisme scientifique: les fonctions de l'invention verbale dans le livre IX de Martianus Capella », dans Biville F., Lhommé M.-K., VALLAT D. (éd.), Latin vulgaire - Latin tardif IX. Actes du IXe colloque international sur le latin vulgaire et tardif, Lyon, 2-6 septembre 2009, Lyon (Collection de la Maison de l'Orient et de la Méditerranée, 49), p. 573-584.

Guldentops G., 1997 - « Henry Bate's Encyclopaedism », dans Binkley P. (éd.), Pre-Modern Encyclopaedic Texts. Proceedings of the Second COMERS Congress, Groningen, 1-4 July 1996, Leiden/New York/Köln, p. 227-237.

Guldentops G., 2001a - « Henry Bate's Theory of sensible Species », Recherches de Théologie et Philosophie Médiévales, 68, p. 75-110.

GuLdENTOPS G., 2001b - « Albert's Influence on Bate's Metaphysics and Noetics », dans SenNer W. et al. (éd.), Albertus Magnus. Zum Gedenken nach 800 Jahren : Neue Zugänge, Aspekte und Perspektiven, Berlin (Quellen und Forschungen zur Geschichte des Dominikanerordens, Neue Folge, 10), p. 195-206.

Guldentops G., 2001c - « Averroes in Henry Bate's Metaphysics », Documenti e Studi sulla Tradizione Filosofica Medievale, 12, p. 523-547.

Guldentops G., 2001d - " Henry Bate's aristocratic Eudaemonism », dans AerTsen J. A., EMERY K. Jr., SPEER A. (éd.), Nach der Verurteilung von 1277. Philosophie an der Universität von Paris im letzten Viertel des 13. Jahrhunderts. Studien und Texte, Berlin/New York (Miscellanea Mediaevalia, 28), p. 657-681.

Guldentops G., 2002 - « Beyond Averroism and Thomism : Henry Bate on the Potential and the Agent Intellect », Archives d'Histoire Doctrinale et Littéraire du Moyen Âge, 69 , p. $115-152$

GuLdENTOPS G., 2005 - «'Famous Expositor...'. On Bate's (Anti-) Thomism », Recherches de Théologie et Philosophie Médiévales, 72, p. 191-231.

Gutzwiller K., 2007 - A Guide to Hellenistic Literature, Oxford.

Guyot-BAChy I., 1993 - « Les prologues du Memoriale temporum de Jean de Saint-Victor », Journal des savants, 2.2, p. 235-254.

Guyot-BaChy I., 2000 - Le Memoriale historiarum de Jean de Saint-Victor. Un historien et sa communauté au début du XIV siècle, Turnhout (Bibliotheca victorina, XII).

Guyot-BACHY I., 2009 - « La Bible dans le "Memoriale historiarum" de Jean de Saint-Victor: autorité, source et fondement de l'histoire », dans BERNDT R. (éd.), Bibel und Exegese in der Abtei Saint-Victor zu Paris. Form und Funktion eines Grundtextes im europaïschen Raum, Münster, Aschendorff (Corpus victorinum, Instrumenta, 3), p. 473-490.

HAAS M., 1999 - « Über die Funktion der ars musica im Mittelalter », dans SCHAEFER U. (éd.), Artes im Mittelalter, Formationen und transformationen des Wissens, Berlin, p. 13-33.

HADOт P., 1982 - "La préhistoire des genres littéraires philosophiques médiévaux dans l'Antiquité », dans Les Genres littéraires dans les sources théologiques et philosophiques médiévales : définition, critique et exploitation. Actes du colloque international de 
Louvain-La-Neuve, 25-27 mai 1981, Louvain-La-Neuve, (Publication de l'Institut d'études médiévales, $2^{\mathrm{e}}$ série, 5), p. 1-9.

Наdот I., 1984 - Arts libéraux et philosophie dans la pensée antique, Paris.

НАDOт P., 1998 - « La figure du sage dans l'Antiquité gréco-latine », dans НADOt P., Études de philosophie ancienne, Paris, p. 233-257.

HAdoт I., 2005 [1984] - Arts libéraux et philosophie dans la pensée antique, Paris (Textes et traditions, 11).

HAMEL J., 2006 - « Johannes de Sacroboscos Sphaera. Text- und frühe Druckgeschichte eines astronomischen Bestsellers », Gutenberg Jahrbuch, 81, p. 113-136.

Hamesse J., 1990 - « Les dossier Aristote dans l'œuvre de Vincent de Beauvais. À propos de l'Éthique ", dans Paulmier-Foucart M., Lusignan S. et Nadeau A. (éd.), Vincent de Beauvais. Intentions et réceptions d'une ouvre encyclopédique au Moyen Âge. Actes du XIV Colloque de l'Institut d'Études médiévales, 27-30 avril 1988, Saint Laurent/Paris (Cahiers d'études médiévales. Cahier spécial, 4), p. 197-217.

Hankinson R.J., 1995 - «Philosophy of science », The Cambridge Companion to Aristotle, p. 109-139.

HäRING N., 1955 - « The Creation and Creator of the World according to Thierry of Chartres and Clarenbaldus of Arras », AHDLMA, 30, p. 137-216.

HARRIS-MCCOY D. E., 2008 - Varieties of encyclopedism in the early Roman Empire : Vitruvius, Pliny the Elder, Artemidorus, dissertation, University of Pennsylvania.

de Hartmann C. C., 2007 - Lateinische Dialoge 1200-1400. Literarhistorische Studie und Repertorium, Leiden/Boston.

Hartog F., 2002 - Régimes d'historicité. Présentisme et expériences du temps, Paris.

Harvey St. (éd.), 2000 - The Medieval Hebrew Encyclopedias of Science and Philosophy. Proceedings of the Bar-Ilan University Conference, Dordrecht.

HASKINS C. H., 1927 - The Renaissance of the twelfth century, New York.

HaSSE D. N., 2000 - Avicenna's De anima in the Latin West. The Formation of the Peripatetic Theory of the Soul, 1160-1300, Londres/Turin (Warburg Institute Studies and Texts, 2000).

HASSE D. N., 2008 - « The early Albertus Magnus and his Arabic sources on the Theory of the soul », dans PERLER D. (éd.), Transformation of the Soul. Aristotelian psychology, 12501650, Vivarium, 46.3, p. 232-252.

HaVelock E., 1963 - Preface to Plato, Cambridge.

Hegel G. W. F., 1952 [1817] - Précis de l'encyclopédie des sciences philosophiques, Paris.

Hellmann O., 2010 - «Antike Verkürzungen biologischer Texte », dans Horster M., Reitz C. (dir.), Condensing texts - Condensed texts, Stuttgart, p. 555-583.

Hemmerdinger B., 1989 - «L'art d'éditer Athénée », Bollettino dei Classici, 10, p. 106-117.

HENne P., 2006 - Introduction à Hilaire de Poitiers, suivie d'une anthologie, Paris (Initiations aux Pères de l'Église).

Henningsen J., 1966 - «Enzyklopädie ». Zur Sprach- und Bedeutungsgeschichte eines pädagogischen Begriffs (Archiv für Begriffsgeschichte, 10), p. 271-362.

Henkel H., 1991 - « Der Promptus des Dietrich Engelhus und seine Stellung innerhalb der mittelalterlichen enzyklopädischen Tradition », dans Honemann V. (éd.), Dietrich Engelhus. Beiträge zu Leben und Werk. Actes du Congrès de Einbeck, 28 sept.-1 ${ }^{\text {er }}$ oct. 1989, Köln/Weimar/Wien, p. 179-202.

Hoenen M. J. F. M., de Libera A. (éd.), 1995 - Albertus Magnus und der Albertismus. Deutsche philosophische Kultur des Mittelalters, Leyde/New York/Cologne, 1995 (STGgM, 48). 
Holford-Strevens L., 2003 [1988] - Aulus Gellius. An Antonine scholar and his achievement, Oxford.

Holtz L. (éd.), 1981 - Donat et la tradition de l'enseignement grammatical : étude sur l' "Ars Donati” et sa diffusion (IVe-IXe siècle), Paris (Documents, études et répertoires - IRHT).

Holtz L., 1996 - « Glossaires et grammaire dans l'Antiquité », dans HAMESSE J. (éd.), Les Manuscrits des lexiques et glossaires de l'Antiquité tardive à la fin du Moyen Âge. Actes du Colloque international organisé par le "Ettore Majorana Centre for Scientific Culture", Erice, 23-30 septembre 1994, Louvain-la-Neuve, p. 1-21.

Holtz L., 2000 - « Priscien dans la pédagogie d'Alcuin », dans de Nonno M., DE Paolis P., Holtz L. (éd.), Manuscripts and tradition of grammatical texts from Antiquity to the Renaissance, Cassino, p. 289-326.

Holtz L., 2004 - «Le dialogue de Franco et de Saxo », dans Depreux P., Judic B. (éd.), Alcuin, de York à Tours: écriture, pouvoir et réseaux dans l'Europe du haut Moyen Âge, Annales de Bretagne et des Pays de l'Ouest, 111.3, p. 133-145.

Honnefelder L. et al. (éd.), 2005 - Albertus Magnus und die Anfänge der AristotelesRezeption im lateinischen Mittelalter : von Richardus Rufus bis zu Franciscus de Mayronis /Albertus Magnus and the beginnings of the medieval reception of Aristotle in the Latin West, Münster (Subsidia Albertina, 1).

Honnefelder L. et al. (éd.), 2009 - Via Alberti. Texte - Quellen - Interpretationen, Münster (Subsidia Albertina, 2).

Hossfeld P., 1980 - « Der Gebrauch der aristotelischen Übersetzungen in den Meteora des Albertus Magnus », Medieval Studies, 42, p. 395-406.

Hossfeld P., 2001 - « Das zweite Buch der Meteora des Albertus Magnus », dans AnZulewicz H., SenNer W. et al. (éd.), Albertus Magnus. Zum Gedenken nach 800 Jahren. Neue Zugänge, Aspekte und Perspektiven, Berlin (Quellen und Forschungen zur Geschichte des Dominikanerordens, 10), p. 413-426.

HüE D., 1990 - « Encyclopédisme et Moralisation », Cahier Diderot, 3, p. 17-56.

HüE D., 1993 - « Tracé, écart: le sens de la carte chez Opicinus de Canistris », Colloque d'Orléans, Terres Médiévales, avril 1990, Orléans (coll. Sapience), p. 129-158.

HüE D., 1995 - « Pour la lettre et pour le trait: Formes et formation de l'Europe », Colloque d'Orléans, De la Chrétienté à l'Europe, mai 1993, Orléans (coll. Sapience), p. 105-131.

HüE D., 1999 - « Espace et Paysage chez Pierre Bersuire et quelques Avignonnais », Cahiers de Recherches Médiévales, 6, p. 41-57.

Huglo M., 2001 - «Les arts libéraux dans le Liber glossarum », Scriptorium, 55, p. 3-33.

Hugonnard-Roche H., 1984 - « La classification des sciences de Gundissalinus et l'influence d'Avicenne », dans Jolivet J., RAshed R. (éd.), Études sur Avicenne, Paris (Sciences et philosophie arabes, Études et reprises), p. 41-75.

HüNEMÖRDER C., 1987 - « Die Vermittlung medizinisch-naturwissenschaftlichen Wissens in Enzyklopädien », dans WolF N. R. (éd.), Wissensorganisierende und Wissens-vermittlende Literatur im Mittelalters. Perspektiven ihrer Erforschung. Kolloquium (5.-7. Dez. 1985), Wiesbaden, p. 255-277.

HünEMÖRDER C., 1994 - « Des Zisterziensers Heinrich von Schüttenhofen Moralitates de naturis animalium. Beobachtungen $\mathrm{zu}$ seiner Quellenbenutzung und zur frühen Rezeptionsgeschiche von Bartholomäus Anglicus und Thomas III », dans Domes J., GerabeK W. E., HaAge B. D. et al. (éd.), Licht der Natur. Medizin in Fachliteratur und Dichtung. Festschrift für G. Keil zum 60. Geburtstag, Göppingen, p. 195-224.

HÜNEMÖRder C., 1997 - «John Folsham », Lexikon des Mittelalters, 5, München/Berlin, p. 576. 
Hunt R. W., 1950 - «Hugutio and Petrus Helias », Mediaeval and Renaissance Studies, 2, p. $174-178$.

Hunt R. W., 1958 - « The "Lost" Preface to the Liber derivationum of Osbern of Gloucester », Mediaeval and Renaissance Studies, 4, 1958, p. 267-282.

Hunt R. W., Gibson M., 1984 - The Schools and the Cloister. The Life and Writings of Alexander Nequam (1157-1217), Oxford.

Hunzinger C., 1995 - « La notion de thôma chez Hérodote », Ktèma, 20, p. 47-70.

Huot S., 1994 - « The Courtly Lover and Job in Machaut's Motets 2 and 3 », Medium Aevum, 63, p. 222-238.

Huygens R. B. C., 1953 - «Accessus ad auctores », Latomus, 12, p. 296-311 et 460-484.

Huygens R. B. C., 1991 - La tradition manuscrite de Guibert de Nogent, La Haye.

ImbaCh R., Flüeler C. (éd.), 1985 - Albert der Große und die deutsche Dominikanerschule. Philosophische Perspektiven (Freiburger Zeitschrift für Philosophie und Theologie, 32).

ImbaCh R., Lindblad U., 1985 - « 'Compilatio rudis ac puerilis'. Hinweise und Materialien zu Nikolaus von Strassburg O.P. und seiner Summa » dans IMBACH R., FLÜELER C. (éd.), Albert der Grosse und die deutsche Dominikanerschule. Philosophische Perspektiven (Freiburger Zeitschrift für Philosophie und Theologie, 32), p. 155-233.

ISAGER J., 1991 - Pliny on Art and Society. The Elder Pliny's Chapters on the History of Art, Londres.

Isnardi Parente M., 1966 - Techne. Momenti del pensiero greco da Platone ad Epicuro, Florence.

ЈАсов C., 1992 - Alexandrie, III siècle av. J.-C. : tous les savoirs du monde, ou Le rêve d'universalité des Ptolémée, Paris.

JАсов C., 1996 - «Athènes-Alexandrie », dans SchaER R. (éd.), Tous les savoirs du monde. Encyclopédies et bibliothèques, de Sumer au XXIe siècle, Paris, p. 44-53.

ЈАсов C., 2004a - «La citation comme performance dans les Deipnosophistes d'Athénée », dans DARBo-Peschanski C. (dir.), La citation dans l'antiquité, Grenoble, p. 147-174.

JACOB C., 2004b - «La construction de l'auteur dans le savoir bibliographique antique: à propos des Deinosophistes d'Athénée », dans Calame C., Chartier R. (dir.), Identités d'auteur dans l'antiquité et la tradition européenne, Grenoble, p. 127-158.

ЈАСОв C., 2004c - «Questions sur les questions: Archéologie d'une pratique intellectuelle et d'une forme discursive », dans Volgers A., Zamagni C. (éd.), Erotapokriseis. Early Christian Question-and-Answer Literature in Context, Leuven/Paris/Dudley, p. 25-54.

JACOBI D., 1986 - Diffusion et vulgarisation. Itinéraires du texte scientifique, Paris (Annales littéraires de l'Université de Besançon, Série Linguistique et sémiotique, 5).

JaCobi D., Schiele B. (dir.), 1988 - Vulgariser la science : le procès de l'ignorance, Seysel.

JaCquemard C. et al. (éd.), 2013 - «Hortus sanitatis » : Livre IV, «Les Poissons », Caen (Fontes et paginae).

JACQUes F., 1979 - Dialogiques. Recherches logiques sur le dialogue, Paris (Philosophie d'aujourd'hui, 12).

JäGER W., 1997 [1923] - Aristote : fondements pour une histoire de son évolution, Paris.

JAHN O., 1850 - « Über römische Encyclopädien », Berichte über die Verhandlungen der Kön. Sächsischen Gesellschaft der Wissensch. zu Leipzig, Phil.-hist. Kl., 2, p. 263-287.

JAIL C., 2001 - L'étrange et le merveilleux en terres d'Islam, Paris.

JAMES-RAOul D., 1997 - La Parole empêchée dans la littérature arthurienne, Paris (Nouvelle bibliothèque du Moyen Âge, 40). 
JANSEN-Sieben R. (éd.), 1989 - Artes mechanicae en Europe médiévale, Bruxelles (Archives et bibliothèques de Belgique, NS 34).

JEANNERET Y., 1994 - Écrire la science. Formes et enjeux de la vulgarisation, Paris.

JEAuneau E., 1973 - Lectio philosophorum. Recherches sur l'école de Chartres, Amsterdam.

Jeauneau E., 1995 - L'âge d'or des écoles de Chartres, Chartres.

Joly H., 1974 - Le renversement platonicien. 'Logos, Episteme, Polis', Paris.

JoLy R., 1960 - Recherches sur le traité pseudo-hippocratique 'Du régime', Paris.

JourJon D., 1992 - Trois entretiens sur les Pères de l'Église de France: Hilaire, Sidoine Apollinaire, Césaire, Lyon.

Kaderas C., 1998 - Die Leishu der imperialen Bibliothek des Kaisers Qianlong, Wiesbaden.

KaylOr N. H. Jr., 1999 - « Boethius' De Consolatione Philosophiae didaktisch aufbereitet: Die anonyme mittelenglische Übersetzung von Buch I (...) », dans SCHAEFER U. (éd.), Artes im Mittelalter, Fortschreibungen von Wissenbeständen, Berlin, p. 187-197.

Kedar B. Z., Kohlberg E., 1995 - « The Intercultural Career of Theodore of Antioch », Mediterranean Historical Review, 10, p. 165-176.

Kellermann K., 1999 - « Zwischen Gelehrsamkeit und Information: Wissen und Wahrheit im Umbruch vom Mittelalter zur Neuzeit », dans SchaEfer U. (éd.), Artes im Mittelalter, Formationen und transformationen des Wissens, Berlin, p. 124-140.

Kentron (revue), 2013 - Revue pluridisciplinaire du monde antique, 29 [dossier thématique L'Hortus sanitatis, rassemblé par C. JACQUEMARD et B. GAUvin].

Kerbrat-Orecchioni C., 1971 - «Introduction », dans Kerbrat-Orecchioni C. (dir.), La Question, Lyon (Linguistique et sémiologie), p. 5-37.

Kerbrat-Orecchioni C., 1978 - « Déambulation en territoire aléthique », Stratégies discursives. Actes du Colloque du Centre de Recherches linguistiques et sémiologiques de Lyon, 20-22 mai 1977, Lyon, p. 53-102.

Kerbrat-Orecchioni C., 1992 - Les Interactions verbales, t. II, Paris.

Kerbrat-Orecchioni C., 2005 - Les Actes de langage dans le discours. Théorie et fonctionnement, Paris.

KLEPPER D. C., 2007 - The insight of unbelievers : Nicholas of Lyra and Christian Reading of Jewish Texts in the Later Middle Ages, Philadelphia.

KuINCK R., 1970 - Die lateinische Etymologie des Mittelalters, Munich (Medium Aevum, 17).

KNoch W., 1999 - «Die theologische Summa: Zur Bedeutung einer hochmittelalterlichen Literaturgattung », dans SCHAEFER U. (éd.), Artes im Mittelalter, Fortschreibungen von Wissenbeständen, Berlin, p. 151-160.

KöHLER T. W., 2000 - Grundlagen des philosophisch-anthropologischen Diskurses im dreizehnten Jahrhundert. Die Erkenntnisbemühung um den Menschen im zeitgenössichen Verständnis, Leyde/Boston/Cologne (Studien und Texte zur Geistesgeschichte des Mittelalters [STGgM], 71).

KöHLER T. W., 2008 - Homo animal nobilissimum Konturen des spezifisch Menschlichen in der naturphilosophischen Aristoteleskommentierung des dreizehnten Jahrhunderts, Teilband I, Leyde / Boston/Cologne (STGgM, 94).

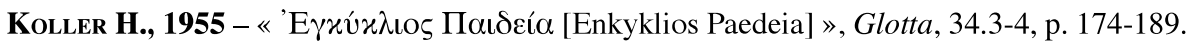

KowalsKa M., 1967 - « Remarks on the unindentified cosmography Tuhfat al-garā'ib », Folia Orientalia, 9, p. 11-18.

KREY P. D., SMith L. J. (éd.), 2007 - Nicholas of Lyra : the Senses of Scripture, Leyde / Boston / Cologne (Studies in the History of the Christian Thought, 40). 
Kurz J.-L., 2001 - « The Politics of Collecting Knowledge: Song Taizong's Compilations Project », T'oung Pao, 87.4-5, p. 289-316.

KURZ J.-L., 2007 - « The Compilation and Publication of the Taiping yulan and the Cefu yuangui », Extrême-Orient Extrême-Occident, hors-série, p. 39-76.

LABbÉ D., 1985 - « Nous, les communistes », Mots, 10, p. 133-146.

LaChenaud G., 1997 - «L'enkuklios paideia et l'esprit encyclopédique dans l'Antiquité », Revue de Philologie, 71, p. 65-101.

LACOSTE F., 1958 - «Un commentaire scripturaire du XII ${ }^{\mathrm{e}}$ siècle : le Tractatus in Hexaemeron de Hugues d'Amiens », AHDLMA, 25, p. 227-294.

Langlois C. V., 1911 - La connaissance de la nature et du monde au Moyen Âge, d'après quelques écrits français à l'usage des laïcs, Paris.

LANGlois C.-V., 1926-1928 - La connaissance de la nature et du monde au Moyen Âge, Paris 1926-1928 [réimp. Genève, 1970], t. III.

LARGier N., 2000 - « Time and Temporality in the German Dominican School. Outlines of a Philosophical Debate between Nicolaus of Strasbourg, Dietrich of Freiberg, Eckhart of Hoheim and Iohannes Tauler », dans Porro P. (éd.), The Medieval Concept of Time. The Scholastic Debate and Its Reception in Early Modern Philosophy, Leyde / Boston/Cologne (Studien und Texte zur Geistesgeschichte des Mittelalters, 75), p. 221-254.

LARreya P., 1979 - Énoncés performatifs. Présupposition, Paris.

LAw V., 1982 - The insular Latin grammarians, Woodbridge.

Lawn B., 1963 - The Salernitan Questions. An introduction to the History of Medieval and Renaissance Problem Literature, Oxford.

Lawn B., 1993 - The Rise and Decline of the Scholastic 'Quaestio Disputata' with Special Emphasis on its Use in the Teaching of Medicine and Science, Leyde/New York/Cologne (Education and Society in the Middle Ages and Renaissance, 2).

LE BLOND J.-M., 1939 - Logique et méthode chez Aristote, Paris.

LE GoFf J., 1957 - Les intellectuels au Moyen Âge, Paris.

LE Goff J., 1964 - La Civilisation de l'Occident médiéval, Michigan (Les Grandes civilisations, 3).

LE GofF J., 1994 - «Pourquoi le XIII ${ }^{\mathrm{e}}$ siècle a-t-il été un siècle d'encyclopédisme? », dans Picone M. (éd.), L'enciclopedismo medievale, Ravenne, p. 23-40.

LE GoFf J., 1995 - Saint Louis, Paris.

LEAR J., 1990 - Aristotle. The Desire to understand, Cambridge.

Lebel M., 1991 - Le concept de l'Encyclopedia. Acta Conventus Neo-latini Torontonensis, Bighampton.

LEFÈVRE Y., 1954 - L'Elucidarium et les lucidaires. Contribution, par l'histoire d'un texte, à l'histoire des croyances religieuses en France au Moyen Âge, Paris.

LEJBowicz M., 1988 - « Le choc des traductions arabo-latines du XII ${ }^{\mathrm{e}}$ siècle et ses conséquences dans la spécialisation sémantique d'astrologia et d'astronomia: Dominicus Gundissalinus et la scientia iudicandi », dans LOUIS P., ROGER J. (dir.), Transfert de vocabulaire dans les sciences, Paris, p. 213-276.

LeJbowicz M., 1991 - «Les antécédents de la distinction isidorienne astrologia/astronomia », dans Ribémont B. (dir.), Observer, lire, écrire le ciel au Moyen Âge, Paris, p. 173-212.

LEMERLE P., 1971 - Le premier humanisme byzantin. Notes et remarques sur enseignement et culture à Byzance des origines au $\mathrm{X}^{\mathrm{e}}$ siècle, Paris.

Lemoine M., 1998 - Théologie et platonisme au XII siècle, Paris.

Lemoine M., 2004 - Théologie et cosmologie au XII siècle, Paris. 
Lenoble R., 1969 - Histoire de l'idée de nature, Paris.

Letronne A., 1833 - Observations philologiques et archéologiques sur les noms des vases grecs, Paris.

Letrouit J., 1991 - « À propos de la tradition manuscrite d'Athénée », Maia, 43, p. 33-40.

LEVy C., 1996 - Le concept de nature à Rome. La physique, Paris.

Lewicki T., 1978 - «Al-Kazwīnī », Encyclopédie de l'Islam, Leiden, 2éd., vol. 4, p. 898-900.

DE Libera A., 1999 - Maître Eckhart et la mystique rhénane, Paris (Initiations au Moyen Âge).

LIDAKA, 1997 - «Bartholomaeus Anglicus in the Thirteenth Century », dans BINKLEY P. (éd.), Pre-Modern Encyclopedic Texts. Proceedings of the second COMERS Congress, Groningen, 1-4 July 1996, Leiden/New York/Köln, p. 393-406.

Lindgren U., 1992 - Die Artes liberales in Antike und Mittelalter. Bildungs- und Wissenschaftsgeschichtliche Entwicklungslinien, München (Algorismus, 8).

LiNKE H., 1880 - Quaestiones de Macrobii Saturnaliorum fontibus, diss. Breslau.

Liтt T., 1963 - Les corps célestes dans l'univers de saint Thomas d'Aquin, Paris/Louvain.

Lochrie K. D., Mccracken P., Schultz J. A. (éd.), 1998 - Constructing Medieval Sexuality, Minneapolis (Medieval Culture, 11).

LOEwE R., 1958 - «Alexander Neckam's Knowledge of Hebrew », Medieval and Renaissance Studies, 4, p. 17-34.

Long A. A., Sedley D. N., 2001 - Les philosophes hellénistiques, II, Paris.

Long J., 2007 - « livre III et livre IV », dans VAN DEN ABEele et al. (éd), Bartholomaeus Anglicus. De proprietatibus rerum. Volume I : Prohemium, Livre I-IV, Turnhout (De diversis artibus 78, NS 41), p. 135-199.

Lours P., 1955 - « Le mot ioto@í $\alpha$ chez Aristote », Revue de philologie, 81, p. 39-44.

LOUyest B., 2009 - Athénée de Naucratis. Mots de poissons. Le banquet des sophistes. Livres VI et VII, Villeneuve d'Ascq.

Love I., 1968 - « Kantharos or Karchesion », dans SANDLER L. (éd.), Essays in Memory of Lehmann K., Marsyas, suppl. 1, p. 204-222.

LuFF R., 1999 - Wissensvermittlung im europaischen Mittelalter: 'Imago-mundi'-Werke und ihre Prologe, Tübingen.

Lukinovich A., 1985 - « La poikilia chez Athénée », REL, 63, p. 14-16.

Lukinovich A., 1990 - « The Play of Reflection between Literary Form and the Sympotic Theme in the Deipnosophists of Athenaeus », dans Murray O. (dir.), Sympotica. A Symposion on the Symposion, Oxford, p. 263-271.

Lusignan S., 1979 - Préface au Speculum maius de Vincent de Beauvais : réfraction et diffraction, Montréal/Paris.

Lynch C. H., 1938 - Saint Braulio, bishop of Saragossa (631-651): his life and writings, Washington.

LyOTARD J.-F., 1979 - La condition postmoderne. Rapport sur le savoir, Paris.

Maffia Scariati I. (éd.), 2008 - A scuola con Ser Brunetto. Indagini sulla ricezione di Brunetto Latini dal Medioevo al Rinascimento. Atti del Convegno Internazionale di Studi, Università di Basilea, 8-10 Giugno 2006, Firenze (Archivio Romanzo, 14).

Magallón García A.-I., 1996 - La tradición gramatical de differentia y etymologia hasta Isidoro de Sevilla, Saragosse.

Mấle E., 1958 - L'Art religieux du XII siècle en France, tome 1, Paris.

MaLtby R., 1991 - A Lexicon of Ancient Latin Etymologies, Leeds. 
Manco A., Silvestri D. (éd.), 2011 - L'etimologia. Atti del XXXV Convegno della Società Italiana di Glottologia, Napoli, 21-23 ottobre 2010, Roma.

Mandosio J.-M., 2005 - « Encyclopédies en latin et encyclopédies en langue vulgaire (XIII ${ }^{\mathrm{e}}$ $\mathrm{XVIII}^{\mathrm{e}}$ siècle) », dans Bury E. (éd.), Tous vos gens à latin: le latin, langue savante, langue mondaine (XIV'-XVII s.), Genève, p. 113-136.

Manetri G., 1988 - « Perception, Encyclopedia, and Language Among the Stoics in Signs of Antiquity/Antiquity of Signs », Versus : Quaderni di Studi Semiotici, 50-51, p. 123-144.

MAR Jonsson E., 1990 - «Le sens du titre Speculum aux XII et XIII ${ }^{\mathrm{e}}$ siècles et son utilisation par Vincent de Beauvais ", dans Vincent de Beauvais: Intentions et réceptions d'une oeuvre encyclopédique au Moyen Âge. Actes du XIV colloque de l'Institut d'Études Médiévales, 27-30 avril 1988, Saint-Laurent/Paris, p. 11-32.

Marcovich M., 1971 - « Voces animantium and Suetonius », Ziva Antika, 21, p. 399-416.

Marguin-Hamon E., 2003 - L'Ars lectoria Ecclesie de Jean de Garlande. Une grammaire versifiée du XIII siècle et ses gloses, Turnhout.

Marinoni A. (éd.), 1955 - Dal Declarus di A. Senisio : I vocaboli siciliani, Palerme.

Marinoni A., 1988 - «Per una edizione delle Derivationes di Uguccione da Pisa », dans Cornagliotti A., Fontanella L., Piccat M., Rossebastiano A., Vitale-Brovarone A. (éd.), Miscellanea di studi romanzi offerta a G. Gasca Queirazza per il suo $65^{\circ}$ compleanno, Alessandria, p. 637-644.

MARQuet Y., 1990 - «Ikhwān al-ṣafā’ », Encyclopédie de l'Islam, 2e éd., Leiden, 3, p. 1098-1103.

Marrou H. I., 1958 - Saint Augustin et la fin de la culture antique, Paris.

Martin J., 1931 - Symposion. Die Geschichte einer literarischen Form, Studien zur Geschichte und Kultur des Altertums, 17, Padeborn.

Massé H., 1944 - Le livre des merveilles du monde, Paris.

McGeachy J. A. Jr., 1938 - « The Glossarium Salomonis and Its Relationship to the Liber Glossarum », Speculum, 13, p. 309-318.

Mehren A.F., 1874-Manuel de la cosmographie du Moyen Âge, traduit de l'arabe, Copenhague.

MEIER C., 1979-Gemma spiritalis. Methode und Gebrauch der Edelsteinallegorese vom frühen Christentum bis ins 18. Jahrhundert, Munich (Münstersche Mittelalter-Schriften, 34).

Meier-Staubach C., 1984 - « Grundzüge der mittelalterlichen Enzyklopädik. Zu Inhalten, Formen und Funktionen einer problematischen Gattung », dans Grenzmann L., STARKMAN K. (éd.), Literatur und Laienbildung im Spätmittelalter und in der Reformationszeit. Symposium Wolfenbüttel, 1981, Stuttgart (Germanistische Symposien. Berichtsbände, 5), p. 467-500.

Meier C., 1988 - « Cosmos politicus. Der Funktionswandel der Enzyklopädie bei Brunetto Latini », Frühmittelalterliche Studien, 22, p. 315-356.

MeIER C., 1992 - «Vom homo caelestis zum homo faber. Reorganisation der mittelalterlichen Enzyklopädie für neue Gebrauchsfunktionen bei Vinzenz von Beauvais und Brunetto Latini », dans Keller H., Grubmüller K., Staubach N. (éd.), Pragmatische Schriftlichkeit im Mittelalter. Erscheinungsformen und Entwicklungsstufen, München (Münstersche Mittelalterschriften, 65), p. 157-175.

MeIER C., 1995 - « Der Wandel der Enzyklopädie des Mittelalters von Weltbuch zum Thesaurus sozial gebundenen Kulturwissens : am Beispiel der Artes mechanicae», dans EyBL F. et al. (éd.), Enzyklopädien der frühen Neuzeit. Beiträge zu ihrer Erforschung, Tübingen, p. 19-42.

Meier C., 1997 - « Organisation of Knowledge and Encyclopedic ordo : Functions and Purposes of a Universal Literary Genre », dans BinKLEY P. (éd.), Pre-Modern Encyclopaedic Texts. Proceedings of the Second COMERS Congress, Groningen, 1-4 July 1996, Leiden/New York/Köln, p. 103-216. 
MeIER C., 2002 - «Enzyklopädischer Ordo und sozialer Gebrauchsraum. Modelle der Funktionalität einer universalen Literaturform », dans MeIER C. (éd.), Die Enzyklopädie im Wandel vom Hochmittelalter bis zur Frühen Neuzeit, München, p. 511-532.

Meier C., Schuler S., Heckenkamp M. (éd.), 2002 - Die Enzyklopädie im Wandel vom Hochmittelalter bis zur frühen Neuzeit. Akten des Kolloquiums des Projekts D im Sonderforschungsbereich 231, 29.11.-01.12.1996, München.

MeIneCKe B., 1991 - «Glossae iussu Salomonis... sub breuitate collectae», Sprachwissenschaft, 16, p. 459-469.

Meinecke B., 1994 - Liber Glossarum und Summarium Heinrici. Zu einem Münchener Neufund, Götttingen.

Melczer W., 1988 - «Les encyclopédies », L'époque de la Renaissance 1400-1600. L'avènement de l'esprit nouveau, vol. I, Budapest, p. 337-347.

Melzer A., 2007 - « On the pedagogical motive for esoteric writing », Journal of Politics, 69, p. $1015-1031$.

Meschonnic H., 1997 - « L'encyclopédie sortant de son mot pour se voir », dans SCHAER R., Tous les savoirs du monde. Encyclopédies et bibliothèques, de Sumer au XXIe siècle, Paris, p. 19-25.

Mette H. J., 1960 - «Enkyklios paideia », Gymnasium, 67, p. 300-307.

Meyer C., 1998 - « Métaphore instrumentale et représentation du système acoustique à l'époque carolingienne ", dans Hentschel F. (éd.), Musik und die Geschichte der Philosophie und Naturwissenschaften im Mittelalter: Fragen zur Wechselwirkung von Musica und Philosophia im Mittelalter, Leyde/Boston/Cologne (Studien und Texte zur Geistesgeschichte des Mittelalters, 62), p. 141-149.

Meyer H., 1990 - «Zum Verhältnis von Enzyklopädik und Allegorese im Mittelalter », Frühmittelalterlische Studien, 24, p. 290-313.

Meyer H., 1991 - «Ordo rerum und Registerhilfen in mittelalterlichen Enzyklopediehandschriften », Fruhmittelalterlichen Studien, 25, p. 315-339.

Meyer H., 2000 - Die Enzyklopädie des Bartholomäus Anglicus. Untersuchungen zur Überlieferungs- und Rezeptionsgeschichte von 'De proprietatibus rerum', Münster (Münstersche Mittelalter-Schriften, 77).

Meyer H., 2001 - « Die Problematik und Leistungen der Allegoriedefinitionen Beda Venerabilis », Frühmittelalterliche Studien, 35, p. 183-200.

Meyer H., 2002 - « Die Predigerenzyklopädie. Textsorte und Gebrauch unter methodischen Aspekten », dans Keller H., Meier C., Suntrup R. (éd.), Pragmatische Dimensionen mittelalterlicher Schriftkultur. Akten des Internationalen Kolloquiums 26.-29. Mai 1999, München (Münstersche Mittelalterschriften, 79), p. 177-190.

Michaud-Quantin P., 1966 - «Les petites encyclopédies du XIII ${ }^{\mathrm{e}}$ siècle », Cahiers d'Histoire mondiale, 3, p. 580-595.

Michel P. (éd.), 2006-Allyouneed to know : Encyclopaedias and the Idea ofGeneral Knowledge, dans Michel P. (éd.), Conference, Prangins, Switzerland, 18-20 Sept. 2003, www.enzyklopaedie.ch.

Michel P., Herren M., 2007 - « Unvorgreifliche Gedanken zu einer Theorie des Enzyklopädischen », dans Michel P., Herren M., RüESCH (éd.), Allgemeinwissen und Gesellschaft, p. 9-74.

Minervini V., 1977 - « Schede sulla tradizione manoscritta del "Livre de Sidrach" », dans Annali dell' Istituto universitario orientale-sezione romana, XIX, 2, Naples, p. 539-570.

Moatti C., 1997 - La raison de Rome. Naissance de l'esprit critique à la fin de la République, Paris. 
MoEsChler J., 1985 - Argumentation et Conversation. Éléments pour une analyse pragmatique du discours, Paris (Langues et apprentissage des langues, 11).

MoJsisch B., 1991 - « Hugo Ripelin von Straßbourg OP, Theologe und Philosoph », Lexikon des Mittelalters, 5, Munich, col. 176.

Monjou P., 2008 - La Vulgarisation théologique du xIIIe au XVIe siècle d'après le "Compendium theologicae veritatis" de Hugues Ripelin de Strasbourg, 2 vol., [Thèse non éditée] sous la direction de CAROZZI C., Aix-Marseille.

Morel P. M., 1997 - Aristote et la notion de nature, Bordeaux.

Moreton J., 1994 - « John of Sacrobosco and the Calendar », Viator, 25, p. 225-244.

Mortier G., 1991 - «Préface », dans BecQ A. (éd.), L'Encyclopédisme. Actes du colloque de Caen, 12-16 janvier 1987, Paris, p. 13-15.

Morton A. G., 1986 - « Pliny on Plants : his Place in the History of Botany », dans FrENCH R., Greenaway F. (éd.), Science in the Early Roman Empire. Pliny the Elder, his Sources and Influence, Londres / Sydney.

Moulis M., 1993 - «Éducation, apprentissages, initiation au Moyen Âge », Les Cahiers $d u$ CRISIMA, 1, p. 333-346.

Mudry P., 1986 - « Science et conscience. Réflexions sur le discours scientifique à Rome », Sciences et techniques à Rome, Etudes de Lettres, p. 74-86.

MurPhy T., 2004-Pliny the Elder's « Natural History ». The empire in the Encyclopedia, Oxford.

Murray O. (dir.), 1990 - Sympotica. A Symposion on the Symposion, Oxford.

NaAs V., 2000 - « L'Histoire naturelle, œuvre scientifique? », dans Callebat L., Desbordes O. (éd.), Science antique, science médiévale, Hildesheim/Zürich/New York, p. 255-271.

NaAs V., 2002 - Le projet encyclopédique de Pline l'Ancien, Roma (Collection de l'École Française de Rome 303).

NAAS V., 2004 - «Ratio ... multis inuoluta miraculis (Pline l'Ancien, NH, II, 62): autour de la ratio plinienne », dans NAAS V. (éd.), En-deçà et au-delà de la 'ratio', Lille, p. 29-37.

NAAS V., 2008 - « Pline l'Ancien a-t-il cru à ses mythes? » Pallas, 78, p. 133-151.

NAAs V., 2011a - « L'Histoire naturelle de Pline l'Ancien, texte fondateur de l'encyclopédisme? » dans Groult M. (éd.), Les encyclopédies. Construction et circulation du savoir de l'Antiquité à Wikipédia, Paris, p. 25-45.

NAAS V., 2011b - «Imperialism, Mirabilia and Knowledge. Some Paradoxes in the Naturalis Historia », dans Gibson R. K., Morello R. (éd.), Pliny the Elder. Visions and Context, Leyde, p. 57-70.

NaAs V., 2011c - «Philhellénisme et identité romaine chez Pline l'Ancien (nat. VII, 81-130)», dans Bonadeo A., Canobbio A., Gasti F. (éd.), Filellenismo e identità romana in età flavia, Pavie, p. 35-58.

NADDAF G., 1992 - L'origine et l'évolution du concept grec de 'phusis', Lewiston.

Nicolet C., 1996 - L'inventaire du monde. Géographie et politique aux origines de l'empire romain, Paris ( $1^{\text {re }}$ éd. 1988).

NiEDEREHE H.-J., 1976 - « Friedrich Diez und die Etymologie des 13. Jahrhunderts », dans Niederehe H. J., HaARmann H. (éd.), In Memoriam Friedrich Diez. Akten des Kolloquiums zur Wissenschaftsgeschichte der Romanistik, Trier, 2.-4.Oktober 1975, Amsterdam, p. 21-31.

Nifadopoulos C. (éd.), 2003 - Etymologia. Studies in Ancient Etymology. Proceedings of the Cambridge Conference on Ancient Etymology, 25-27 September 2000, Münster.

Nølke H., 2005 - « Le locuteur comme constructeur de sens », dans Bres J., Haillet P. P., Mellet S., Nølke H., Rosier L. (dir.), Dialogisme et polyphonie. Approches linguistiques, Bruxelles, p. 111-124. 
Obrist B., Caiazzo I. (éd.), 2011 - Guillaume de Conches. Philosophie et science au XII siècle, Firenze (Micrologus' Library, 42).

O'NeIL M., 2009- « Wikipédia ou la fin de l'expertise », Le Monde Diplomatique, avril 2009, p. 20.

OLdoni M., 1994 - « Giovanni da San Gimignano », dans Picone M. (éd.), L'enciclopedismo medievale. Atti del convegno «l'enciclopedimo medievale », San Gimignano 8-10 ottobre 1992, Ravenna (Memoria del tempo, 1), p. 213-228.

Olson S., Sens A., 2000 - Archestratos of Gela, Greek Culture \& Cuisine in the Fourth Century, Oxford.

Ouy G., 1999 - Les manuscrits de l'abbaye de Saint-Victor. Catalogue établi sur la base du répertoire de Claude de Grandrue (1514), 2 vol., Turnhout (Bibliotheca victorina, X).

Palmer N., 1989 - " Kapitel und Buch. Zu den Gliederungsprinzipien mittelalterlicher Bücher », Frühmittelalterliche Studien, 23, p. 43-88

Palmieri N. (éd.), 2003 - Rationnel et irrationnel dans la médecine ancienne et médiévale, Saint-Étienne.

Panckoucke C.-J., 1783 - Encyclopédie méthodique ou par ordre des matières ou Bibliothèque complete de toutes les conoissances humaines, Liège.

Papadoyannakis Y., 2006 - « Instruction by Question and Answer: The Case of Late Antique and Byzantine Erotapokriseis », dans JoHnson S. F. (éd.), Greek Literature in Late Antiquity, Aldershot, p. 91-106.

PARet R., 1966 - « Contribution à l'étude des milieux culturels dans le Proche-Orient médiéval : "l'encyclopédisme" arabo-musulman de 850 à 950 de l'ère chrétienne », Revue historique, 477, p. 47-100 .

Parroni P., 1989 - « Scienza e produzione letteraria », dans Cavallo G., Fedeli P., Giardina A. (dir.), Lo Spazio letterario di Roma antica, I, Rome, p. 469-505.

Parrot G. F., 1821 - Entretiens sur la physique, t. IV, Dorpat.

Paulmier-Foucart M., 1994 - «Une des tâches de l'encyclopédiste: intituler, les titres des chapitres du Speculum naturale de Vincent de Beauvais », dans Picone M. (éd.), L'enciclopedismo medievale, Ravenne, p. 147-162.

Paulmier-Foucart M., 2001 - « L'actor et les auctores. Vincent de Beauvais et l'écriture dans le Speculum majus », dans Zimmermann M. (éd.), Auctor et auctoritas. Invention et conformisme dans l'écriture médiévale. Actes du colloque tenu à l'Université de VersaillesSaint-Quentin-en-Yvelines (14-16 juin 1999), Paris (Mémoires et documents de l'École des Chartes, 59), p. 145-160.

Paulmier-Foucart M., Duchenne M.-C., 2004 - Vincent de Beauvais et le Grand Miroir du monde, Paris (Témoins de notre Histoire).

Paulmier-Foucart M., Lusignan S., Nadeau A. (éd.), 1990 - Vincent de Beauvais : Intentions et réceptions d'une oeuvre encyclopédique au Moyen Âge. Actes du XIV colloque de l'Institut d'Études Médiévales, 27-30 avril 1988, Saint-Laurent/Paris, 1990.

Pedersen O., 1985 - « In quest of Sacrobosco », Journal of the History of Astronomy, 16, 47, p. $175-221$.

Pellat C., 1990 - «Mawsū‘a. Encyclopédie », Encyclopédie de l'Islam, 2éd., Leiden, 6, p. 894-898.

Pellicer A., 1966 - 'Natura'. Etude sémantique et historique du mot latin, Paris.

Percival W. K., 1998 - « Saussure on Etymology », dans Liver R., Werlen I., Wunderli P. (éd.), Sprachtheorie und Theorie der Sprachwissenschaft. Geschichte und Perspektiven. Festschrift für R. Engler zum 60. Geburstag, Tübingen. 
Perelman C., 1955 - « La méthode dialectique et le rôle de l'interlocuteur dans le dialogue », Revue de Métaphysique et de Morale, 60, p. 26-31.

Perelman C., Olbrechts-Tyteca L., 1970 - Traité de l'Argumentation. La nouvelle rhétorique, Bruxelles (Collection de sociologie générale et de philosophie sociale).

Pérez Rodríguez E., 1998 - « La Summa artis gramatice de Hugutio y la gramática del s. XII », dans Leonardi C. (éd.), Gli Umanesimi medievali. Atti del II Congresso dell'"Internationales Mittellateinerkomitee »Firenze, Certosa del Galluzzo, 11-15 settembre 1993, Florence, p. 479-484.

Perifano A., 2011 - « Pline à la Renaissance. Transmission, réception et relecture d'un encyclopédiste antique », dans Perifano A. (éd.), Archives Internationales d'Histoire des Sciences, 61, 166-167.

Peris A., 1998 - « La lista de Voces animantium del Matritensis B.N. 19: estudio de sus fuentes y nueva edición », Cuadernos de Filología Clásica. Estudios Latinos, 15, p. 405-427.

Peruzzi E., 1976 - « Lat. lupa », dans Pisani V., SANToro C. (éd.), Italia linguistica nuova ed antica. Studi linguistici in memoria di Parlangèli O., vol. 1, Galatina, p. 173-177.

Peters F. E., 1968 - Aristotle and the Arabs, New York.

Petit A., 1997 - « 'L'art imite la nature': les fins de l'art et les fins de la nature », dans Morel P. M. (éd.), Aristote et la notion de nature, Bordeaux, p. 35-43.

Piccione R.-M., 2002 - « Encyclopédisme et enkyklios paideia. À propos de Jean Stobée et de son Anthologion », Philosophie antique, 2, p. 169-197.

Picone M. (éd.), 1994 - L'enciclopedismo medievale. Atti del convegno «l'enciclopedimo medievale », San Gimignano 8-10 ottobre 1992, Ravenna (Memoria del tempo, 1).

Pigeaud J., 1988 - « La greffe du monstre », REL, 66, p. 197-218.

Pinès S., 1985 - «Une encyclopédie arabe du $x^{\mathrm{e}}$ siècle. Les Épîtres des Frères de la Pureté Rasā'il Ikhwān al-Șafā' ", Rivista critica de storia della filosofia Firenze, 40.1, p. 131-136.

Pizzani U., 1990 - « L'enciclopedismo tardoantico e le discipline del quadrivio: prospettive metodologiche », dans GARZYA A. (éd.), Metodologie della ricerca sulla tarda antichità : atti del primo Convegno dell'Associazione di studi tardoantichi, Atti dei Convegni: Associazione di studi tardoantichi, 1, Napoli, p. 49-69.

Pons A., 1986 - Introduction aux extraits de l'Encyclopédie de Diderot, 1, Paris.

del Punta F., Donati S., Trifogli C., 2000 - «Commentaries on Aristotle's Physics in Britain, 1250-1270 », dans MAREnBon J. (éd.), Aristotle in Britain during the Middle Ages and the Renaissance. Proceedings of the International Conference at Cambridge, 8-11 April 1991, Turnhout (Rencontres de Philosophie Médiévale, 5), p. 265-283.

QuaIN E. A., 1945 - « The Medieval Accessus ad Auctores », Traditio, 3, p. 215-264.

RADTKE B., 1987 - « Die älteste islamische Kosmographie Muhammad-i Ṭūs̄̄s 'Ağā'ib ul-mahlūqāt », Der Islam, 64, p. 279-288.

RAdTKE B., 1998 - « Persian Cosmography, Early Tafsir and Nestorian Exegesis », dans VeSEL Z. (éd), La science dans le monde iranien, Téhéran, p. 323-335.

ReiJnders H. F., 1971 - «Aimericus Ars lectoria », Vivarium, 9, p. 119-137.

ReiJnders H. F., 1972 - « Aimericus Ars lectoria », Vivarium, 10, p. 41-101 et 124-176.

ReININK G. J., 1997 - « Communal Identity and the Systematisation of Knowledge in the Syriac "Cause of all causes" », dans BINKLEY P. (éd.), Pre-modern Encyclopaedic Texts. Proceedings of the Second Comers Congress, Groningen, 1-4 July 1996, Leiden/New York/Köln, p. 275-288. 
DE RENTIIS D., 1999 - « Für eine neue Geschichte der Nachahmungskategorie : Imitatio morum und lectio auctorum in Policraticus VII, $10 »$ dans Schaerer U. (éd.), Artes im Mittelalter, «Fortschreibungen von Wissenbeständen », Berlin, p. 161-173.

REY A., 1982 - Encyclopédies et dictionnaires, Paris.

REY A., 2006 - Antoine Furetière : un précurseur des Lumières sous Louis XIV, Paris.

REY A., 2007 - Miroirs du monde: une histoire de l'encyclopédisme, Paris.

Reynolds P. L., 1999 - Food and the Body. Some Peculiar Questions in High Medieval Theology, Leyde/Boston/Cologne (STGgM, 69).

Reynolds S., 1996-Medieval Reading : Grammar, Rhetoric and the Classical Text, Cambridge.

RibÉmont B., 1991 - «Statut de l'astronomie et évolution des connaissances sur le cosmos au Moyen Âge », Observer, lire, écrire le ciel au Moyen Âge, Paris, p. 283-300.

Ribémont B., 1995a - De natura rerum : études sur les encyclopédies médiévales, Orléans.

Ribémont B., 1995b - « Les encyclopédies médiévales. Une première approche du genre », dans Guichard P. et AleXandre-Bidon D. (dir.), Comprendre le XIII siècle. Études offertes à M.-T. Lorcin, Lyon, p. 237-252.

RibÉmont B., 1997 - « On the definition of an encyclopaedic genre in the Middle Ages », dans Binkley P. (éd.), Pre-Modern Encyclopaedic Texts. Proceedings of the Second COMERS Congress, Groningen, 1-4 July 1996, Leiden/New York/Köln, p. 47-61.

RibÉmont B., 1999a - « Repères bibliographiques sur les encyclopédies médiévales de l'Occident latin (XII -XIV ${ }^{e}$ s.) », Cahiers de Recherches Médiévales (XIII $-{ }^{e} V^{e}$ s.), 6, p. 99-109.

RibÉmont B. (dir.), 1999b - Vulgariser la science : les encyclopédies médiévales, Paris.

RiBÉmont B., 1999c - Bartholomaeus. Le livre des propriétés des choses : une encyclopédie au $X I v^{e}$ siècle, Paris.

RibÉmont B., 2001 - Les origines des encyclopédies médiévales d'Isidore de Séville aux Carolingiens, Paris.

RIBÉMONT, 2002a - La « renaissance » du XII siècle et l'encyclopédisme, Paris.

RibÉMONT, 2002b - Qui des sept arz set rien entendre... Études sur le Roman de Thèbes, Orléans.

Rich A., 1867 [1859] - Dictionnaire des antiquités Romaines et Grecques, Paris.

Richelet P., 1694 - Dictionnaire françois, contenant generalement tous les mots et plusieurs remarques sur la langue françoise; les expressions Propres, figurées et burlesques, la Pronontiation des Mots les plus difficiles, le Genre des Noms, la Conjugaison des Verbes, leur régime, celui des adjectifs \& des Prépositions. Avec les Termes les plus connus des Arts \& des Sciences. Le tout tiré de l'usage et des bons auteurs par P. Richelet, Cologne.

RIESSNER C., 1965 - Die «Magnae derivationes » des Uguccione da Pisa und ihre Bedeutung für die romanische Philologie, Roma (Temi e testi, 11).

RIEU C., 1894 - Supplement to the catalogue of the Arabic manuscripts in the British Museum, London.

Riffaterre M., 1980 - «La trace de l'intertexte », La Pensée, 215, p. 4-18.

RIHA O., 1993 - « Ein Buch machen aus allen Büchern. Die Konzeption von Ortolfs "Arzneibuch" », dans KeIL G. (éd.), "Ein teutsch puech machen". Untersuchungen zur landessprachlichen Vermittlung medizinischen Wissens. Ortolf-Studien I, Wiesbaden, p. 15-38.

DE RIJK L. M., 1965 - « 'Egkuklios paideia'. A Study of its Original Meaning », Vivarium, 3, p. 24-93.

Robins F. E., 1912 - The Hexaemeral Litterature. A study of Greek and Latin Commentaries on Genesis, Chicago.

Robrieux J.-J., 1998 - Les Figures de style et de rhétorique, Paris (Les Topos). 
Rohault J., 1671a - Entretiens sur la philosophie, Paris.

Rohault J., 1671b - Traité de physique, Paris.

Romano E., 1994 - « Verso l'enciclopedia di Plinio. Il dibattito scientifico fra I. a.C. e I. d.C. », dans SABBAH G., Mudry P. (éd.), La médecine de Celse. Aspects historiques, scientifiques et littéraires, Saint-Étienne, p. 11-27.

RoMeri L., 2002 - Philosophes entre mots et mets. Plutarque, Lucien et Athénée autour de la table de Platon, Grenoble.

Ronquist E. C., 1997 - « Patient and impatient encyclopedism », dans BinkLey P. (éd.), PreModern Encyclopaedic Texts. Proceedings of the Second COMERS Congress, Groningen, 1-4 July 1996, Leiden/New York/Köln, p. 31-46.

Rosen E., 1949 - « A Review of Lynn Thorndike, The Sphere of Sacrobosco and its Commentators », Isis, 121, p. 257-264.

Rosen V., 1881 - Notices sommaires des manuscrits arabes du Musée asiatique, Saint-Pétersbourg.

Rosier-CataCh I., 1997 - « Roger Bacon and Grammar », dans Hackett J. (éd.), Roger Bacon and the Sciences. Commemorative Essays, Leiden, p. 67-102.

Rosier-Catach I., 1998a - « La Grammatica practica du ms. British Museum V A IV. Roger Bacon, les lexicographes et l'étymologie », dans BurIDANT C. (éd.), Lexique, 14 (L'étymologie, de l'Antiquité à la Renaissance), p. 97-125.

Rosier-Catach I., 1998b - «Quelques textes sur l'étymologie au Moyen Âge », dans Buridant C. (éd.), Lexique, 14 (L'étymologie, de l'Antiquité à la Renaissance), p. 221-229.

Rosier-Catach I., 2009 - « Glosule in Priscianum », dans Stammerjohann H. (éd.), Lexicon Grammaticorum. A Bio-bibliographical Companion to the History of Linguistics, Tübingen, p. 547-547.

Roulet E., 1982 - «De la structure dialogique du discours monologal », Langues et Linguistique, 8.1, p. 65-84.

Roulet E. et al., 1991 - L'Articulation du discours en français contemporain, Berne (Sciences pour la communication, 11).

Rouse M. A., Rouse R. H., 1982 - «Alphabetization », Dictionary of the Middle Ages, I, p. 204-207.

Rouse R.H., Rouse M. A., 1971 - «The text called Lumen anime », Archivum Fratrum Predicatorum, 41, p. 5-113.

Roux G., Laharie M., 1997 - Art et Folie au Moyen Âge. Aventures et Énigmes d'Opicinus de Canistris (1296-1351?), Paris.

Rubincam C., 1997 - « The Organisation of Material in Graeco-Roman World Histories », dans Binkley P. (éd.), Pre-Modern Encyclopedic Texts, Leyde/New York/Cologne, p. 127-136.

RuH K. (éd.), 1997 - Initiation à Maître Eckhart. Théologien, prédicateur, mystique, Fribourg (Vestigia, 23).

Ruhe D., 1994 - «La Roe d'astronomie. Le livre de Sidrac et les encyclopédies françaises du Moyen Âge », Picone M. (éd.), L'enciclopedismo medievale, p. 293-310.

RUhe D., 2003 - « Ratgeber. Hierarchie und Strategien der Kommunikation», dans SPIEss K.-H. (éd.), Medien der Kommunikation im Mittelalter, Wiesbaden (Beiträge zur Kommunikationsgeschichte, 15), p. 63-82.

RUhe D., 2007 - «La divination au Moyen Âge. Théories et pratiques », dans TrachsLER R. (éd.), Moult obscures paroles. Études sur la prophétie médiévale, Paris, p. 17-28.

RuHE E., 1968 - Untersuchungen zu den altfranzösischen Übersetzungen der Disticha Catonis, München (Beiträge zur romanischen Philologie des Mittelalters, 2). 
Ruhe E., 2007 - «L'invention d'un prophète: Le livre de Sydrac », dans TRACHSLER R. (éd.), Moult obscures paroles. Etudes sur la prophétie médiévale, Paris, p. 65-78.

RuITENBEeK K., 1996 - Carpentry and Building in Late Imperial China: A Study of the Fifteenth-Century Carpenter's Manual Lu Ban jing, Leiden.

Ruiz de Elvira A., 1998 - « Universitas y Encyclopaedia », Habis, 29, p. 349-369.

RungGaldier E., 2010 - Die menschliche Seele bei Albertus Magnus : ein nicht-reduktionistischer Beitrag zum Leib-Seele-Problem, Münster/Aschendorff (Lectio Albertina, 11).

Salomon R. G., 1936 - Opicinus de Canistris. Weltbild und Bekenntnisse eines Avignonesicher Klerikers des 14. Jahrunderts, Londres, 2 vol.

SALvan G., 2005 - «Dites-vous ou le dialogisme à l'épreuve du dialogal (et vice versa)», dans Bres J., Haillet P. P., Mellet S., Nølke H., Rosier L. (dir.), Dialogisme et polyphonie. Approches linguistiques, Bruxelles, p. 265-279.

SALVAT M., 1995 - « Les incursions de l'histoire chez Barthélemy l'Anglais et ses traducteurs », dans Baillaud B., De Gramont J., HüE D. (éd.), L'histoire, le savoir et le temps, discours encyclopédiques. Actes du colloque de Mortagne-au-Perche, avril 1994, Rennes (Cahiers Diderot, 7), p. 323-335.

Samaran C., Monfrin J., 1962 - «Pierre Bersuire, prieur de Saint-Éloi de Paris », Histoire littéraire de la France, Paris, 39, p. 259-450.

Sánchez Martínez C., 2002 - La etimología latína. Concepto y métodos, Murcie.

SANdqvist S., 1996 - Le Bestiaire et le lapidaire du Rosarius (BnF fr. 12483), Lund (Études Romanes de Lund, 55).

SANFORD E. M., 1949 - « Famous Latin Encyclopaedias. Compilers of universal knowledge from Varro to Vincent of Beauvais », Classical Journal, 44, p. 462-467.

SARNowsky J., 1999 - « Die Artes im Lehrplan der Universitäten », dans Schaefer U. (éd.), Artes im Mittelalter, Formationen und transformationen des Wissens, Berlin, p. 68-82.

Scarborough J., 1986 - « Pharmacy in Pliny's Naturalis historia: Some Observations on Substances and Sources », dans French R., GreEnaway F. (éd.), Science in the Early Roman Empire. Pliny the Elder, his Sources and Influence, Londres/Sydney, p. 59-85.

SCHAEFER U. (éd.), 1999 - Artes im Mittelalter, Formationen und transformationen des Wissens, Berlin.

Schaer R. (éd.), 1996 - Tous les savoirs du monde. Encyclopédies et bibliothèques, de Sumer au XXIème siècle, Paris.

SCHIPPER K. M. et al., 1981 - Index du Yunji qiqian, Paris.

SснміDт C., 1899 - Quaestiones de musicis scriptoribus Romanis, inprimis de Cassiodoro et Isidoro, diss. Giessen, Darmstadt.

SchmidtP. L., 1977 - « Zur Typologie und Literarisierung des frühchristlichen lateinischen Dialogs », Christianisme et formes littéraires de l'antiquité tardive en occident (Entretiens sur l'antiquité classique, XXIII), p. 101-180.

Schmitr P., 1986 - « Enzyklopädie III.3 : Deutsche Literatur », dans Lexikon des Mittelalters, 3, col. 2035-2036.

Schmiтz T., 1997 - Bildung und Macht. Zur sozialen und politischen Funktion der zweiten Sophistik in der griechischen Welt der Kaiserzeit, Munich.

Schmuki K., Ochsenbein P., Dora C., 1998 - Cimelia Sangallensia. Hundert Kosbarkeiten aus der Stifstbibliothek St. Gallen, St. Gall, p. 100-101.

SCHNEIDER H., 1986 - Das griechische Techniskverständnis, von den Epen Homers bis zu den Anfängen der technologischen Fachliteratur, Darmstadt. 
Sconocchia S., 1993 - « L'opera di Scribonio Largo e la letteratura medicina latina del I. sec. d. C. », dans HaAse W. (éd.), ANRW, II, 37.1, Berlin/New York, p. 843-922.

SEeCK G. A., 1985 - «Plinius und Aristoteles als Naturwissenschaftler », Gymnasium, 92, p. 419-434.

Sellheim R., 1976 - Materialien zur arabischen Literaturgeschichte, I, Wiesbaden, p. 176-186.

SezGin F., 2011 - Anthropogeographie, Teil 2, Frankfurt am Main.

Sezgin F. Amawî M. et al. (éd.), 1998 - Al-Farghânî (fl. c. 850) and Al-Battânî (d. 929). Texts and Studies, Francfort (Publications of the Institute for the History of Arabic-Islamic Science. Islamic Mathematics and Astronomy, 68).

Sezgin F., Ehrig-Eggert F., Neubauer E., 2006 - The reception and assimilation of Islamic mathematics and astronomy in the Occident : texts and studies, Frankfurt.

SHARPLES R., 1998 - Theophrastus of Eresus: Sources for His Life, Writings, Thought and Influence, Commentary. Volume 3.1, Sources on Physics, Leiden.

Shank M. H., 1988 - "Unless You Believe, You Shall Not Understand". Logic, University, and Society in Late Medieval Vienna, Princeton.

Sherwood-SMith M. C., 2000 - Studies in the reception of the "historia scholastica" of Peter Comestor: the "Schwarzwälder Predigten", the "Weltchronik" of Rudolf von Ems, the "Scolastica" of Jacob von Maerlant and "Historiebijbel Van 1360", Oxford (Medium aevum monographs. New series, 20).

SiCARD P., 1991 - Hugues de Saint-Victor et son École, Paris.

Sicard P., 1997 - « Savoir et sagesse dans une école médiévale: le cas de Saint-Victor de Paris », dans SchaER R. (éd.), Tous les savoirs du monde. Encyclopédies et bibliothèques, de Sumer au XXI e siècle, Paris, p. 99-106.

Siebenborn E., 1976 - Die Lehre von der Sprachrichtigkeit und ihren Kriterien. Studien zur antiken normativen Grammatik, Amsterdam.

SIEMERS K., 2006 - Möglichkeiten und Grenzen des gemeinsamen Wissens in der Onlineenzyklopädie Wikipedia, Karlsruhe (http://www.karinsche.de/files/wikipedia.pdf).

SILVI C., 2003a - «Les "petites encyclopédies" du XIII siècle en langue vulgaire. Bibliographie sélective (1980-2000) », Le Moyen Âge, 2, p. 345-361.

SILvI C., 2003b - Science médiévale et vérité. Étude linguistique de l'expression du vrai dans le discours scientifique en langue vulgaire, Paris (Bibliothèque de grammaire et de linguistique, 15).

SILVI C., 2006 - « Fausses et vraies objections dans le discours encyclopédique scientifique au $\mathrm{XIII}^{\mathrm{e}}$ siècle », dans Thomasset C. (dir.), L'Écriture du texte scientifique. Des origines de la langue française au XVIII siècle, Paris (Cultures et civilisations médiévales, 35), p. 49-78.

Sıмon M., 1966 - « Zur Abhängigkeit spätrömischer Enzyklopädien der Artes liberales von Varros Disciplinarum libri », Philologus, 110, p. 88-101.

Smalley B., 1946 - « Two Biblical Commentaries of Simon of Hinton », Recherches de Théologie Ancienne et Médiévale, 13, p. 57-85.

Smalley B., 1948a - « Some More Exegetical Works of Simon of Hinton », Recherches de Théologie Ancienne et Médiévale, 15, p. 97-106.

Smalley B., 1948b - « The Quaestiones of Simon of Hinton », dans Hunt R. W., Pantin W. A., SOUTHERn R. W. (éd.), Studies in Medieval History presented to Frederick Maurice Powicke, Oxford, p. 209-222.

SMalley B., 1983 [1941]- The Study of the Bible in the Middle Ages, Oxford.

Sмiтн L. J., 2009 - The Glossa ordinaria : the making of a medieval Bible commentary, Leyde / Boston/Cologne (Commentaria, 3). 
Southern R., 1970 - « Humanism and the School of Chartres », Medieval Humanism and Other Studies, Oxford, p. 61-85.

Southern R., 1982 - « The School of Paris and the School of Chartres » dans Benson R. L., Constable G. (éd.), Renaissance and Renewal in the Twelfth Century, Cambridge, p. 113-137.

SPARKLES B., 1991 - Greek Pottery : an Introduction, Manchester.

SPEer A. et Wegener L. (éd.), 2005 - Meister Eckhart in Erfurt, Berlin/New York (Miscellanea Mediaevalia, 32).

Speer A., Wegener L. (éd.), 2006 - Wissen über Grenzen, Berlin/New York (Miscellanea Mediaevalia, 33).

SPYRA U., 2005 - Das "Buch der Natur" Konrads von Megenberg. Die illustrierten Handschriften und Inkunabeln, Cologne/Weimar/Vienne (Pictura et poësis, 19).

STAdLer H., 1912 - « Vorbemerkungen zur neuen Ausgabe der Tiergeschichte des Albertus Magnus », Sitzungsberichte der königlich Bayerischen Akademie des Wissenschaften, Philosophisch-philologische und historische Klasse, Abhandlung 1.

STANnard J., 1979 - « Identification of the Plants described by Albertus Magnus, De vegetabilibus, 1. VI », Res Publica litterarum, Studies in the Classical Tradition, 2, p. 281-318.

Starobinski J., 1970 - «Remarques sur l'Encyclopédie », Revue de métaphysique et de morale, 257, p. 284-291

STEEL C., 1996 - «The Individuation of the human Intellect : Henry Bate's PlatonicNominalistic Position », dans Aertsen J. A., SPEer A. (éd.), Individuum und Individualität im Mittelalter, Berlin/New York (Miscellanea Mediaevalia, 24), p. 230-248.

Steel C., Guldentops G. et Beullens P. (éd.), 1999 - Aristotle's animals in the Middle Ages and Renaissance, Congrès international, Institute of Medieval Studies, mai 1997, Louvain (Mediaevalia Lovaniensia, series 1, Studia 27).

STEER G., 1981 - Hugo Ripelin von Strassburg : zur Rezeptions-und wirkungsgeschichte des "Compendium theologicae veritatis" in deustschen Spätmittelalter, Tübingen (Texte und Textgeschichte, 2).

STEER G., 1995 - « Das Compendium theologicae veritatis des Hugo Ripelins von Straßbourg: Anregungen zu Bestimmung seines Verhältnisses zu Albertus Magnus », dans HoENEN M. et De Libera A. (éd.), Albertus Magnus und der Albertismus. Deutsche philosophische Kultur des Mittelalters, Leyde/New York/Cologne (STGgM, 48), p. 133-154.

Stegmüller F., Reinhardt K., 1940-1980-Repertorium biblicum medii aevi, Madrid/Barcelone, 1950-1980 (11 vol.).

STENECK N. H., 1976 - Science and Creation in the Middle Ages. Henry of Langenstein (d. 1397) On Genesis, Notre Dame/Londres.

Stevenson A. J., 2004 - « Gellius and the Roman Antiquarian Tradition », dans HolfordStrevens L., VARdi A. (éd.), The Worlds of Aulus Gellius, Oxford.

Sтотz P., 1996 - Handbuch zur lateinischen Sprache des Mittelalters. Lautlehre, vol. 3, Munich.

Sun Jen I-Tu, Sun HsüEh-ChuAn (trad.), 1966 - Thien Kung Khai Wu, Chinese Technology in the Seventeenth Century, by Sung Yin-hsing, Philadelphie/Londres.

Swiggers P., 2004 - « Alcuin et les doctrines grammaticales », dans Depreux P. et Judic B. (éd.), Alcuin, de York à Tours : écriture, pouvoir et réseaux dans l'Europe du haut Moyen $\hat{A}$ ge, Annales de Bretagne et des Pays de l'Ouest, 111.3, p. 147-161.

TAHMI M., 1998 - L'encyclopédisme musulman à l'âge classique, Paris.

Tarabochia Canavero A., 1981 - Esegesi biblica e cosmologia. Note sull'interpretazione patristica e medievale di Genesi 1-2, Milan. 
TAuer F., 1950 - « Annotations critiques au texte du Tuhfat al-albāb d'Abū Hāmid al-Māzin̄̄ édité par G. Ferrand », Archiv Orientání, 18, p. 298-316.

Tesnière M.-H., 1993 - « Le Reductorium morale de Pierre Bersuire », L'encyclopédisme médiéval. Actes du Colloque San Gimignano, 8-10 octobre 1992, Ravenna, p. 225-242.

Tesnière M.-H., 1997 - « De l'Écriture, "jardin de la Sagesse”, au Livre des merveilles du monde: six modèles d'esprit encyclopédique médiéval », dans SCHAER R. (éd.), Tous les savoirs du monde. Encyclopédies et bibliothèques, de Sumer au XXI siècle, Paris, p. 57-98.

Tesnière M.-H., 2000 - « Pierre Bersuire, un encyclopédiste au XIv e siècle », Plein Chant, 69-70, p. 7-24.

Théry P. G., 1939 - Thomas Gallus : aperçu biographique, Paris.

Thomasset C., Jacouart D., 1985 - Sexualité et savoir médical au Moyen Âge, Paris.

Thorndike L., 1949 - The "Sphere of Sacrobosco" and its Commentators, Chicago (Corpus of medieval scientific Texts, 2).

TORRELl J.-P., 2002² - Initiation à Saint Thomas d'Aquin: sa personne et son æuvre, Fribourg (Vestigia: pensée antique et médiévale, 13).

Traina G., 1994 - La tecnica in Grecia e a Roma, Bari.

Trifogli C., 2000 - Oxford Physics in the Thirteenth Century. Motion, Infinity, Place and Time, Berlin/New York (STGgM, 72).

Trifogli C. (éd.), 2008 - Liber quartus Physicorum Aristotelis. Repertorio delle questioni. Commenti inglesi ca. 1250-1270, Firenze (Corpus Philosophorum Medii Aevi, Subsidia, 16).

Türk E., 1965 - « Macrobe et les Nuits Attiques », Latomus, 24, p. 381-406.

TÜrK M., 2000 - «Lucidaire de grant sapientie ». Untersuchung und Edition der altfranzösischen Übersetzung 1 des «Elucidarium » von Honorius Augustodunensis, Tübingen (Beihefte zur Zeitschrift für Romanische Philologie, 307).

Twomey M. W., 1988 - « Medieval Encyclopedias », Medieval Christian literary imagery. A guide to interpretation, Toronto/Buffalo/London, p. 182-315.

Twomey M. W., 1996 - « Towards a reception history of western medieval encyclopaedias in England before 1500 », dans BinkLey P. (éd.), Pre-Modern Encyclopaedic Texts. Proceedings of the Second COMERS Congress, Groningen, 1-4 July 1996, Leiden/New York/Köln, p. 329-362.

Ullmann M., 1972 - Die Natur- und Geheimewissenschften im Islam, Leiden.

UlmSChNEIDER H., 1992 - « 'Ain puoch von latein... daz hat Albertus maisterlich gesamnet'. $\mathrm{Zu}$ den Quellen von Konrads von Megenberg "Buch der Natur" anhand neuerer Handschrifenfunde », Zeitschrift für deutsches Altertum und deutsche Literatur, 121, p. 36-63.

UlMSCHNEIDER H., 1994 - « 'Ain puoch von latein'. Nochmals zu den Quellen von Konrads von Megenberg "Buch der Natur" », Zeitschrift für deutsches Altertum und deutsche Literatur, 123 , p. 309-333.

Van den Abeele B., 1994 - « Bestiaires encyclopédiques moralisés. Quelques succédanés de Thomas de Cantimpré et de Barthélemy l'Anglais », Reinardus, 7, p. 209-228.

Van den Abeele B., 1997 - «Vincent de Beauvais naturaliste : les sources des livre des animaux du Speculum naturale », dans PAulmier-FoucART M., Lusignan S. (dir.), Lector et compilator. Vincent de Beauvais frère prêcheur. Un intellectuel et son milieu au XIII siècle, Grâne, p. 127-151.

VAN DEN AbEELE B., 2002 - « Moralisierte Enzyklopädien in der Nachfolge von Bartholmäus Anglicus », dans MeIER C. (éd.), Die Enzyklopädie im Wandel vom Hochmittelalter bis zur frühen Neuzeit. Akten des Kolloquiums des Projekts D im Sonderforschungsbereich 231, 29.11.-01.12.1996, Munich (Münstersche Mittelalter-Schriften, 78), p. 279-304. 
VAN Den Abeele B., 2004 - « The Macrologus of Liège. An Encyclopedic Lexicon at the Dawn of Humanism », dans MacDonald A. A., Twomey M. W. (éd.), Schooling and Society. The Ordering and Reordering of Knowledge in the Western Middle Ages, Leuven/Paris/Dudley, MA., p. 43-60.

Van den Abeele B., Meyer H. (éd.), 2005 - Bartholomaeus Anglicus, "De proprietatibus rerum”. Texte latin et réception vernaculaire - Lateinischer Text und volkssprachige Rezeption, Turnhout (De diversis artibus, 74, NS 37).

VAN DEN Abeele B., 2007a - Fortune et mutations des encyclopédies latines durant le Moyen Âge tardif, Thèse d'agrégation, Université de Louvain, Louvain-la-Neuve.

VAN den Abeele B., 2007b - "Introduction générale », dans VAN den Abeele et al. (éd), Bartholomaeus Anglicus. De proprietatibus rerum. Volume I : Prohemium, Livre I-IV, Turnhout (De diversis artibus 78, NS 41), p. 135-199.

VAN den AbeEle B., 2008 - « Diffusion et avatars d'une encyclopédie : le Liber de natura rerum de Thomas de Cantimpré », dans de Callataÿ G., Van den Abeele B. (éd.), Une lumière venue d'ailleurs, Héritages et ouvertures dans les encyclopédies d'Orient et d'Occident au Moyen Âge, Louvain-la-Neuve, p. 141-176.

VAN DER Lugt M., 2004 - Le ver, le démon, la vierge. Théories médiévales de la génération extraordinaire. Une étude sur le rapport entre théologie, philosophie naturelle et médecine, Paris.

Van Moos P., 1975 - «Le silence d'Héloïse et les idéologies modernes », dans LouIs R., Jolivet J. et Châtillon J. (dir.), Pierre Abélard, Pierre le Vénérable: les courants philosophiques, littéraires et artistiques en Occident au milieu du XII siècle, Paris (Colloques internationaux du Centre national de la recherche scientifique, 546), p. 425-468.

VANWunsberghe D., 2000 - De fin or et d'azur. Les commanditaires de livres et le métier de l'enluminure à Tournai à la fin du Moyen Âge, Leuven.

VARDI A., 2004 - «Genre, Conventions, and Cultural Programme in Gellius' Noctes Atticae », dans Holford-Strevens L., VARd A. (éd.), The Worlds of Aulus Gellius, Oxford.

DE VauX C., 1984 - Les Penseurs de l'islam, tome IV, Paris.

Vegetti M., 1981 - « Lo spettacolo della natura, Circo, teatro e potere in Plinio », Aut Aut, 184-185, p. 111-125.

Vegetti M., 1982 - «Zoologia e antropologia in Plinio », dans Alfonsi L. (éd.), Plinio il Vecchio sotto il profilo storico e letterario, Côme, p. 117-131.

Vegetti M., 1984 - «La scienza ellenistica: problemi di epistemologia storica », dans Giannantoni G., Vegetti M., (dir.), La scienza ellenistica, p. 427-470.

Vegetti M., 1992 - «Aristotele, il Liceo e l'enciclopedia del sapere », dans Cambiano G., Canfora L., Lanza D., (dir.), Lo spazio letterario della Grecia antica, vol. 1, Roma/Salerno, p. 587-610.

Ventura I., 1997 - « L'iconografia letteraria di Brunetto Latini », Studi Medievali, III, 38, p. $499-528$

Ventura I., 2001 - «Der Liber Similitudinum Naturalium Konrads von Halberstadt und seine Quellen: ein Fallbeispiel aus der naturwissenschaftlichen Textüberlieferung im Spätmittelalter », Frümittelatlerliche Studien, 35, p. 349-406.

VENTURA I., 2003a - « Die moralisierten Enzyklopädien des späteren Mittelalters : ein Überblick unter Berücksichtigung der Fallbeispiele des Lumen Anime, des Liber de exemplis et similitudinibus rerum und des Liber Similitudinum Naturalium », Reti medievali, 4 (http://www. storia.unifi.it/_RM/rivista).

Ventura I., 2003b - « L'erbario alfabetico del De Proprietatibus Rerum di Bartolomeo Anglico e le sue fonti : una panoramica sul ruolo della botanica nelle enciclopedie del XIII 
secolo », dans Stammen T., Weber W. E. J. (éd.), Wissensicherung, Wissensordnung und Wissensverarbeitung : Das europäische Modell der Enzyklopädien. Akten des Kolloquiums Augsburg, 26-28 September 2001, Berlin, p. 291-337.

Ventura I., 2004a - « Enciclopedie per una società civile: Il Tresor di Brunetto latini e l'encyclopedismo laico del duecento italiano », dans MAVrodin H. (dir.), Deteriorarea tensiunii ideale în cultura şi arta. Lo scadere della tensione ideale nella cultura e nell'arte, Atti del Simposio Bucarest, instituto di cultura italiano, 17-18 nov. 2003, Bucarest, p. 223-235.

VENTURA I., 2004b - «Quaestiones and Encyclopedias. Some aspects of the Late Medieval Reception of pseudo-Aristotelian Problemata in Encyclopaedic and Scientific Culture », dans MacDonald A. A., Twomey M. W. (éd.), Schooling and Society. The Ordering and Reordering of Knowledge in the Western Middle Ages. International Conference Kowledge and Learning, 14-17 November 2001, Groningen, Leuven/Paris/Dudley (Groningen Studies in Cultural Change, 6), p. 23-42.

Ventura I., 2006 - « Aristoteles fuit causa efficiens huius libri. On the Reception of PseudoAristotle's Problemata in Late Medieval Encyclopedic Culture », dans GoYENS M., DE LeEMANs P. (éd.), Aristotle's Problemata in Different Times and Tongues (Interdisciplinary Workshop, Leuven, Katholieke Universiteit, 30-31), Leuven (Mediaevalia Lovaniensia. Series 1, Studia, 39), p. 113-144.

Ventura I., 2007a - « Formen des Dominikanischen Enzyklopädismus im 14. Jahrhundert: Heinrich von Herford, Konrad von Halberstadt, Jakob von Soest », Sborník prací filozofické fakulty Brnĕnské Univerzity. Studia minora facultatis philosophicae Universitatis Brunensis, 12, p. 131-151.

Ventura I., 2007c - «Plant Symbolism in Thirteenth-Century Biblical Exegesis and in Bartholomaeus Anglicus' De proprietatibus rerum », Schola Salernitana Annali, 12, p. 121-134

VentuRA I., 2007d - «Per modum quaestionis compilatum... The Collections of Natural Questions and their Development from the Thirteenth to the Sixteenth Century », dans Michel P. (éd.), All you need to know : Encyclopaedias and the Idea of General Knowledge. Conference, Prangins, Switzerland, 18-20 Sept. 2003, publié sur le site web www.enzyklopaedie.ch.

Ventura I., 2008 - « On Philosophical Encyclopaedism in the Fourteenth Century : the Catena aurea entium of Henry of Herford », dans de Callataÿ G. et Van den Abeele B. (éd.), Une lumière venue d'ailleurs. Héritages et ouvertures dans les encyclopédies d'Orient et d'Occident au Moyen Âge. Actes du Colloque de Louvain-la-Neuve, 19-21 Mai 2005, Turnhout/Louvain-la-Neuve (Réminisciences, 9), p. 199-245.

Verger J., 1986 - «Enzyklopädie II.2: Spätmittelalter und Humanismus », Lexikon des Mittelalters, 3, col. 2033-2034.

Vesel Z., 1986 - Les encyclopédies persanes: essai de typologie et de classification des sciences, Paris.

VESEL Z., 2008 - « Les encyclopédies persanes: culture scientifique en langue vulgaire », dans de Callataÿ G., VAn den Abeele B. (éds), Une lumière venue d'ailleurs. Héritages et ouvertures dans les encyclopédies d'Orient et d'Occident au Moyen Âge, Louvain-laNeuve, p. 49-89.

Vıola C., 1982 - « Manières personnelles et impersonnelles d'aborder un problème: saint Augustin et le $\mathrm{XII}^{\mathrm{e}}$ siècle. Contribution à l'histoire de la quaestio », dans Les Genres littéraires dans les sources théologiques et philosophiques médiévales: définition, critique et exploitation. Actes du colloque international de Louvain-La-Neuve, 25-27 mai 1981, Louvain-La-Neuve (Publication de l'Institut d'études médiévales, $2^{\mathrm{e}}$ série, 5), p. 11-30. 
VION R., 2005 - « Modalités, modalisations, interaction et dialogisme », dans BRES J., Haillet P. P., Mellet S., Nølke H., Rosier L. (dir.), Dialogisme et polyphonie. Approches linguistiques, Bruxelles, p. 143-156.

Virolleaud C., 1955 - « La littérature assyro-babylonienne », Histoire des littératures, tome 1, Paris (Encyclopédie de la Pléiade), p. 253-276.

Vollmann B. K., 2002 - «Enzyklopädie im Wandel: Thomas von Cantimpré, De natura rerum », dans MeIER C., Die Enzyklopädie im Wandel vom Hochmittelalter bis zur frühen Neuzeit, München (Münstersche Mittelalter-Schriften, 78), p. 169-188.

VON BÜREN V., 2002 - «Écrites au IX $\mathrm{x}^{\mathrm{e}}$, perdues au Xx $\mathrm{x}^{\mathrm{e}}$, retrouvées au $\mathrm{XV}^{\mathrm{e}}$ : à propos des gloses de Végèce "De re militari" », dans Fera V., Ferraù G., Rizzo S. (éd.), Talking to the Text: Marginalia from Papyri to Print. Actes du Colloque tenu à Erice, 26 septembre - 3 octobre 1998 au Centro Interdisciplinare di studi Umanistici, Messina, p. 269-287.

von Büren V., 2003 - « Isidore, Végèce et Titanus au VIII e siècle », dans Defosse P. (éd.), Hommages à Carl Deroux, vol. 5, Bruxelles, p. 39-49.

von DEN BRINCKEN A. D., 1978 - « Geschichtsbetrachtung bei Vincenz von Beauvais. Die Apologia Actoris zum Speculum Maius », Deutsches Archiv für Erforschung des Mittelalters, 34, p. 410-499.

vON HeEs S., 2002 - Enzyklopädie als Spiegel des Weltbildes. Qazwīn̄̄s Wunder der Schögfung - eine Naturkunde des 13. Jahrhunderts, Wiesbaden.

vON HEES S., 2006 - « Al-Qazwīn̄̄'s 'ajā’ib al-makhlūqāt », dans EnDRESS G. (éd.), Organizing Knowledge. Encyclopaedic Activities in the Pre-Eighteenth Century Islamic World, Leiden, p. 171-186.

VoorbIJ J., 1986 - The "Speculum historiale" : Some Aspects of its Genesis and Manuscript Tradition », dans Aerts J. W., Smits E. R., VoorbiJ J. B. (éd.), Vincent of Beauvais and Alexander the Great. Studies on the Speculum Maius and its Translations into Medieval Vernaculars, Groningen (Mediaevalia Groningana, 7), p. 11-55.

VoorbiJ J., 1991 - Het Speculum Historiale Van Vincent Van Beauvais. Een studie Van zijn ontstaansgeschiedenis, Groningen.

Vosковоynikov O., 2006 - Arts, savoirs et visions de la nature à la cour de Frédéric II, ParisEHESS (thèse).

VRIN J., 1969 - Arts libéraux et philosophie au Moyen Âge. Actes du $4^{e}$ congrès international de Philosophie médievale, 27 août-2 sept. 1967, Montréal/Paris.

WAGNer C., 1986 - Materie im Mittelalter : Edition und Untersuchungen zur "Summa" (II,1) des Nikolaus von Strassburg O.P., Fribourg (Studia Friburgensis. Neue Folge, 67).

WeIgand R., 1991 - Vinzenz von Beauvais. Scholastische Universalchronistik als Quelle volkssprachiger Geschichtsschreibung, Hildesheim (Germanistische Texte und Studien, 36).

WeIJERS O., 1989 - « Lexicography in the Middle Ages », Viator, 20, p. 139-153.

WeiJers O., 1990 - « Les dictionnaires et autres répertoires », dans WeIJERs O. (éd.), Méthodes et instruments du travail intellectuel au Moyen Âge. Études sur le vocabulaire, Turnhout, p. 197-208.

WeIJERS O., 1991 - Dictionnaires et répertoires au Moyen Âge. Une étude du vocabulaire, Turnhout.

WEIJERs O., 1994 - «L'enseignement du trivium à la faculté des arts à Paris : la "quaestio" », dans HAMESSE J. (éd.), Manuels, programmes de cours et techniques d'enseignement dans les universités médiévales. Actes du Colloque International de Louvain-la-Neuve, 9-11 septembre 1993, Louvain-la-Neuve (Publications de l'Institut d'Études Médiévales. Textes, Études, Congrès, 16), p. 57-74.

Weijers O., 1995 - La “disputatio" à la Faculté des arts de Paris (1200-1350 environ). Esquisse d'une typologie, Turnhout (Studia Artistarum, 2). 
WeiJers O. (éd.), 1996 - Le Maniement du savoir. Pratiques intellectuelles à l'époque des premières universités (XIII'-XIV' siècles), Turnhout.

WEIL E., 1946 - «L'anthropologie d'Aristote », Revue de Métaphysique et de Morale, 51, p. 7-36.

WeISEL B., 1993 - « Die Überlieferung des "Livre de Sidrac" in Handschriften und Drucken », dans Brunner H., Wolf N. R. (éd.), Wissensliteratur im Mittelalter und in der Frühen Neuzeit. Bedingungen, Typen, Publikum, Sprache, Wiesbaden, p. 53-66.

Wilkins J., 2000a - « Athenaeus and the Fishes of Archippus », dans BRAUnd D., WiLkins J. (dir.), Athenaeus and his World, Exeter, p. 323-335.

Wilkins J., 2000b - « Dialogue and Comedy », dans Braund D., Wilkins J. (dir.), Athenaeus and his World, Exeter, p. 23-37.

Wille G., 1967 - Musica Romana. Die Bedeutung der Musik im Leben der Römer, Amsterdam.

Williams S., 2003 - The Secret of Secrets. The scholarly career of a Pseudo-Aristotelian text in the Late Middle Ages, Ann Arbor.

Wins B., 1993 - " "Le Livre de Sidrac" - Stand der Forschung und neue Ergebnisse », dans BRUNNER H., Wolf N. R. (dir.), Wissensliteratur im Mittelalter und in der Frühen Neuzeit. Bedingungen, Typen, Publikum, Sprache, Wiesbaden (Wissensliteratur im Mittelalter. Schriften des Sonderforschungsbereichs 226 Würzburg/Eichstätt, 13), p. 36-52.

Wissowa G., 1880 - De Macrobii Saturnaliorum fontibus capita tria, diss. Breslau.

Woesthuis M., 1997 - «Vincent of Beauvais and Helinand of Froidmont », dans Lusignan S. et Paulmier-Foucart M. (dir.) et Duchenne M.-C., Lector et compilator. Vincent de Beauvais, frère prêcheur, un intellectuel et son milieu au XIII siècle, Nancy/Montréal, p. 233-247.

Wooldridge T. R., Lancashire I. (dir.), 1995 - Les bases de dictionnaires anciens, Paris.

Wüstenfeld F. (éd.), 1849 - El-Cazwini's Kosmographie, Göttingen.

ZAHORA T., 2012 - « Amending Aquinas: Textual Bricolage of the Speculum dominarum as an Authorial Strategy in the Compilation Speculum morale », Cahiers de Recherches Médiévales et Humanistes, 24, p. 505-524.

Zahora T., 2013 - « Virtue and the Politics of Salvation in the Age of the Apocalypse: the Case of the Speculum morale », (inédit).

ZAHORA T., à paraître - The tropological universe of Alexander Neckam : Nature, Virtue, and the Boundaries of Encyclopedic Knowledge, Turnhout, Brepols (Europa Sacra).

Zahora T., Nikulin D., Mews C., Squire D., 2012 - « Decompiling the Speculum morale. Uncovering Franciscan Voices in an Encyclopedia of Ethics with the Aid of Factotum Software », à paraître dans les actes du congrès de la FIDEM 2012.

ZAMboni A., 1989 - L'etimologia, Bologna.

ZeCChINI G., 1989 - La cultura storica di Ateneo, Milan.

Zecchini G., 2007 - «Athénée et les historiens », dans Lenfant D. (éd.), Athénée et les fragments d'historiens, Strasbourg, p. 19-27.

ZELLER E., 1897 - Aristotle and the earlier Peripatetics, London.

Zimmermann B., 1994 - « Osservazioni sulla "enciclopedia" nella letteratura latina », dans Picone M. (éd.), L'enciclopedismo medievales, Ravenna, p. 41-51.

Zonta M., 1995 - «The Reception of al-Fârâbî’s and ibn Sînâ's Classifications of the Mathematical and Natural Sciences in the Hebrew Medieval Philosophical Literature », Medieval Encounters, 1.3, p. 358-382.

ZuCKer A., 2005 - Aristote et les classifications zoologiques, Louvain-la-Neuve.

ZuCKer A., 2012 - « Qu'est-ce qu'épitomiser? Étude des pratiques dans la Syllogé zoologique byzantine », Rursus, 7, mars 2012 [http://rursus.revues.org/961] (38 p.). 